\title{
AN EXPLORATION OF TABLET-BASED PRESENTATION SYSTEMS AND LEARNING STYLES
}

\author{
A Thesis \\ presented to \\ the faculty of California Polytechnic State University, \\ San Luis Obispo
}

\author{
In Partial Fulfillment \\ of the Requirements for the Degree \\ Master of Science in Computer Science
}

by

Ngan Phan

October 2008 


\section{ABSTRACT}

\section{AN EXPLORATION OF TABLET-BASED PRESENTATION SYSTEMS AND LEARNING STYLES}

By Ngan Phan

Learning in the classroom can occur as a combination of students' personal effort to study class material, the instructor's attempt to present class material, and the interaction that takes place between instructor and students. In a more traditional setting, instructors can lecture by writing notes on a chalkboard or a whiteboard. If instructors want to display prepared lecture slides, they can use the overhead projector and write additional notes on top of these overhead transparencies. With many technological advances, various researchers are advocating towards integration between technology and learning. With the advent of tablet PCs, researchers recognize the potential usefulness of its functions within the classroom. Not only can electronic materials be presented via the computer, tablet PCs allow instructors to handwrite notes on top of the slides, mimicking manual devices such as the overhead.

Even though the use of tablet PCs can be advantageous to instructors and students, no research found so far has focused on the issue of how well tablet PC features address varying learning styles of students (e.g. visually oriented vs. text-based learning). According to Felder, "understanding learning style differences is thus an important step in designing balanced instruction that is effective for all students" [22]. Hence, this research explores the correlation between tablet-based presentation systems and learning styles by taking two approaches: performing a pilot study and distributing a survey. The results from these approaches are evaluated to yield statistically significant conclusions 
on how well tablet-based presentation systems encompass the different learning needs of student. 


\section{ACKNOWLEDGEMENTS}

First and foremost, I would like to thank my thesis advisor, Dr. Franz Kurfess, for being such a wonderful teacher and mentor. Without his guidance, it would have been very difficult for me to complete this thesis. I would also like to thank Dr. Clark Turner for his insights which have aided me in improving the quality of my research. I also want to thank Dr. David Janzen and Dr. Michael Haungs for being a part of my thesis committee at such late notice. Despite this, they have given me very valuable feedback to bring clarity to my research. Moreover, I want to thank Dr. Ulric Lund for his advising on how to carry out statistical analysis for my research.

I also want to thank HP for giving Cal Poly students access to using tablet PCs. It would be impossible for me to perform my experiment without having these tablets readily available. In the same context, I would like to give special thanks to Dr. Linda Norton and Dr. Veronica Bandy from the University of Pacific. Due to their cooperation, I was able to obtain a large amount of participants for the distributed survey.

In addition, I want to thank my teammates from my class CPE 484. I could not have completed the experiment successfully without their contributions. I would also like to thank Marcia Conner for giving me permission to use the learning styles test. Furthermore, I want to thank Vovici, formerly known as WebSurveyor, for having the surveying tools available for use. 
Last but not least, I want to give special thanks to my family and friends. There are no words that can express my gratitude for their love and support for me throughout my college years. I would not be who I am without their presence. Thank you everyone! 


\section{TABLE OF CONTENTS}

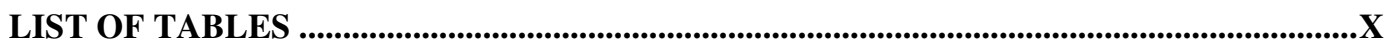

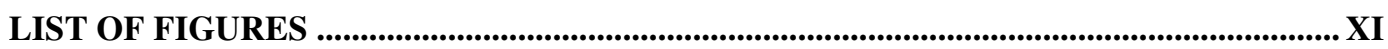

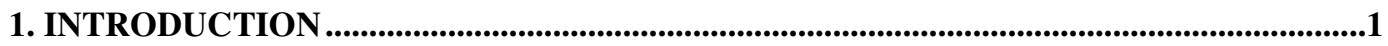

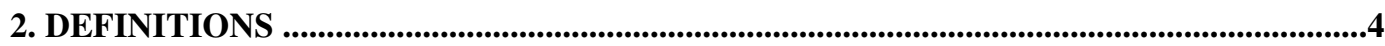

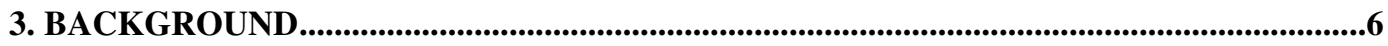

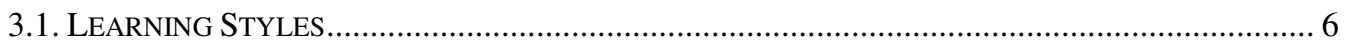

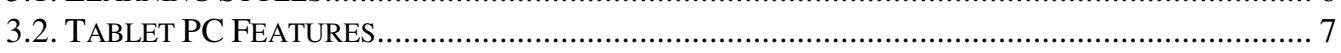

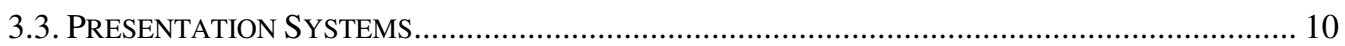

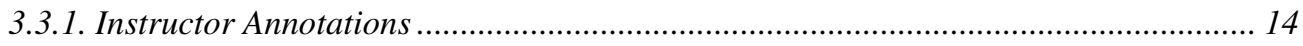

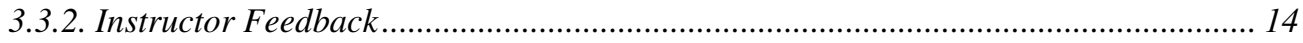

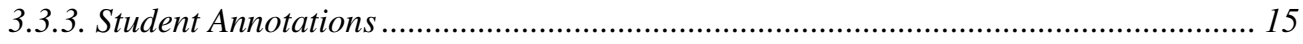

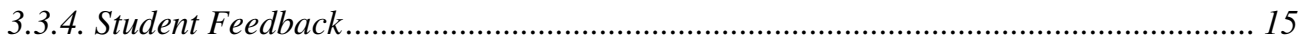

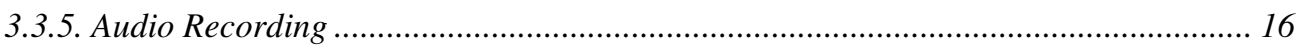

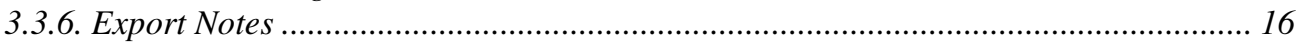

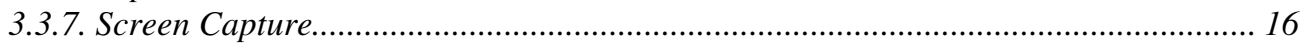

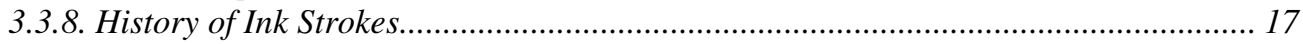

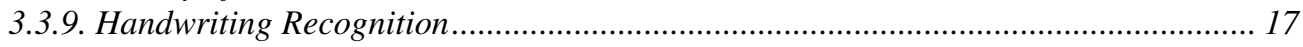

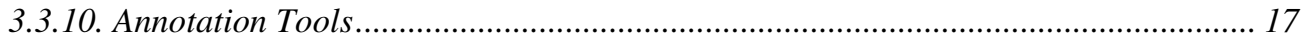

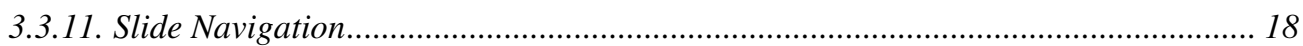

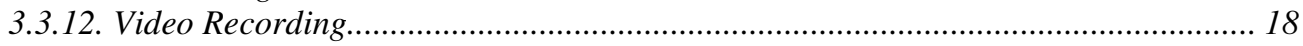

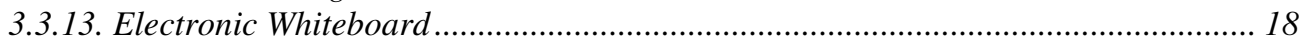

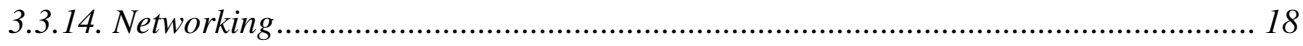

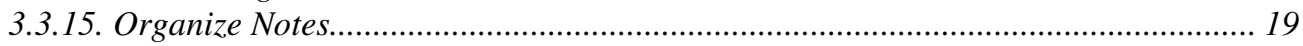

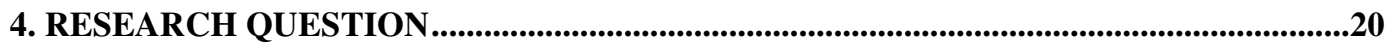

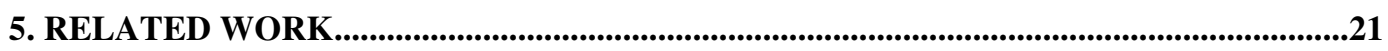

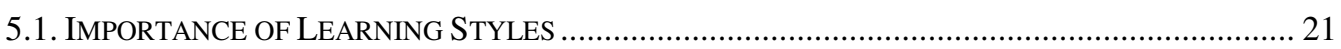

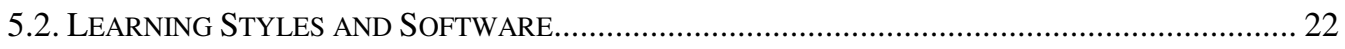

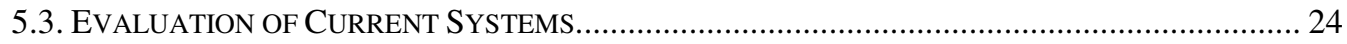

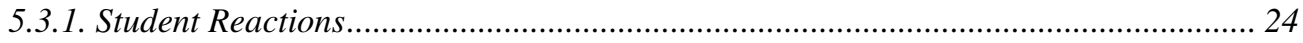

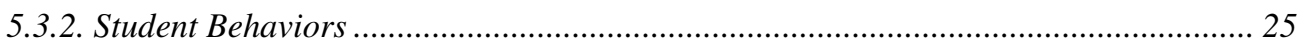

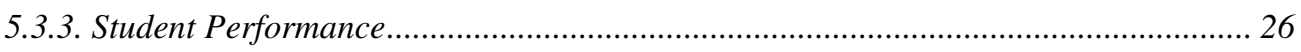

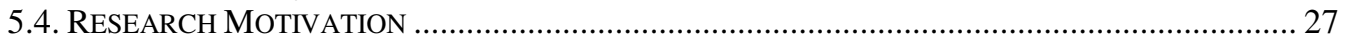

6. RESEARCH APPROACH .........................................................................................................29

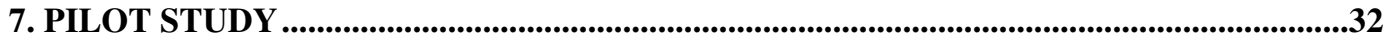

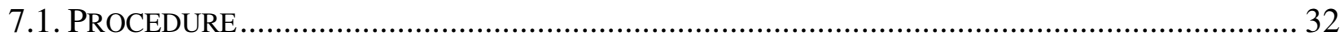

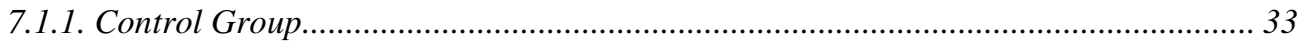

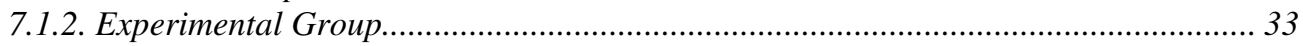

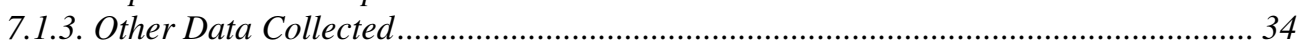

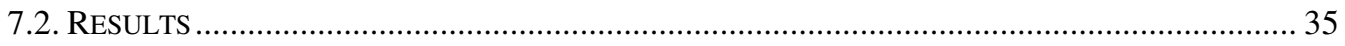

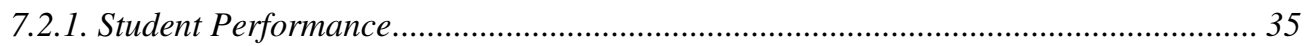

7.2.2. Student Behavior ................................................................................................. 37

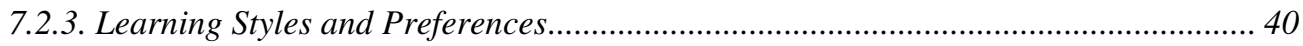

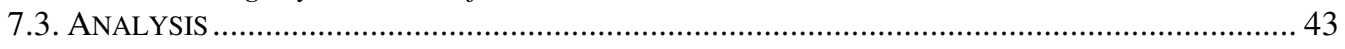

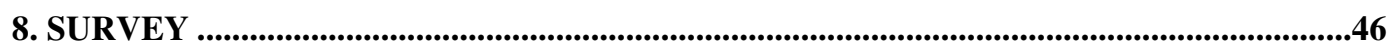

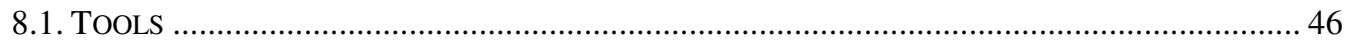




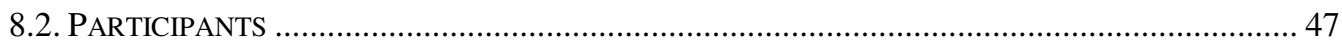

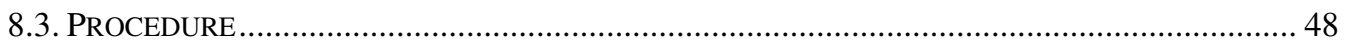

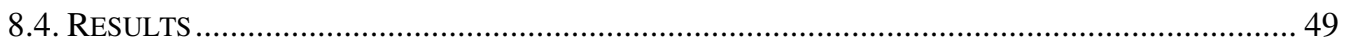

8.4.1. Feature 1: Using the tablet PC, instructors can handwrite additional notes on top of slides to illustrate difficult concepts or to give explanations of important ideas........ 51

8.4.2. Feature 2: Capturing instructors' handwritten notes during lecture using the tablet PC.

8.4.3. Feature 3: Sending instant electronic responses to students' questions or

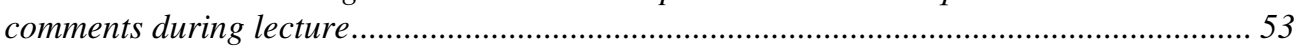

8.4.4. Feature 4: Handwriting your own digital notes on top of lecture slides using the tablet $P C$.

8.4.5. Feature 5: Separate views for lecture notes with instructors' annotations and lecture notes with your own annotations ........................................................................... 55

8.4.6. Feature 6: Sending instant electronic questions to instructors during lecture ........... 56

8.4.7. Feature 7: Sending anonymous electronic questions to instructors during lecture .... 57 8.4.8. Feature 8: Taking real-time quizzes or assessments on the tablet PC and submit them to the instructor electronically. 58 8.4.9. Feature 9: Instructors share students' electronic submissions to the class via the tablet PC ....................................................................................................................... 59

8.4.10. Feature 10: Recording instructors' voices during lecture ....................................... 60

8.4.11. Feature 11: When reviewing lecture notes, recorded instructors' voices are synchronized with the slide you are on and the notes that you took during class.......

8.4.12. Feature 12: Using speech recognition capabilities to convert instructors' voices to text ................................................................................................................. 62

8.4.13. Feature 13: Reviewing your notes in the order that you wrote them by using the tablet PC to replay the handwritten notes stroke-by-stroke ........................................... 63 8.4.14. Feature 14: Ink strokes change color over time to differentiate notes taken during different periods of the lecture.

8.4.15. Feature 15: Handwritten notes using the tablet PC are automatically converted to printed text...

8.4.16. Feature 16: Using the tablet PC to search through handwritten notes for

keywords

8.4.17. Feature 17: Having access to blank slides to take additional notes ........................ 67

8.4.18. Feature 18: Navigating through all lecture slides without being restricted to the slide that the instructor is lecturing on....

8.4.19. Feature 19: Highlighting key words or ideas using the tablet PC.......................... 69

8.4.20. Feature 20: Erasing ink marks or strokes written using the tablet pen .................. 70

8.4.21. Feature 21: Changing to different color ink when taking notes ............................. 71

8.4.22. Feature 22: Peer-to-peer networking of tablet PCs to allow you to share applications or chat with your instructors or other students ........................................... 72

8.4.23. Average Ratings for Visual ................................................................................. 73

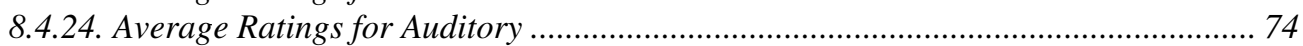

8.4.25. Average Ratings for Tactile/Kinesthetic .......................................................... 75

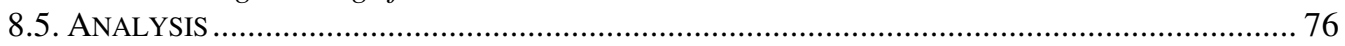

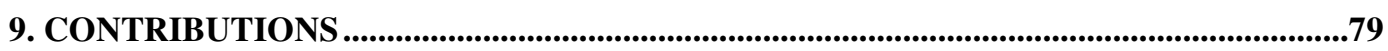

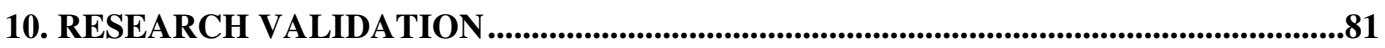

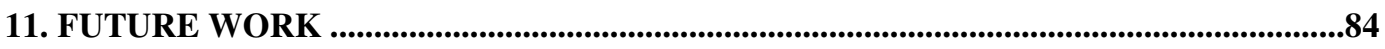

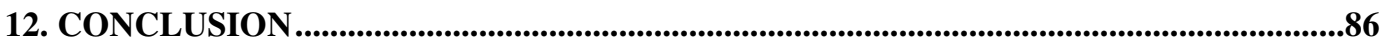

APPENDIX A: SURVEY ON TABLET PCS AND LEARNING STYLES .............................88

APPENDIX B: MINITAB OUTPUT FOR SURVEY ...............................................................96

APPENDIX C: STATISTICAL ANALYSIS FOR SURVEY ..................................................107

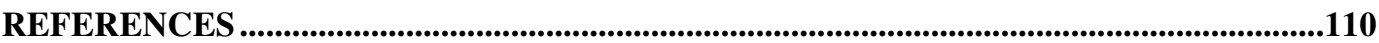




\section{LIST OF TABLES}

TABLE 1: HARDWARE FOR PRESENTATION SYSTEM SOFTWARE …….................................................. 10

TABLE 2: AVAILABLE FEATURES For PRESENTATION SySTEM SOFTWARE .................................... 13

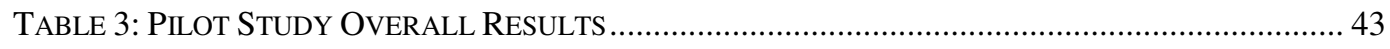

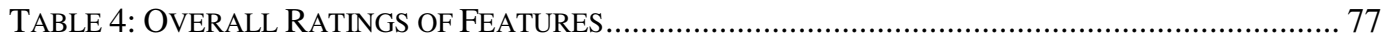




\section{LIST OF FIGURES}

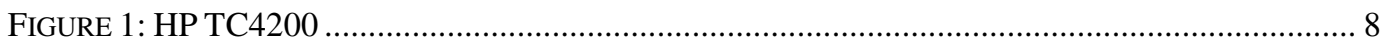

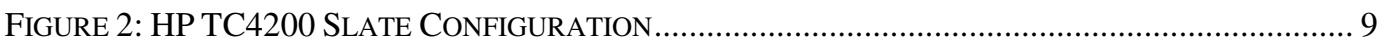

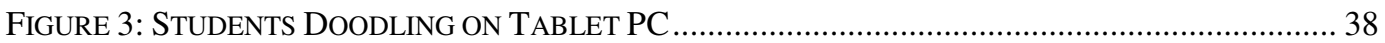

FIGURE 4: CLASSROOM INTERACTION FOR TABLET AND NON-TABLET USERS ................................ 39

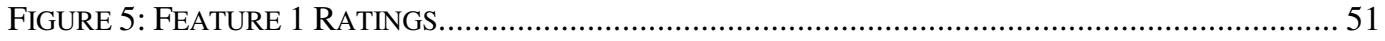

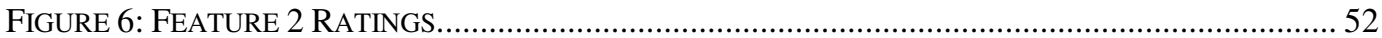

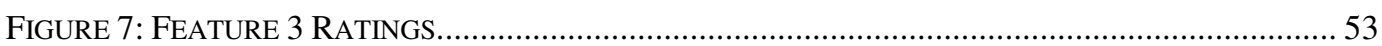

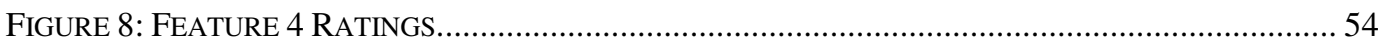

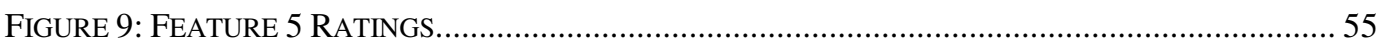

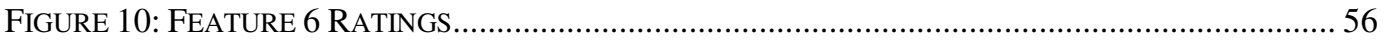

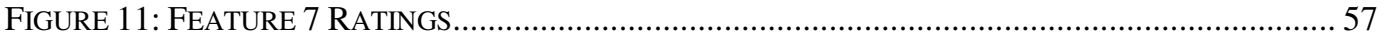

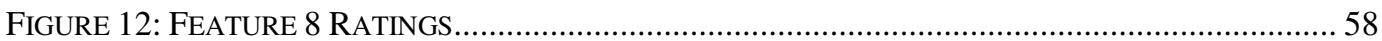

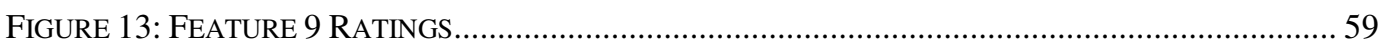

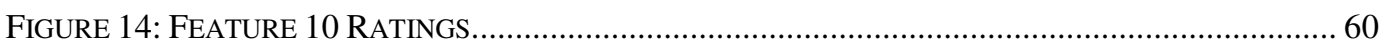

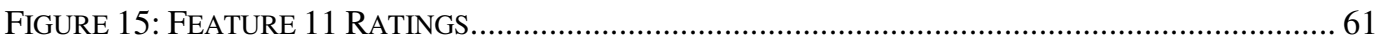

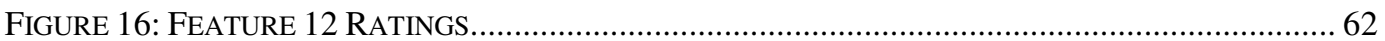

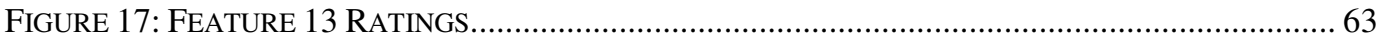

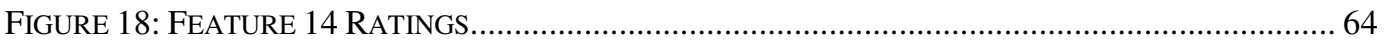

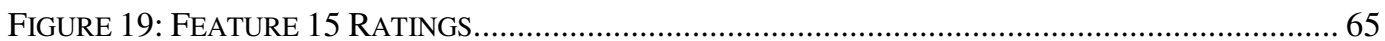

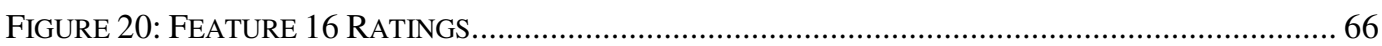

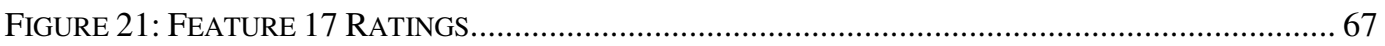

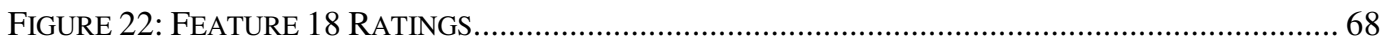

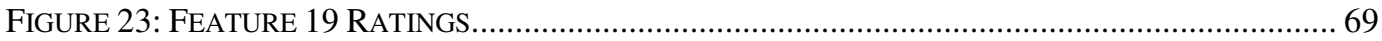

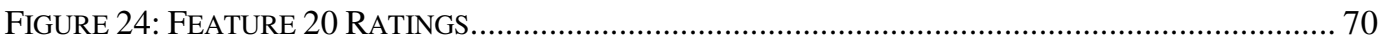

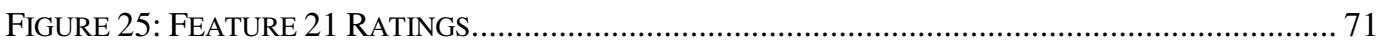

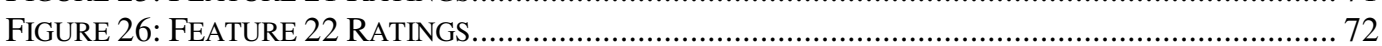

FIGURE 27: AVERAGE RATINGS FOR VISUAL LEARNERS............................................................. 73

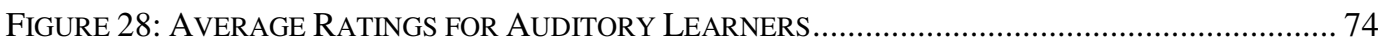

FIGURE 29: AVERAGE RATINGS FOR TACTILE LEARNERS ............................................................... 75 


\section{INTRODUCTION}

By definition, to learn is "to gain knowledge or understanding of or skill in by study, instruction, or experience" [36]. Learning in the classroom can occur as a combination of students' personal effort to study class material, the instructor's attempt to present class material, and the interaction that takes place between instructor and students in the classroom. According to Abowd, there are four common teaching styles that instructors use to convey class material to students: presentation by slides, public notes, private notes, and discussion [3]. Instructors using any of these four teaching styles need some sort of mechanism to present their material. In a more traditional setting, instructors can lecture by writing notes on a chalkboard or a whiteboard. If instructors want to display prepared lecture slides, they can use the overhead projector and write additional notes on top of these overhead transparencies.

With many technological advances, various researchers are advocating towards integration between technology and learning $[1-10,15,26,29-32,37-39,42,44,47-49$, $51,54,55,59-61]$. Instead of using a regular chalkboard, instructors can write notes on an electronic whiteboard which can be saved for later review. Audio and video of the lecture can be captured and synchronized with the notes to help students have a more comprehensive record of class material. As mentioned by Abowd, "an integrated, multimedia record of an experience can aid in the recall of the meaning or significance of past events" [2]. With the advent of tablet PCs, researchers recognize the potential usefulness of its functions within the classroom. Not only can electronic materials be presented via the computer, tablet PCs allow instructors to handwrite notes on top of the 
slides, mimicking manual devices such as the overhead [4]. By allowing lecture slides to be dynamically annotated, the use of tablet PCs can increase student-teacher interaction within the classroom. As Willis has concluded, the capabilities of tablet PCs can help instructors and students carry out their needed tasks in the learning environment [61]. Such tasks include note-taking, creating and giving presentations, document mark-up, teaming and collaboration, and information management.

Even though tablet PCs are useful to instructors and students, no research found so far has addressed the issue of how well tablet PC features match up with student learning styles. In reference to Felder, "understanding learning style differences is thus an important step in designing balanced instruction that is effective for all students" [22]. If tablet PCs are to be used as an educational tool in the classroom, it is important to explore the correlation between tablet PC features and students' learning preferences. By doing this, some light could be shed on how well tablet PCs address the different learning needs of students.

In this respect, the purpose of this paper is to explore the correlation between tablet-based presentation systems and learning styles.

The paper is organized as follows: Chapter 2 defines important terminology, Chapter 3 gives background information on learning styles, tablet PCs, and presentation systems, Chapter 4 states the research topic, Chapter 5 offers related work, Chapter 6 presents the research approach, Chapter 7 describes the pilot study and its results, Chapter 8 addresses the survey approach and its results, Chapter 9 lists the contributions 
of this research, Chapter 10 validates the research as a whole, Chapter 11 describes possible future work, and Chapter 12 is the conclusion. 


\section{DEFINITIONS}

\section{Learning Styles}

There are a few definitions available when trying to define the term learning styles. In his article [23], Felder defined learning styles as a model that "classifies students according to where they fit on a number of scales pertaining to the ways they receive and process information." Similarly, O'Brien offered his version of learning styles as "traits that serve as relatively stable indicators of how learners perceive, interact with, and respond to the learning environment" [40]. Even though these definitions seem to be pretty good, they do not address the core meaning of "style," which is defined as "a distinctive manner or custom of behaving or conducting oneself" [36]. To have a style of learning means that students have a specific way of learning that they have grown accustomed to and prefer. Therefore, for the context of this paper, a learning style is defined as follows:

A learning style classifies students according to their preferred method of perceiving, processing, interacting with, and responding to the learning environment.

Specific learning styles will be mentioned in Chapter 3.

\section{Computer-Based Presentation System}

The author has not had much luck with finding a definition for a computer-based presentation system. Wikipedia defines a "presentation program" as "a computer software package used to display information, normally in the form of a slide show" [46]. 
However, this definition is nowhere near adequate and refers to a "presentation program," not a computer-based "presentation system." As defined by Webster, a presentation is "something set forth for the attention of the mind" [36] and a system is "a group of devices or artificial objects or an organization forming a network especially for distributing something or serving a common purpose" [36]. By aggregating these definitions and noting that this paper focuses on computer-based presentation systems for the classroom, the author offers a definition of a computer-based presentation system as the following:

A computer-based presentation system is a group of computer devices and software working together to help instructors and students perform their needed tasks in the learning environment. As an abbreviation, a computerbased presentation system will be referred to as a presentation system.

\section{Tablet-based Presentation System}

Tablet PCs are like extensions of laptops with inking capabilities using a stylus as an input device that allows writing on the screen; more details on tablet PCs will be given in a later chapter. For now, based on the definition of a presentation system, the author defines a tablet-based presentation system as follows:

A tablet-based presentation system is a presentation system centered on the use of tablet PCs. 


\section{BACKGROUND}

\subsection{Learning Styles}

There are numerous models to classify students' learning styles. Some of the more popular models are the Kolb's Learning Style Inventory [50], the Myers-Briggs inventory [22, 40], the Soloman Inventory of Learning Styles [37], and the Felder and Silverman Learning Style model $[1,23,26]$. The Kolb Learning Style Inventory describes the four learning stages as concrete experience, reflective observation, abstract conceptualization, and active experimentation. The Myers-Briggs inventory focuses more on how personality types affect learning. The Soloman Inventory of Learning Styles groups learners into four dimensions: processing (active/reflective), perception (sensing/intuitive), input (visual/verbal), and understanding (sequential/global). And finally, Felder and Silverman Learning Style model also uses the same categories as the Soloman Inventory of Learning Styles.

This paper uses Marcia Conner's learning styles model as an assessment tool for students' learning preferences [13]. Although this model seems too focused on the use of sensory channels and lacks some important learning dimensions offered by other models mentioned, the assessment tool is easy to use, concise, and freely available. More details on the reason why this particular model is chosen will be addressed in Chapter 10 when validation of the research is explored. Having said that, Marcia Conner's learning styles model categorizes learners into three dimensions: visual, auditory, and tactile/kinesthetic. 


\section{Visual learners}

Visual learners learn through seeing. They prefer to look at what they are learning which includes both the instructor and the material being presented. They usually think in pictures and learn best from visual displays such as diagrams, illustrated textbooks, overhead transparencies, videos, flipcharts, and hand-outs.

\section{Auditory learners}

There are two types of auditory learners: auditory listener and verbal processor. Auditory listeners learn through listening. They interpret meaning from listening to sounds, intonations, and words. They learn best from verbal lectures and listening to others. They usually enjoy reading because it gives them a chance to hear the story in their mind's ear. On the other hand, verbal processors feel the need to say things out loud in order to comprehend the given information. They learn best from discussions, talking things through, and repeating information aloud.

\section{Tactile/Kinesthetic learners}

Tactile/Kinesthetic learners learn through moving, doing, and touching. They learn best through a hands-on approach such as role-playing and participating in cooperative games and simulations. They may get distracted when sitting still for too long because of their need for activity and exploration.

\subsection{Tablet PC Features}

Tablet PCs have been known as "PDAs on steroids or extensions of laptops with multimodal input options" [61]. The main difference between tablet PCs and regular 
laptops is their interaction paradigm; tablet PCs allow pen-based inputs on top of other input options for laptops such as keyboard, mouse, and touchpad. Some tablet PCs are more like slates because they do not have an attached keyboard. There are others that are more like laptops but with the capability of converting the screen into a slate configuration. Figure 1 and Figure 2 show the HP TC4200, a typical example of what a tablet PC looks like.

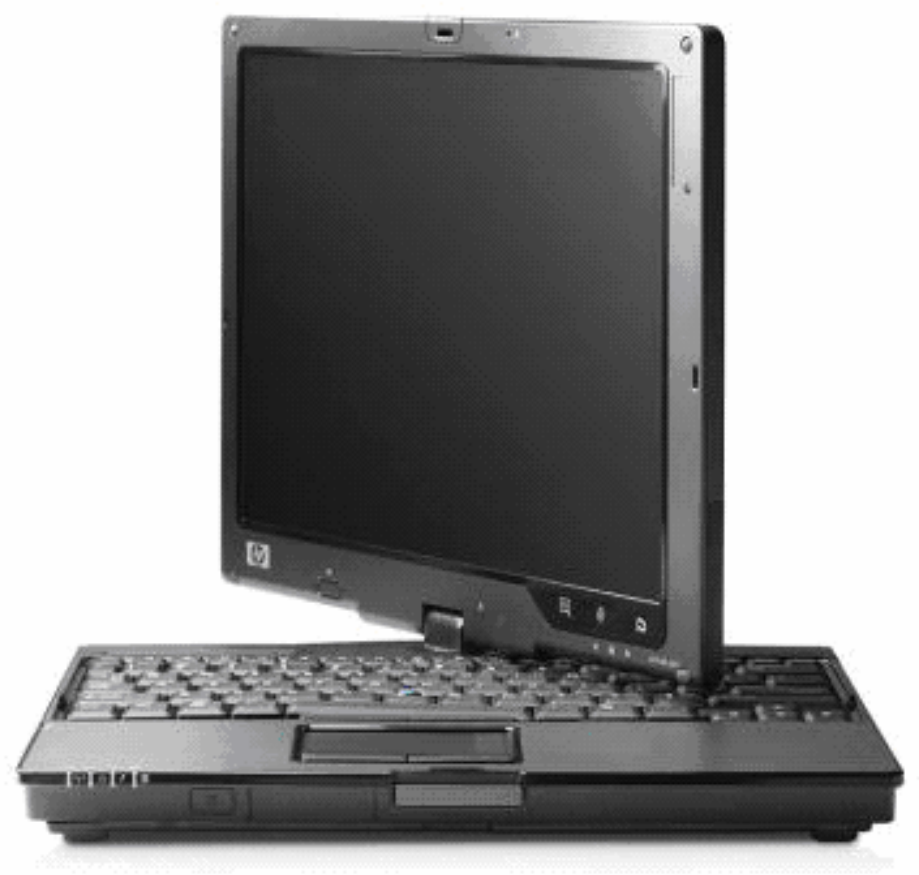

Figure 1: HP TC4200 


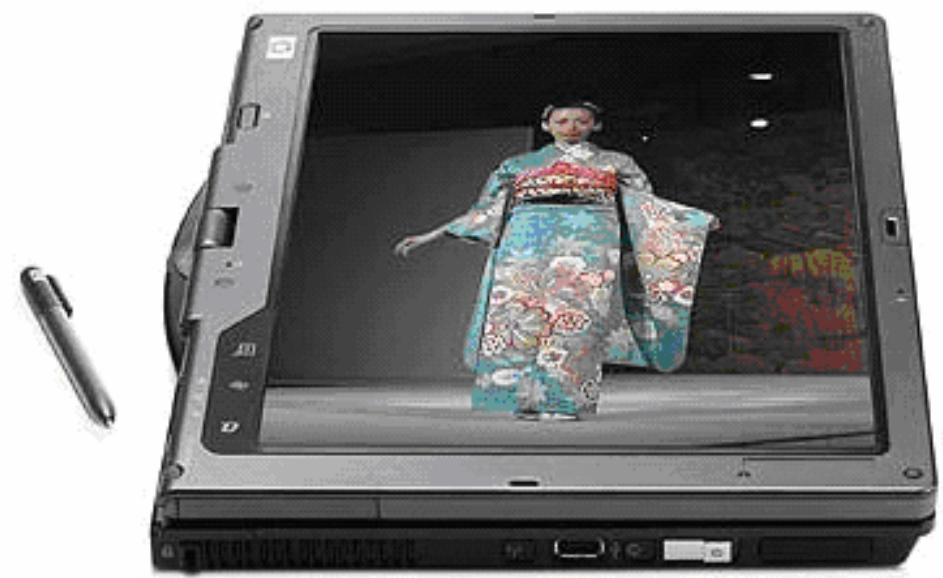

Figure 2: HP TC4200 Slate Configuration

Surveying several tablet PCs such as the Lenovo Thinkpad X60 [34], HP Pavilion tx1000 Entertainment [27], Toshiba R400 [53], TabletKiosk's Sahara i440D [52], and the HP TC4200 [28], below is a list of features that typical tablet PCs are currently equipped with.

- Core hardware including a processor, memory, hard drive, graphics card, and typically no optical drive (which is often available in a docking station)

- Windows Vista Operating System

- Various connectivity options include the modem, Ethernet, IR, Bluetooth, WLAN, and WWan

- USB ports, PC Card slots, headphone and microphone jacks

- Built-in stereo speakers and microphone

- A stylus and an attached eraser

- Fingerprint reader to log into your computer

- Touch screen or pressure-sensitive active digitizer, or both 
- External DVD drive

- Buttons located on the screen bezel for navigation and screen rotation

- Screen size ranging from 10.4" to 14.1 " [61]

- Weight ranging from $2.6 \mathrm{lb}$ to $8.4 \mathrm{lb}$ [61]

- Battery life ranging from 3 hours to 9 hours [61]

\subsection{Presentation Systems}

Abowd mentioned in his paper that pen-based laptops, PDAs, tablets, or palmtop PCs are less intrusive and allow for more natural handwritten note-taking [3]. For this reason, many presentation systems make use of these tools. Table 1 lists a few of these pen-based devices and the corresponding software that is used in various presentation systems.

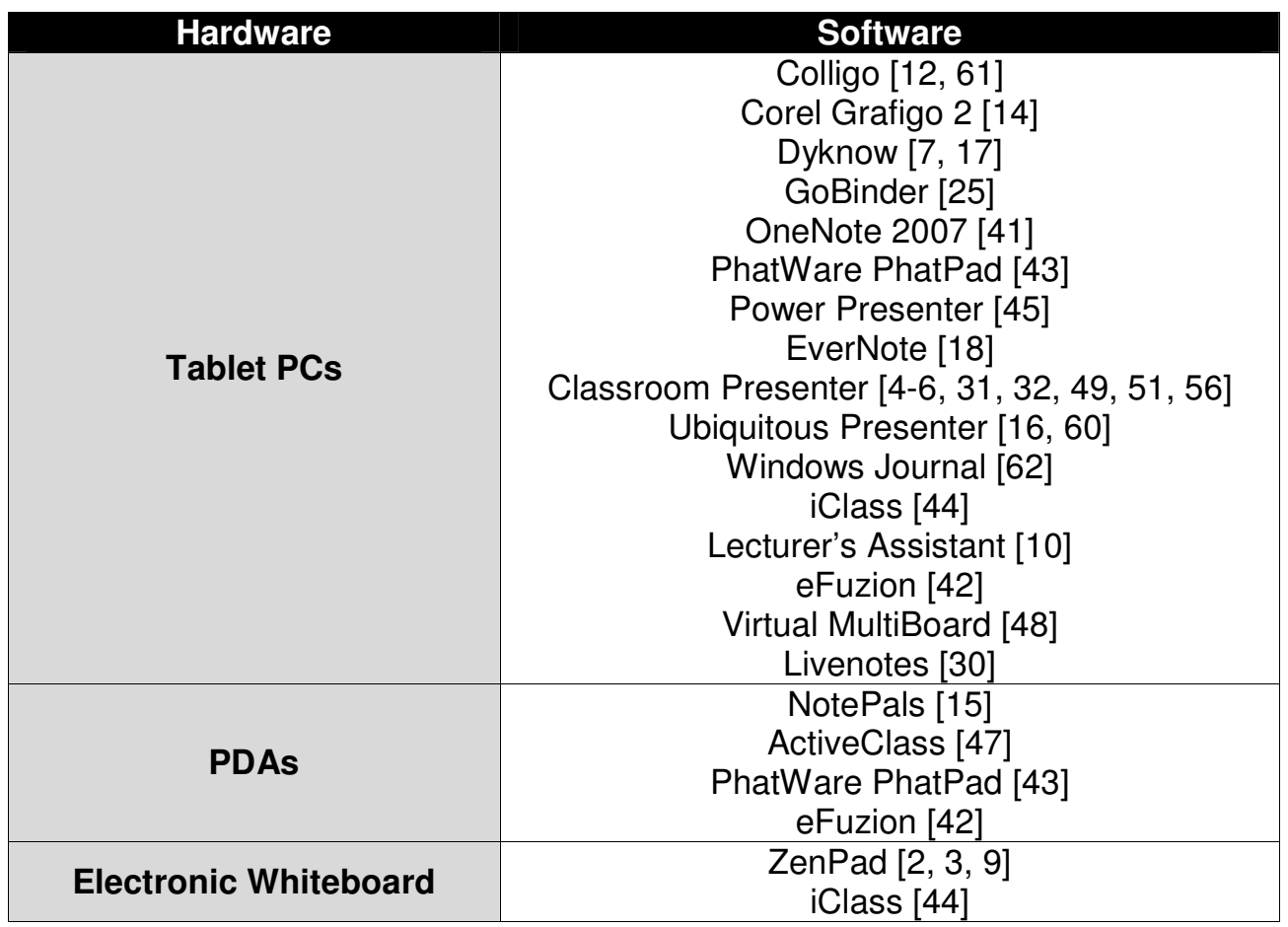

Table 1: Hardware for Presentation System Software 
Presentation systems have much functionality that aids teachers and students in the classroom. With the combination of hardware and software listed above, each presentation system offers at least one of the following features:

\section{Features of Presentation Systems:}

Annotation

- instructor annotations

- student annotations

- electronic whiteboard

Feedback

- instructor feedback

- $\quad$ student feedback

Recording

- audio recording

- video recording

Tools

- $\quad$ screen capture

- handwriting recognition

- annotation tools

- history of ink strokes

- export notes

- organize notes 


\section{Navigation}

- slide navigation

\section{Collaboration}

- Networking

This list is not a comprehensive list of features offered by every possible presentation system; however, it does capture the essential aspects of a typical presentation system.

For the sake of this paper, a presentation system is distinguished by the kind of software that it uses. Hence, for better organization, Table 2 groups presentation systems by the features that they offer. The subsections that follow will provide more explanations on what these features are and how they can be utilized in the classroom environment. 


\begin{tabular}{|c|c|c|c|}
\hline $\begin{array}{c}\text { Presentation System } \\
\text { Software }\end{array}$ & Features & $\begin{array}{c}\text { Presentation System } \\
\text { Software }\end{array}$ & Features \\
\hline Colligo & $\begin{array}{l}\text { - Instructor Feedback } \\
\text { - Student Feedback } \\
\text { - Networking }\end{array}$ & Lecturer's Assistant & $\begin{array}{l}\text { - Instructor Annotations } \\
\text { - Student Feedback } \\
\text { - History of Ink Strokes }\end{array}$ \\
\hline Corel Grafigo 2 & $\begin{array}{l}\text { - Instructor Annotations } \\
\text { - Student Annotations } \\
\text { - Export Notes } \\
\text { - Screen Capture } \\
\text { - Annotation Tools } \\
\text { - Slide Navigation } \\
\text { - Networking } \\
\end{array}$ & iClass & $\begin{array}{l}\text { - Instructor Annotations } \\
\text { - Student Annotations } \\
\text { - Audio Recording } \\
\text { - History of Ink Strokes } \\
\text { - Annotation Tools } \\
\text { - Video Recording } \\
\text { - Electronic Whiteboard }\end{array}$ \\
\hline Dyknow & $\begin{array}{l}\text { - Instructor Annotations } \\
\text { - Instructor Feedback } \\
\text { - Student Annotations } \\
\text { - Student Feedback } \\
\text { - Screen Capture } \\
\text { - History of Ink Strokes } \\
\text { - Handwriting Recognition } \\
\text { - Annotation Tools } \\
\text { - Electronic Whiteboard } \\
\text { - } \quad \text { Networking } \\
\end{array}$ & OneNote 2007 & $\begin{array}{l}\text { - Student Annotations } \\
\text { - Audio Recording } \\
\text { - Export Notes } \\
\text { - Handwriting Recognition } \\
\text { - Annotation Tools } \\
\text { - Slide Navigation } \\
\text { - Video Recording } \\
\text { - Electronic Whiteboard } \\
\text { - Networking } \\
\text { - } \text { Organize Notes } \\
\end{array}$ \\
\hline GoBinder & $\begin{array}{l}\text { - Student Annotations } \\
\text { - Export Notes } \\
\text { - Handwriting Recognition } \\
\text { - Annotation Tools } \\
\text { - Slide Navigation } \\
\text { - Organize Notes }\end{array}$ & eFuzion & $\begin{array}{l}\text { - Instructor Annotations } \\
\text { - Instructor Feedback } \\
\text { - Student Annotations } \\
\text { - Student Feedback } \\
\text { - Annotation Tools }\end{array}$ \\
\hline Windows Journal & $\begin{array}{l}\text { - Student Annotations } \\
\text { - Export Notes } \\
\text { - Handwriting Recognition } \\
\text { - Annotation Tools } \\
\text { - Electronic Whiteboard } \\
\end{array}$ & ZenPad & $\begin{array}{l}\text { - Instructor Annotations } \\
\text { - Audio Recording } \\
\text { - History of Ink Strokes } \\
\text { - Video Recording } \\
\text { - Electronic Whiteboard } \\
\end{array}$ \\
\hline PhatWare PhatPad & $\begin{array}{l}\text { - Instructor Annotations } \\
\text { - Student Annotations } \\
\text { - Audio Recording } \\
\text { - Export Notes } \\
\text { - Handwriting Recognition } \\
\text { - Annotation Tools } \\
\end{array}$ & Livenotes & $\begin{array}{l}\text { - Student Annotations } \\
\text { - Annotation Tools } \\
\text { - Slide Navigation } \\
\text { - Electronic Whiteboard } \\
\text { - Networking }\end{array}$ \\
\hline ActiveClass & $\begin{array}{l}\text { - Instructor Feedback } \\
\text { - Student Feedback }\end{array}$ & NotePals & $\begin{array}{ll}\text { - } & \text { Student Annotations } \\
\text { - } & \text { Handwriting Recognition } \\
\text { - } & \text { Organize Notes } \\
\end{array}$ \\
\hline EverNote & $\begin{array}{l}\text { - Student Annotations } \\
\text { - Export Notes } \\
\text { - Screen Capture } \\
\text { - Handwriting Recognition } \\
\text { - Annotation Tools } \\
\text { - Organize Notes } \\
\end{array}$ & Power Presenter & $\begin{array}{l}\text { - Instructor Annotations } \\
\text { - Student Annotations } \\
\text { - Export Notes } \\
\text { - History of Ink Strokes } \\
\text { - Annotation Tools } \\
\text { - Slide Navigation } \\
\end{array}$ \\
\hline Classroom Presenter & $\begin{array}{ll}\text { - Instructor Annotations } \\
\text { - Student Annotations } \\
\text { - Student Feedback } \\
\text { - Export Notes } \\
\text { - Annotation Tools } \\
\text { - Slide Navigation } \\
\text { - Electronic Whiteboard }\end{array}$ & Virtual MultiBoard & $\begin{array}{l}\text { - Instructor Annotations } \\
\text { - Student Annotations } \\
\text { - Student Feedback } \\
\text { - History of Ink Strokes } \\
\text { - Annotation Tools } \\
\text { - Video Recording } \\
\text { - Electronic Whiteboard }\end{array}$ \\
\hline Ubiquitous Presenter & $\begin{array}{l}\text { - Instructor Annotations } \\
\text { - Student Feedback } \\
\text { - History of Ink Strokes } \\
\text { - Annotation Tools } \\
\text { - Slide Navigation } \\
\text { - Electronic Whiteboard }\end{array}$ & & \\
\hline
\end{tabular}

Table 2: Available Features for Presentation System Software 


\subsubsection{Instructor Annotations}

Instructor annotations can be split into two types, those that transmit to students and those that do not. Usually when instructors lecture in class, they have the ability to write additional notes on top of the slides if they were to use a pen-based device. These handwritten notes can either be accessible to only the instructor and projected on a screen for students to see, or these notes can be transmitted wirelessly to students' own copy of the slides on their devices and can be saved by the students for later review. Additionally, instructors have the option of writing notes on top of prepared slides or on top of blank slides. Also, instructors can make private notes such as writing on work submitted by students or for personal use. With these distinctions, Dyknow, Classroom Presenter, Ubiquitous Presenter, eFuzion, and Virtual Mutliboard are all examples of software that allows instructors to annotate on top of prepared slides that can be transmitted to students' electronic devices. Power Presenter, ZenPad, iClass, and Lecturer's Assistant

allow instructors to annotate on top of slides but not transmit. Finally, Corel Grafigo 2 and PhatWare PhatPad act as a sort of "whiteboard" which let instructors annotate on top of blank slides and not be transmitted to students.

\subsubsection{Instructor Feedback}

Instructor feedback allows the instructor to communicate with his/her students electronically. During class, students can submit questions in the form of an inked slide or quick notes and instructors can reply to these questions in the same manner. Colligo, Dyknow, eFuzion, and ActiveClass have this capability, but only Dyknow can provide instructor feedback even when class is not in session. 


\subsubsection{Student Annotations}

Student annotations comprise of students taking notes with their pen-based devices during lecture. Students either have access to lecture slides before class starts and they can write additional information on top of these slides, or they can take notes on blank slides in the style of a regular notebook. Corel Grafigo 2, PhatWare PhatPad, EverNote, NotePals, and Windows Journal offer students the ability to freely take notes on blank slides. Dyknow, GoBinder, Power Presenter, OneNote, Classroom Presenter, iClass, eFuzion, Virtual MultiBoard, and Livenotes support students taking notes on top of lecture slides. Student notes are usually kept private on their own pen-based devices and are not transmitted to the rest of the class. However, Dyknow does allow students to take control of the lecture and broadcast their writings to the rest of the class if needed.

\subsubsection{Student Feedback}

There are two types of student feedback, feedback to instructors and feedback to the class. Often times, instructors would like to test students' understanding of the topics being discussed in class. They could either poll the class for student reactions or pose some questions for students to answer. From here, students can submit an inked slide to the instructor with their answers, opinions, or questions about the class so far. Colligo, Dyknow, Classroom Presenter, Ubiquitous Presenter, eFuzion, Virtual MultiBoard, and ActiveClass have this feature available. In addition, Dyknow, Classroom Presenter, and Ubiquitous Presenter give instructors the ability to project some of students' submissions to the rest of the class. Furthermore, Lecturer's Assistant allows students to use their 
tablet PC to take control of the projection screen. They can write, draw, or point to certain elements on the screen when asking questions about the lecture slides.

\subsubsection{Audio Recording}

Sometimes having an audio recording of the lecture can be helpful for students. Also, if the audio is synchronized with the lecture slides, students can listen to the recording and know exactly what the instructor said at a specific place in the slide. PhatWare PhatPad, OneNote, ZenPad, and iClass have this capability. OneNote and ZenPad also let students search through the audio by keywords.

\subsubsection{Export Notes}

Notes created using any kind of software are more useful when they can easily be viewed by many people. To do this, it is important to be able to export notes from the application and convert them to a more common format like HTML, JPEG, or TIFF. Corel Grafigo 2, GoBinder, PhatWare PhatPad, EverNote, Power Presenter, OneNote, Classroom Presenter, and Windows Journal allow students to export their notes to other formats.

\subsubsection{Screen Capture}

Corel Grafigo 2, Dyknow, and EverNote let students select portions of any application or Web site and save it as an image. The image can be inserted into the notes and students can write additional notes on top of it. 


\subsubsection{History of Ink Strokes}

Whether it is instructor annotations or student annotations, it is very useful for students if the notes can be replayed stroke-by-stroke. This helps students understand the chronology of the marks to aid in the recall of information. Dyknow, Power Presenter, Ubiquitous Presenter, ZenPad, iClass, Lecturer's Assistant, and Virtual MultiBoard all have this feature implemented.

\subsubsection{Handwriting Recognition}

Dyknow, GoBinder, EverNote, PhatWare PhatPad, OneNote, and Windows Journal let students search through handwritten notes for keywords. PhatWare PhatPad, OneNote, NotePals, and Windows Journal can also convert handwritten notes to printed text.

\subsubsection{Annotation Tools}

It is useful to provide students and instructors with annotation tools like varying thickness of pen and highlighter, different ink colors, and an eraser. Dyknow, GoBinder, PhatWare PhatPad, EverNote, Power Presenter, OneNote, Classroom Presenter, Ubiquitous Presenter, iClass, eFuzion, Virtual MutliBoard, and Windows Journal have these tools. Also, some systems like Corel Grafigo 2, GoBinder, and OneNote have drawing tools for drawing basic shapes and forms. Other than handwritten notes, Dyknow, EverNote, OneNote, and Livenotes allow students to enter typed text when taking notes. 


\subsubsection{Slide Navigation}

Sometimes students want access to all of the lecture slides so that they can freely navigate through the material without having to depend on the pace of the lecture. Corel Grafigo 2, Power Presenter, Classroom Presenter, Ubiquitous Presenter, GoBinder, OneNote, and Livenotes give students navigation tools to navigate through the slides without having to depend on what slide the instructor is lecturing on.

\subsubsection{Video Recording}

Using external cameras, OneNote, ZenPad, iClass, and Virtual MultiBoard permit recorded video of lectures to be synchronized with audio recording and lecture slides.

\subsubsection{Electronic Whiteboard}

Electronic whiteboards give students and instructors access to blank slides to write or draw on. Dyknow, Classroom Presenter, Ubiquitous Presenter, ZenPad, iClass, Virtual MultiBoard, and Windows Journal have this option. OneNote and Livenotes allow for a shared whiteboard where students and instructors can synchronously write on the same blank space.

\subsubsection{Networking}

There are times when it is helpful for students to be wirelessly connected to one another and share a note-taking medium so any writings done by one student can be seen by others. Corel Grafigo 2, Dyknow, OneNote, and Livenotes give students this 
capability. Colligo also lets students chat, share files, folders, printers, and internet connections.

\subsubsection{Organize Notes}

There are a few tools that allow students to organize their notes into categories, sorted by date and subject. These tools are GoBinder, EverNote, OneNote, and NotePals. GoBinder, EverNote, and OneNote also let students flag certain key concepts so that they can be located easier. 


\section{RESEARCH QUESTION}

An interesting research topic is to validate the effectiveness of using tablet PCs in the classroom. More concretely, the research needs to address how well tablet PCs satisfy the different learning needs of students. By understanding the relationship between tablet PCs and learning styles, it could potentially allow for more efficient use of tablet PCs in the classroom. Because tablet PCs offer a variety of functionality, this paper focuses on the use of tablet PCs in presentation systems. Therefore, given the presented learning styles model, presentation system features, and tablet PC capabilities, this paper explores the correlation between tablet-based presentation systems and learning styles. 


\section{RELATED WORK}

\subsection{Importance of Learning Styles}

Differences in learning styles and personality types can affect how well students perform in the classroom. Based on a study composed of 83 engineering students, O'Brien found that $72 \%$ of these students are Sensing type while $28 \%$ are Intuitive based on the Myers-Briggs Type Indicator [40]. However, traditional teaching often favors the Intuitive type; hence, Intuitive students have significantly higher grades than Sensing students.

Similarly, Felder explored the effects of personality type on engineering student performance [22]. 116 students participated in the study to explore how well students perform in the class based on personality differences. As a result, the study revealed that Intuition, Judging students had a B average grade. Intuition, Perceiving students had a Bor $\mathrm{C}+$ average. Sensing, Judging students had a $\mathrm{C}$ average. And Sensing, Perceiving students had a C- or D+ average. This shows that differences in personality types do have an effect on students' achievements in the classroom. Furthermore, the study concluded that courses with more cooperative, hands-on learning can improve Extraversion, Sensing students' learning.

In addition, students can either succeed or fail in the classroom depending on their learning style. According to Felder, most engineering students are visual, sensing, inductive, active, and global learners [23]. However, Felder claimed that most engineering education is auditory, intuitive, deductive, passive, and sequential. Hence, 
"These mismatches lead to poor student performance, professorial frustration, and a loss to society of many potentially excellent engineers [23]."

As evident, an effective learning environment needs to be designed with an awareness of and address students' differences in learning styles and personality types.

\subsection{Learning Styles and Software}

There are various computer systems that have been developed using learning styles as a foundation for design criteria. An example of such a system is the Adaptive Educational System based on Cognitive Styles, also known as AES-CS [54]. AES-CS is a Web-based learning tool that can adapt to student's learning needs. A student first interacts with the system to generate a profile that will categorize him/her as either a field independent or a field dependent learner. A field independent learner is analytical, introverted, and needs self-defined goals. A field dependent learner is global, extrovert, and needs goals to be defined externally. Once the student's learning model has been established by the system, the system will present the learning material in a manner that best fits that student's learning preferences. The use of AES-CS has been evaluated by five teaching experts and ten students. Everyone seemed satisfied and thought the system was easy to use and understand.

A similar tool to the AES-CS is the Interactive Teaching Tutorial or ITT for short [1]. This is an online learning tool that applies Felder and Silverman's learning style which consists of four learning dimensions: active/reflective, sensing/intuitive, visual/verbal, and sequential/global. Users of the system first take a questionnaire to 
determine their learning style. The system will then adapt to this style and display information accordingly. 25 students were surveyed after using this system. Most of the students thought that ITT was useful and they would be willing to use it if it was available. However, the study mentioned that students felt the generated learning style did not match their own preferences when learning and they also felt that the system could use some further improvements.

Yet another example of these types of programs is the Adaptive Hypermedia Educational System or AHES [26]. AHES is an interactive software for educational repositories which collect teaching material to be used in the classroom. On first use, the system asks users 16 questions to categorize their learning style based on Felder and Silverman's learning model. From there, the program continues to refine this categorization through user interaction with the software. No evaluations were reported in this study to show how students reacted to the use of this program.

Finally, another example of these systems is the four teaching tutorial programs developed at the University of Michigan; these programs are Pressure/Temperature, Multiphase Systems, Mass Balances, and an Encyclopedia of Chemical Engineering Equipment [37]. These programs try to address the needs of all learning styles by providing components that might seem useful to each type. The study uses Soloman's inventory of learning styles based on four dimensions: Processing (active/reflective), perception (sensing/intuitive), input (visual/verbal), and understanding (sequential/global). Having surveyed 143 students, the study reveals that the use of 
multimedia in the classroom is effective in addressing the learning styles typically neglected by traditional teaching methods.

When reviewing the systems mentioned, one common deficiency of all these studies is their system evaluations. These evaluations are based on very small numbers and they are conducted mostly by the developers themselves. Therefore, the results could be skewed towards the developers' expectations and the conclusions cannot be validated due to the small sample size. This leads to the idea that perhaps a more effective study would involve a larger group of participants who have no relations to the product being tested. Even then, such a study might not be the optimal solution but it offers an approach worth investigating.

\subsection{Evaluation of Current Systems}

Based on the research found, there are three main factors that are being determined when evaluating presentation systems: student reactions, student behavior, and student performance.

\subsubsection{Student Reactions}

When evaluating presentation systems, many researchers try to determine how students are reacting to the use of these systems. Berque surveyed 117 students and found that overall, students enjoyed using DyKnow. They felt that it enhances their understanding, helps them take better notes, be more attentive in class, and they would definitely recommend classes that use DyKnow to others [7]. Similarly, Anderson surveyed 1000 students and found that the use of Classroom Presenter increases students' 
attention and understanding in the classroom and they would encourage instructors to make use of this system [4]. In addition, Kam surveyed 21 students who have used Livenotes and found that students overall felt that Livenotes assisted their learning [30]. $66 \%$ of these students thought that the system allowed them to take more comprehensive notes and to be more attentive in class.

Many researchers have performed more general analyses of student reactions to using certain presentation systems. For example, Simon surveyed 18 students and concluded that the students had a positive reaction to using Classroom Presenter [49]. Abowd surveyed 24 students and found that students also had a positive reaction to using ZenPad on the tablets but a negative response to using palm top PCs because of the small screen [3]. In addition, students had a positive reaction to using Lecturer's Assistant [10], eFuzion [42], and Virtual Multiboard [48].

\subsubsection{Student Behaviors}

Often times, researchers want to see how the use of presentation systems affect the way students behave in the classroom. Subhlok noticed that when using Classroom Presenter, access to lecture slides with synchronized audio recording reduces the time that students spend on reading the textbook [51]. However, $65 \%$ of the students still use both textbook and the slides to study for their midterm and final. Another study was done

by Denning, who put together mock lectures with students using tablets and laptops with Ubiquitous Presenter [16]. From his work, Denning found that pen-based devices allow for more collaboration when used in groups compared to using PCs. 
ZenPad is another good example of a presentation system that was evaluated based on student behaviors [2]. The system was deployed in 12 courses and students were videotaped, interviewed, and questioned. As a result, Abowd found that out of 165 students, $70 \%$ of these students did not feel like having access to class notes encourages them to miss class. $58 \%$ of students said that their note-taking practices have changed since they spend more time in class listening to lecture and not have to worry about writing down notes. Instructor's annotations are automatically captured by the software and will be made available. Similarly, Kam reported that without the use of Livenotes, students spend $92.4 \%$ of their time in class on taking notes; however, when using Livenotes, students spend $53.6 \%$ on note-taking and the rest of the time on commentary, asking questions, giving answers, and participating in class discussions [30]. Also, students seem to be more active in the classroom when they are allowed to submit electronic questions to instructors during class time [47]. Ratto showed that with the use of ActiveClass, students submit an average of eight questions per class period. The system also allows other students to vote on the importance of the submitted questions. And on average, students make about 40 votes per class period.

\subsubsection{Student Performance}

Other than evaluating student reaction and behavior, some researchers want to test whether or not presentation systems can actually improve students' performance in the classroom. In a study done in spring 2006, Koile made use of Classroom Presenter in two courses [31]. Before the first midterm, Class A used tablet PCs with Classroom Presenter

while Class B did not have access to these tools. On average, Class A scored $80 \%$ while 
Class B had 76.4\%. After the first midterm, Class A gave Class B the tablets. Therefore, Class B now uses the tablets with Classroom Presenter while Class A no longer has access to these tools. Both classes took their second midterm and this time, Class A scored an average of $78.5 \%$ and Class B scored $85.3 \%$. Also, results from the study showed that students who submitted an average of 3.5 electronic feedbacks to instructors per class scored an average of $89.6 \%$ on the second midterm. Students who submitted an average of 1.1 feedbacks scored $75.5 \%$ on average. These results are statistically significant.

Another study was done by Kurtz using Classroom Presenter as well [32]. In fall 2005, students were taught using traditional learning methods. During spring 2006, the same course was being taught with the same instructor using Classroom Presenter and students using OneNote. As a result, Kurtz showed that students' project grades are higher during spring quarter than fall quarter. Also, students' overall course grades for spring quarter are $9.5 \%$ higher on average than fall quarter.

\subsection{Research Motivation}

As mentioned in the previous section, researchers have been evaluating presentation systems based on student reactions to using the systems, the impact the systems have on student behaviors, and how well the systems can enhance student learning. However, none of the research found so far has evaluated how well presentation systems can address the needs of different learning styles. Again, it is important to consider different learning styles in the classroom in order to create an unbiased, well- 
balanced environment effective for all students. Therefore, the purpose of this paper is to explore the relationship between tablet-based presentation systems and learning styles. 


\section{RESEARCH APPROACH}

The two approaches that this research takes are performing a pilot study and administering a survey. More details on the structure of these approaches and the results yielded can be found in the next two chapters. Before continuing to these chapters, it is important to mention the features for tablet-based presentation systems. As described in Section 3.3, there are numerous features for presentation systems in general. However, it is not feasible to include all of these features in the study given the patience of the participants involved and the tablet PC capabilities. As outlined in Section 3.2, most tablet PCs are not equipped with a built-in webcam or video recording equipment. Therefore, the video recording feature for presentation systems can be left out when trying to evaluate tablet-based presentation systems. Below is a list of all the features that will be addressed when evaluating tablet-based presentation systems.

\section{Features of Tablet-Based Presentation System:}

\section{Instructor Annotations}

1. Using the tablet PC, instructors can handwrite additional notes on top of slides to illustrate difficult concepts or to give explanations of important ideas

2. Capturing instructors' handwritten notes during lecture using the tablet PC

Instructor Feedback

3. Sending instant electronic responses to students' questions or comments during lecture 


\section{Student Annotations}

4. Handwriting student digital notes on top of lecture slides using the tablet PC

5. Separate views for lecture notes with instructors' annotations and lecture notes with student annotations

\section{Student Feedback}

6. Sending instant electronic questions to the instructor during lecture

7. Sending anonymous electronic questions to the instructor during lecture

8. Taking real-time quizzes or assessments on the tablet PC and submit them to the instructor electronically

9. Instructor shares students' electronic submissions to the class via the tablet PC

\section{Voice Recording}

10. Recording instructor's voice during lecture

11. When reviewing lecture notes, recorded instructor's voice are synchronized with the slide you are on and the notes that you took during class

12. Using speech recognition capabilities to convert instructor's voice to text

\section{History of Ink Strokes}

13. Reviewing the notes in the order that instructor/students wrote them by using the tablet PC to replay the handwritten notes stroke-by-stroke

14. Ink strokes change color over time to differentiate notes taken during different periods of the lecture 


\section{Handwriting Recognition}

15. Handwritten notes using the tablet PC are automatically converted to printed text

16. Using the tablet PC to search through handwritten notes for key words

\section{Electronic Whiteboard}

17. Having access to blank slides to take additional notes

\section{Slide Navigation}

18. Navigating through all lecture slides without being restricted to the slide that the instructor is lecturing on

\section{Annotation Tools}

19. Highlighting key words or ideas using the tablet PC

20. Erasing ink marks or strokes written using the tablet pen

21. Changing to different color ink when taking notes

Networking

22. Peer-to-peer networking of tablet PCs to allow you to share applications or chat with your instructors or other students 


\section{PILOT STUDY}

During winter 2007, a group of Cal Poly students, consisting of Natalia Alarcon, Khang Duong, Bryan Estrada, Andrew LeBeau, along with the author as the project leader, performed a study of learning techniques in the classroom. The team evaluated the effectiveness of tablet PCs as a learning device, and specifically the Classroom Presenter software package. The team wanted to assess how the use of this presentation system affects student performance, student behavior in the classroom, and the needs of different learning styles. In order to do this, two mock lectures were held. The following sections outline the specific structure of the study and the results of the experiment.

\subsection{Procedure}

The data collection procedure consisted of two independent lectures with one instructor and several students. Both lectures used the same slides and covered a topic: the sport of fencing. This topic was chosen so that no student would have a significant background knowledge advantage over any other student. This is true because no students raised their hands when asked if they are familiar with the topic of fencing. At the end of both lectures, all students took a short quiz. Both lectures were approximately 30 minutes long and the quiz featured 13 multiple choice questions about the material covered in the lecture. All students were made aware that they would be taking a quiz on the lectured material before the classes began. 


\subsubsection{Control Group}

The first lecture was the control group, consisting of 10 students from various majors, and was modeled after the traditional learning environment. The instructor used a tablet PC to display slides using Classroom Presenter software. Slides were displayed using a computer projector. Each student was given a printed copy of the slides and was encouraged to take notes if they felt necessary. They did not have access to tablet PCs. The instructor annotated notes on the slides using the tablet PC and asked the students to respond to questions at specific points. At the end of the lecture, students were given about 5 minutes to review their notes and prepare for the quiz. Then the students' notes were collected and the quizzes were passed out. Students were given as much time as needed to complete the quiz.

\subsubsection{Experimental Group}

The students in the second lecture were the experimental group, consisting of 5 students from various majors, and used tablet PCs. The instructor used the same materials as the first lecture, but each student had a tablet PC displaying the slides using Classroom Presenter software. The students were given a brief tutorial on how to use the Classroom Presenter software before the lecture started. During the lecture, instructor annotations were very close to what they were during the first lecture. The same questions were asked by the instructor at the same points. Students were encouraged to use the electronic submission capability at one point near the end of the lecture, but during all other points, students were free to respond to questions in any way they desired. After the lecture, students were given about 5 minutes to prepare for the quiz. Just before the quizzes were 
passed out, the students were asked to save their notes and their tablet PCs were collected.

\subsubsection{Other Data Collected}

Before the lecture, students were given a Memletics learning style test that consisted of 70 multiple choice questions [35]. This test was used for an analysis of the test results after the experiment. During the lecture and quiz, each student was assigned a number that was linked to his or her quiz score and the notes that he or she took. Additionally, each question asked or answered by a student was noted by members of the research team in the back of the room for a comparison of classroom interaction versus quiz performance. No video recordings were made to track student behavior. However, four team members sat in the back of the lecture room to fill out pre-structured tables outlining the frequency of the following metrics:

- Hand raises. This metric counted the number of hand raises per student.

- Questions. This metric counted the number of questions per student.

- Answers. This metric counted the answers given aloud per student.

- Distractions. This metric counted the number of distractions per student, which can include talking amongst themselves, looking around, and falling asleep.

- Comments. This metric counted how many times a student made a comment. 
After the lecture and quiz, for the experimental lecture group only, students were given a questionnaire about general tablet PC presentation software and which features the students perceived as useful/helpful. Not all of the features in the questionnaire were available in the Classroom Presenter software, but many of them were. The list of features is shown in the previous chapter.

\subsection{Results}

Having carried out the experiment described above, below are the results that the team extracted from the data that was collected.

\subsubsection{Student Performance}

One of the main purposes of the experiment was to test if Classroom Presenter enhances learning in the classroom. More specifically, the quiz questions only deal with retention and not analysis of information; therefore, this experiment is testing whether or not Classroom Presenter enhances retention in the classroom. As a reminder, Koile has shown in his study that the use of Classroom Presenter does improve students' learning [31]. However, this experiment was done without having knowledge of Koile's findings. Therefore, the experiment was carried out without any biases or preconceived expectations for certain results to occur.

When the experiment took place, students who used tablet PCs for the first time were very excited about the new technology. They seemed more interested in playing around with the tablet PCs than learning the material. From this observation, the team 
first predicted that students who use tablet PCs would do worse on tests than students who only use papers and pencils.

However, the test scores proved this assumption to be false. On average, students who used Classroom Presenter (Group A) scored $71 \%$ on the quiz while students who did not have access to tablet PCs (Group B) scored 66\%. The highest score for Group A was 84.6\% while the highest score for Group B was 76.9\%. The lowest score for Group A was $53.9 \%$ while for Group B was 38.5\%. Based on the results, students using Classroom Presenter have test scores 5\% higher than students not using the software on average. The difference between the highest scores of the two groups is $7.7 \%$ and the difference between the lowest scores is $15.4 \%$. Even though Group A performed better than Group B on the quiz, it can not be concluded that the use of Classroom Presenter improves students' grades. The difference between scores could be due to one group having more capable individuals than the other. Also, students using tablet PCs can be more motivated and attentive during lecture because they were given a toy to play with. Moreover, the small sample size limits the author from making any conclusive claims based on the results.

Another important factor that must be considered is Group A had 5 students and Group B had 10 students. The number of students who were using papers and pencils doubled the number of students who were using tablet PCs. This could skew the test results. Maybe the grade distribution would be different had the same number of students for both groups was used. However, taking the average score should alleviate this problem. 


\subsubsection{Student Behavior}

Besides looking at test scores, the team also took notes of how students behaved and interacted in the classroom with or without the use of tablet PCs. Below are some of these observations:

\subsubsection{Note-Taking}

The first noticeable difference between tablet and non-tablet students can be found in student notes. All tablet PC users took notes while only $40 \%$ non-tablet PC users took lecture notes. The first question that arises is: does the tablet PC encourage note taking? Classroom Presenter does offer many annotation tools that could encourage students to take more notes. While these numbers can suggest this, the sample size remains too small to draw any solid conclusions. The group may simply have been composed of fervent note takers that are not necessarily representative of a real student population.

Interestingly enough, those that took the most notes did not necessarily do well on the test. Several factors influence this. Those that took many notes may only be regurgitating the instructor's annotations and did not really comprehend the presentation. Also, the test came immediately after the lecture, which is not a standard test delivery method. This may have catered more to a subset of students with stronger lecture comprehension skills. 


\subsubsection{Doodling}

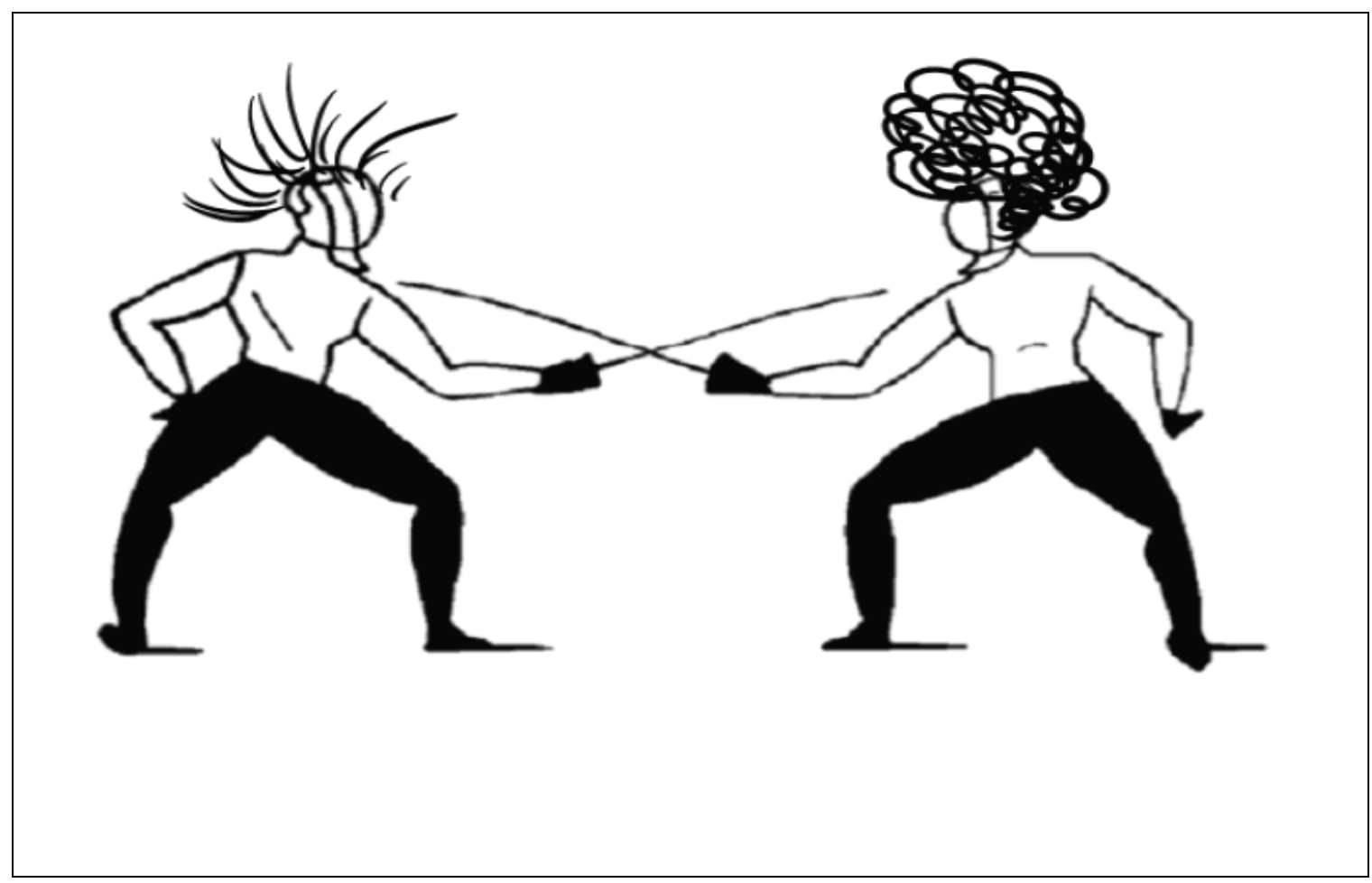

Figure 3: Students Doodling on Tablet PC

Another difference gleaned from the notes showed that while zero non-tablet students doodled on their notes, $40 \%$ of tablet PC users drew pictures that did not pertain to the lecture. Figure 3 shows a doodle of a tablet PC student that does not pertain to the lecture. Does the tablet PC encourage doodling? It provides a wider palette of colors than is normally available to a student during lecture, which might tempt the doodler in a student to come out. However, more conclusive evidence requires a larger sample size. 


\subsubsection{Interaction}

As mentioned earlier, the team took notes of various student interactions during the two lectures. Figure 4 shows the data collected for tablet and non-tablet using students.

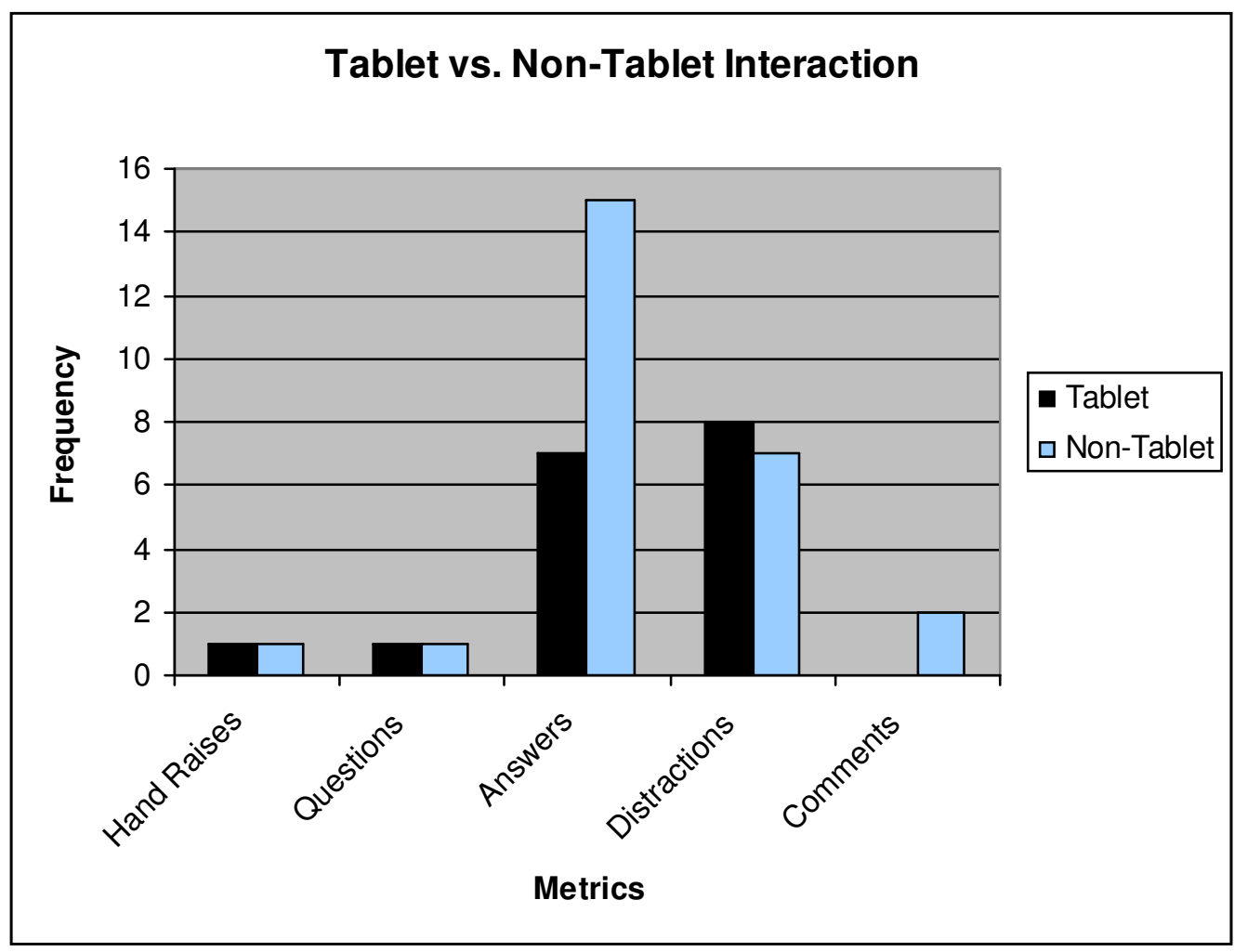

Figure 4: Classroom Interaction for Tablet and Non-Tablet Users

From looking at the data, there were only two tablet using students that submitted electronic feedback to the instructor in the classroom. These two students happened to score the highest out of all the students from both tablet and non-tablet students. This fact does not directly indicate that the feedback submission feature from Classroom Presenter helps students learn better. However, it shows that the software allows students to be 
more focused and engaged in the classroom, which could eventually help them learn the material better.

On another note, two students using the tablet PCs were very distracted with using the technology for the first time. They were seen doodling, writing notes to each other, and talking during the experiment. Subsequently, they scored the lowest out of all the students that were using tablet PCs.

There is one student from the non-tablet PC group that performed counter to what is expected. This student answered the most questions during lecture out of all the students in this experiment. But the test score shows that this student only scored $69.2 \%$ on the quiz. Even though this score is not bad compared to the lowest score, which is $38.5 \%$, the student did not do as well as expected. Considering the data gathered, it cannot be concluded that more involvement in the classroom would help students learn better. However, this topic is outside the scope of the experiment and this route was not explored any further.

\subsubsection{Learning Styles and Preferences}

The participants of this experiment were given a learning style test to determine their learning style preference. The Memletics Learning Styles Inventory categorizes learners into 7 categories: visual, verbal, aural, physical, logical, social, and solitary [35]. The test assigns each test-taker a point value for every learning dimension; one dimension could get a higher point value than another dimension depending on how strongly the test-taker prefers to learn in that mode. 
In addition to taking the learning styles test, participants were also given a tablet PC survey. The survey lists the features that a typical tablet-based presentation system would contain and asks participants to rate the usefulness of each feature on a scale from 1 to 5 (the list of features can be found in Chapter 6). By giving participants both the survey and the learning styles test, the team was trying to see how well features from tablet-based presentation systems match the needs of different learners.

Based on the data collected from both questionnaires, an average rating of every tablet-based presentation system feature was calculated for each of the learning styles. The calculation is done using a weighting system. The formula is the following:

Given:

- $\mathrm{T}(\mathrm{x})$ be student $\mathrm{x}$ rating of a feature

- $\mathrm{L}_{\mathrm{s}}(\mathrm{x})$ be the learning style score in the area $\mathrm{s}$ of a student $\mathrm{x}$

- $\mathrm{u}_{\mathrm{r}}$ be the $\mathrm{r}^{\text {th }}$ user in a group

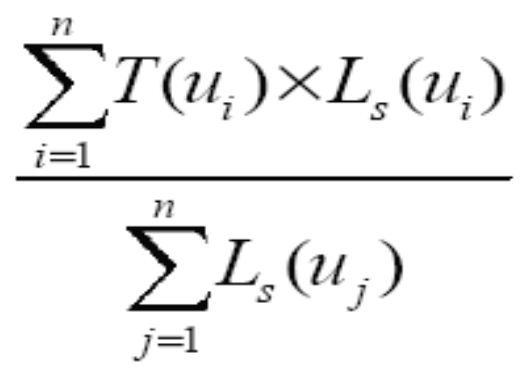

The above formula definitely has very little to no statistical validity due to its small sample size but it seems to be sufficient for the scope of the experiment. By using this formula, every participant's data could contribute to the analysis and no data had to be excluded; this is important given the small sample size of the experiment. The function seems to make sense when put into context of the experiment. Given a scenario where 
Student A rates Feature 1 to be a 4 and he/she scores a 10 on the visual learning dimension. And Student B only scores a 5 on the visual but rates Feature 1 to be a 2 . When trying to find an average rating of Feature 1 for visual learners, the rating from Student A should count more towards the average than Student B since Student A has a stronger preference for visual learning. The author understands that this method offers little confidence in the results yielded; however, this is the best approach given the project's limitations. Furthermore, the author has consulted with Dr. Ulric Lund, a statistics professor at Cal Poly, regarding the use of the formula above. Even though the formula cannot be claimed as a statistically valid approach, Dr. Lund advised that this formula can be used to explore the possible outcomes from the collected data.

From looking at the yielded average rating of each feature, the variance in the ratings for different learning styles was not very significant. So in order to extract more interesting information, the team decided to concentrate the analysis on extremes. For each tablet PC feature, only the learning style that gives the highest or lowest rating for those features is considered. Table 3 summarizes these findings. 


\begin{tabular}{|c|c|c|c|c|}
\hline \multicolumn{2}{|c|}{ Features } & Highest Rating & Lowest Rating & $\%$ Difference \\
\hline \multirow{2}{*}{$\begin{array}{c}\text { Instructor } \\
\text { Annotations }\end{array}$} & 1 & Solitary & Social & 1.58 \\
\hline & 2 & Physical & Social & 2.63 \\
\hline $\begin{array}{l}\text { Instructor } \\
\text { Feedback }\end{array}$ & 3 & Social & Solitary & 7.84 \\
\hline \multirow{2}{*}{$\begin{array}{c}\text { Student } \\
\text { Annotations }\end{array}$} & 4 & Solitary & Visual & 4.8 \\
\hline & 5 & Logical & Visual & 2.44 \\
\hline \multirow{4}{*}{$\begin{array}{c}\text { Student } \\
\text { Feedback }\end{array}$} & 6 & Social & Physical & 5.16 \\
\hline & 7 & Social & Physical & 7.26 \\
\hline & 8 & Solitary & Visual & 4.28 \\
\hline & 9 & Social & Aural & 6.16 \\
\hline \multirow{3}{*}{$\begin{array}{c}\text { Voice } \\
\text { Recording }\end{array}$} & 10 & Logical & Solitary & 8.43 \\
\hline & 11 & Logical & Solitary & 7.99 \\
\hline & 12 & Logical & Solitary & 9.25 \\
\hline \multirow{2}{*}{$\begin{array}{l}\text { History of Ink } \\
\text { Strokes }\end{array}$} & 13 & Solitary & Logical & 6.36 \\
\hline & 14 & Aural & Physical & 4.57 \\
\hline \multirow{2}{*}{$\begin{array}{l}\text { Handwriting } \\
\text { Recognition }\end{array}$} & 15 & Aural & Solitary & 1.57 \\
\hline & 16 & Logical & Solitary & 4.06 \\
\hline $\begin{array}{c}\text { Electronic } \\
\text { Whiteboard }\end{array}$ & 17 & Aural & Solitary & 1.86 \\
\hline $\begin{array}{c}\text { Slide } \\
\text { Navigation } \\
\end{array}$ & 18 & Aural & Social & 2.53 \\
\hline \multirow{3}{*}{$\begin{array}{c}\text { Annotation } \\
\text { Tools }\end{array}$} & 19 & Aural & Verbal & 0.92 \\
\hline & 20 & Solitary & Logical & 3.54 \\
\hline & 21 & Aural & Social & 3.23 \\
\hline Networking & 22 & Social & Physical & 5.76 \\
\hline
\end{tabular}

Table 3: Pilot Study Overall Results

\subsection{Analysis}

Because the purpose of this paper is to explore the correlation between tabletbased presentation systems and learning styles, the analysis of this experiment will mainly focus on this aspect. As seen in Table 3, participants with different learning styles do not have significantly different preferences when using tablet-based presentation systems. The following features exhibited the greatest difference ( $7 \%$ and above) between their maximum and minimum preference ratings: 
- Feature 3: Ability to receive instant electronic feedback from the instructor

- Feature 7: Ability to send anonymous electronic questions to the instructor

- Feature 10: Ability to record instructors voices during lecture

- Feature 11: Synchronization of recorded instructors voices with the current slide/notes

- Feature 12: Ability to translate instructors voices to text

In addition, when viewing participants' ratings for all features, the following features are found to be most useful by all learning styles:

- Feature 15: Automatic conversion of handwritten notes to printed text

- Feature 16: Ability to search through handwritten notes for specific keywords

- Feature 18: Ability to navigate through lecture slides independently of the instructor

The features that are found to be the least useful for participants regardless of learning styles are:

- Feature 8: Ability to take real-time quizzes and to submit them electronically

- Feature 9: Ability to view other students electronic submissions on their own tablet

Attention should be brought to the fact that the sample size of this experiment was very small. Therefore, the findings from this study cannot be taken as significant and 
valid until further work is done with more participants. In addition, the formula used to calculate the weighted average rating of each learning style cannot be taken as a statistically sound method of analysis. Also, many participants who took the Memletics Learning Style Inventory test had a very hard time finishing because the test was 70 questions long. Having uncovered so many issues during the pilot study, there is a definite need for employing a different approach to explore the correlation between tablet-based presentation systems and learning styles. This approach needs to involve a much larger sample size, a statistically valid method of analysis, and a shorter learning style test. Having gained experience from doing the pilot study, the next chapter presents the survey approach to explore the correlation between tablet-based presentation systems and learning styles. 


\section{SURVEY}

A survey offers a good method to gather large amounts of information on a certain topic. It is easy to distribute to people in spite of geography, especially online surveys. As seen from the pilot study, the small sample size does not allow the author to have much confidence in the validity of the results. Hence, the second approach of the research is to administer an online survey to explore the correlation between tablet-based presentation systems and learning styles.

\subsection{Tools}

There are a few tools needed when performing an online survey. Below lists the tools that were used and the reasons behind choosing these tools:

- Vovici - Vovici, formerly known as WebSurveyor, is a free online surveying tool that allows users to create and administer surveys on the Web. It is easy to use and is definitely effective for the scope of this study.

- Marcia Conner's learning style test - This is a 12-question-long test that assesses students learning styles. Because participants are more willing to fill out the survey if there are fewer questions involved, this short version of the learning style test seems to be a good choice. It also helps that the test is free and the author received permission to use it as part of this study. However, the author is aware that this learning style model seems to be limited in scope compared to other models available. 
- Excel - Data exported from Vovici is saved as an Excel spreadsheet. From here, data analysis can be done using Excel functions. VBA for Excel was also used to determine participants' learning styles, among other things.

- Minitab - Minitab is a statistics software. It allows cross tabulation of data and the application of the chi-square test for data analysis.

\subsection{Participants}

This study mainly targets college students; therefore, the survey was first distributed to students at Cal Poly, San Luis Obispo. These students vary in major and have an age range representative of college students. The survey was given to students from CSC 110, a general computer applications course where various majors and age groups can take the class. The survey was also given to CPE 484 and CPE 482; these are upper division computer engineering courses consisting of mainly computer science or computer engineering students. Cal Poly students vary in their knowledge of tablet PCs. Some have never used a tablet PC before while others use it on a daily basis.

In addition, the survey was also distributed to students at the University of Pacific. As a fact, every entering pharmacy student there must purchase a tablet PC to be used in the classroom. Hence, distributing the survey to these students would yield more valid results because they have had experience with using the tablet PCs in the classroom environment. In large due to this group of students, $75.1 \%$ of the participants submitting the survey answered yes to having experience with the use of tablet PCs in the classroom. 
Besides students from CPE 484 and CPE 482, all other students taking the survey were given the incentive of earning extra credit. Students from CSC 110 were given an extra three points added on to their midterm if they were to fill out the survey. And students from UOP were given one extra point added to their final. One could question whether or not the incentives cause the students to produce valid information. This question will be addressed in a later section.

\subsection{Procedure}

The first step to administering a survey is to create the survey itself. The survey is composed of two parts: the first part tests a participant's learning style using Marcia Conner's learning style model and the second part asks the participant to rate the usefulness of tablet-based presentation system features on a scale from 1 to 5 (The list of features can be found in Chapter 6). The entire survey can be found in Appendix A. If a participant gives a rating of 3 or less, then the rated feature is considered not useful to the participant. But if the participant gives a rating of 4 or more, then the feature is considered to be useful to that participant. Once the survey has been created, it is published online using an online surveying tool.

The first survey was submitted on 3/12/2007 and the last survey was submitted on $4 / 18 / 2007$. Within this one month period, the author tried to distribute the survey to as many students as possible. As a result, a total of 421 surveys were submitted. Due to the time constraints of the quarter, data collection officially ended on 4/27/2007 and the survey was taken offline. 
There are two phases to analyzing the data collected. The first step was to determine the dominant learning style of each participant. It should be mentioned that for each participant, Marcia Conner's learning style model assigns a point value to each of the three learning dimensions. The dimension with the highest number is the dominant learning style of that participant; however, sometimes the highest number can be the same for two or more dimensions. In this case, the data collected for these participants are omitted from the overall analysis of the study. Therefore, 43 surveys were left out and only 378 surveys were included in the analysis of the data collected.

Having assessed participants' learning styles, the next step is to test the correlation between their learning styles and their ratings for the tablet-based presentation system features. In order to produce statistically sound results, the chi-square significance test is used. For each feature, a chi-square test is applied to show if there is any or no association between participants' learning styles and their preferences for the use of tablet-based presentation systems. The results of this study are shown in the next section.

\subsection{Results}

For each tablet-based presentation system feature, a bar graph shows the ratings given by the three types of learners. Also, a chi-square test was applied to test the association between learning styles and the ratings of these features. A chi-square test is a statistical test that compares observed data with expected data according to a specific hypothesis. The test calculates a p-value (a probability percentage) to determine the null hypothesis, which states that there is no significant difference between the expected and observed result. Within context of this research, the observed data is the learning styles 
and the expected data is the ratings of the features. By using the chi-square test, the author hypothesizes that the ratings of the features are not dependent on varying learning styles if the $\mathrm{p}$-value is greater than 0.05 . If the $\mathrm{p}$-value is less than or equal to 0.05 , then there is a statistically significant pattern to the way students rate the features depending on their learning styles. The following sections will only talk about the chi-square test results; actual Minitab output can be found in Appendix B. 


\subsubsection{Feature 1: Using the tablet PC, instructors can handwrite additional notes on top of slides to illustrate difficult concepts or to give explanations of important ideas}

Most visual, auditory, and tactile learners agree that allowing instructors the ability to handwrite additional notes on top of slides is a useful feature. Only $8.75 \%$ of auditory, $10.34 \%$ of tactile, and $5.83 \%$ of visual learners feel that this feature is not useful to them. According to the chi-square test, the p-value for the Pearson Chi-Square test is 0.401 and the p-value for the Likelihood Ratio Chi-Square test is 0.418. The p-value indicates that there is no statistical significance in the association between learning styles and the ratings of Feature 1.

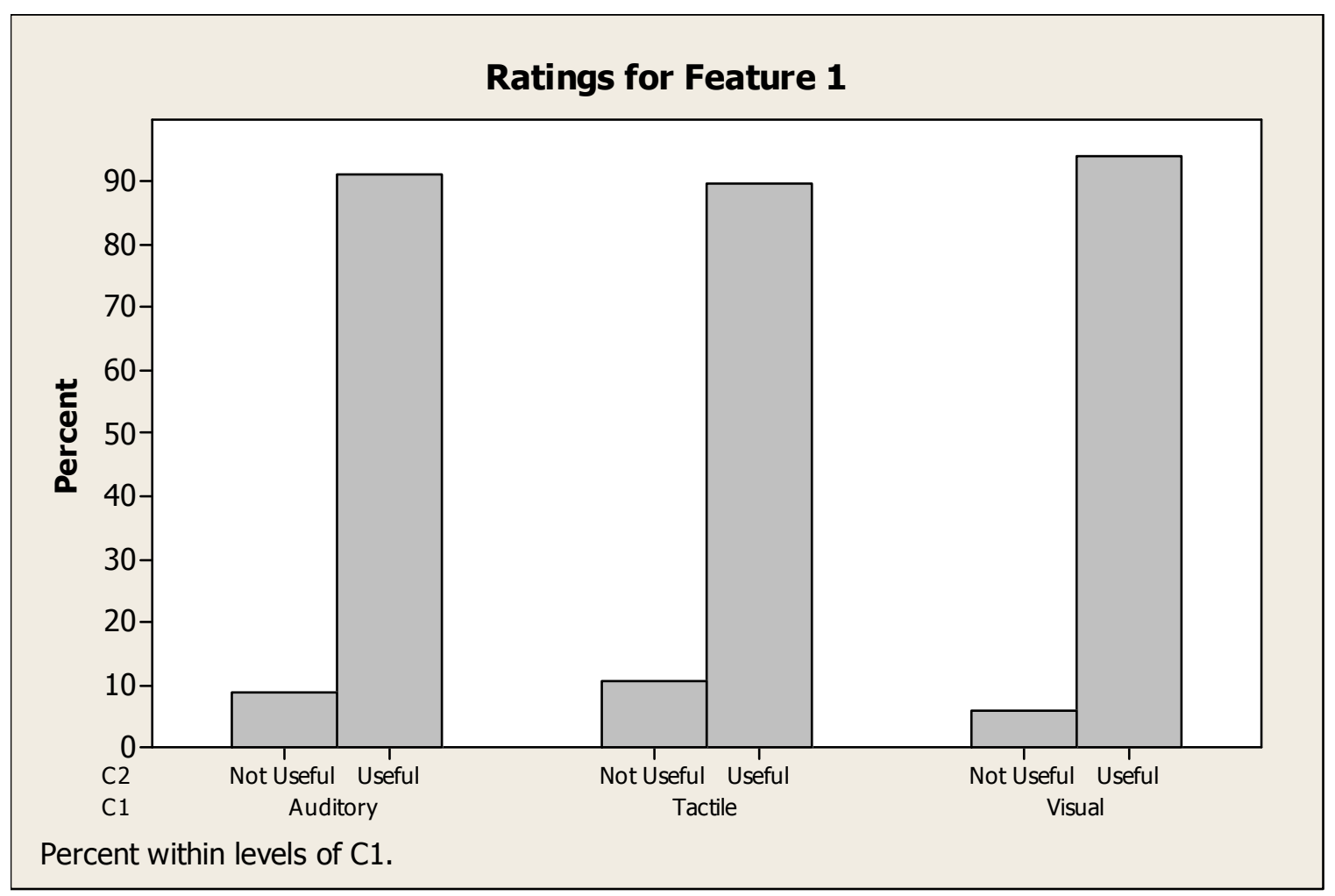

Figure 5: Feature 1 Ratings 


\subsubsection{Feature 2: Capturing instructors' handwritten notes during lecture using the tablet PC}

For the ability to save instructors' handwritten notes, most visual, auditory, and tactile learners feel that this feature is useful. Of all the auditory learners, $13.75 \%$ rate this feature as being not useful. $17.24 \%$ of tactile learners and $15.83 \%$ of visual learners also feel that this feature is not very useful to them. According to the chi-square test, the pvalue for the Pearson Chi-Square test is 0.845 and the p-value for the Likelihood Ratio Chi-Square test is 0.843 . This shows that there is no statistical significance in the association between learning styles and the ratings of Feature 2.

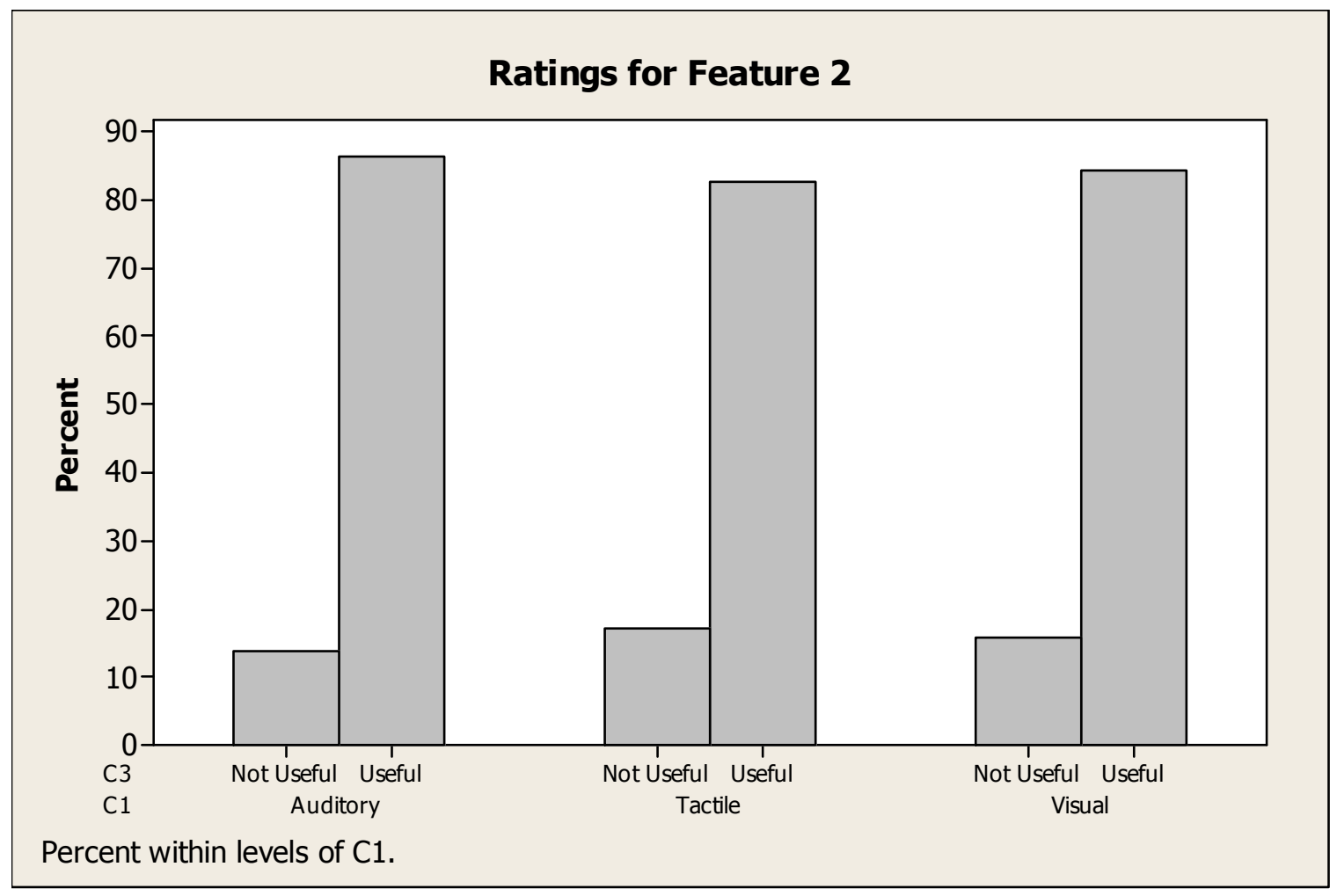

Figure 6: Feature 2 Ratings 


\subsubsection{Feature 3: Sending instant electronic responses to students' questions or comments during lecture}

The graph below shows $68.97 \%$ of tactile learners feel that allowing instructors to send electronic feedback to students during class is not useful. $53.75 \%$ of auditory learners and $52.50 \%$ of visual learners also feel that this feature is not useful to them. There is definitely a split in preferences for auditory and visual learners. However, it is apparent that tactile learners feel more strongly about the usefulness of this feature. According to the chi-square test, the p-value for the Pearson Chi-Square test is 0.074 and the p-value for the Likelihood Ratio Chi-Square test is 0.068. Based on the test, the pvalues show that there is no statistical significance in the association between learning styles and the ratings of Feature 3.

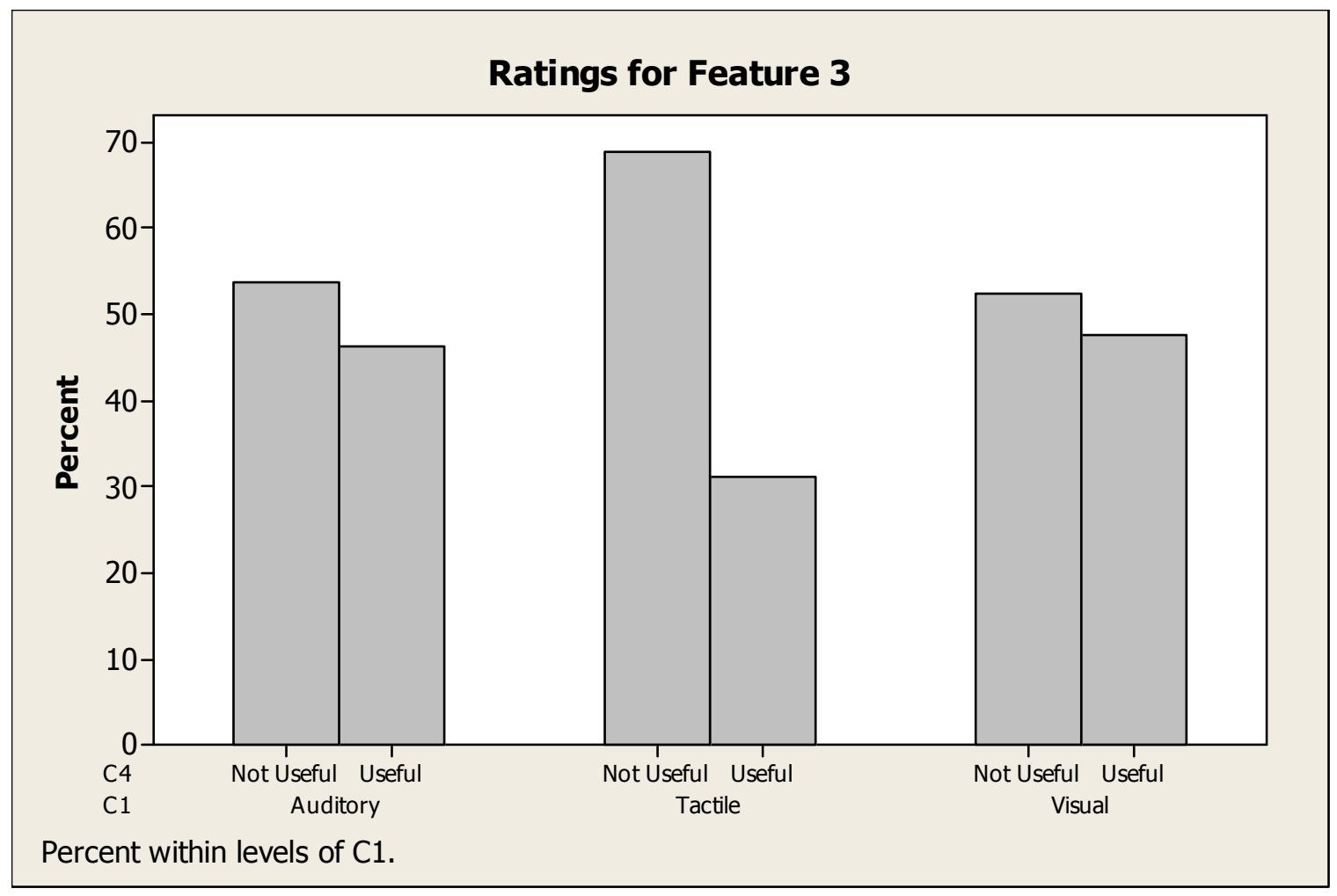

Figure 7: Feature 3 Ratings 


\subsubsection{Feature 4: Handwriting your own digital notes on top of lecture slides using the tablet PC}

Most visual, auditory, and tactile learners rate the ability to handwrite their own notes to be useful. Only $15.00 \%$ of auditory, $15.52 \%$ of tactile, and $8.75 \%$ of visual learners feel that this feature is not useful to them. According to the chi-square test, the pvalue for Pearson Chi-Square test is 0.156 and the p-value for Likelihood Ratio ChiSquare test is 0.166. Statistically, there is no significance in the association between learning styles and the ratings of Feature 4.

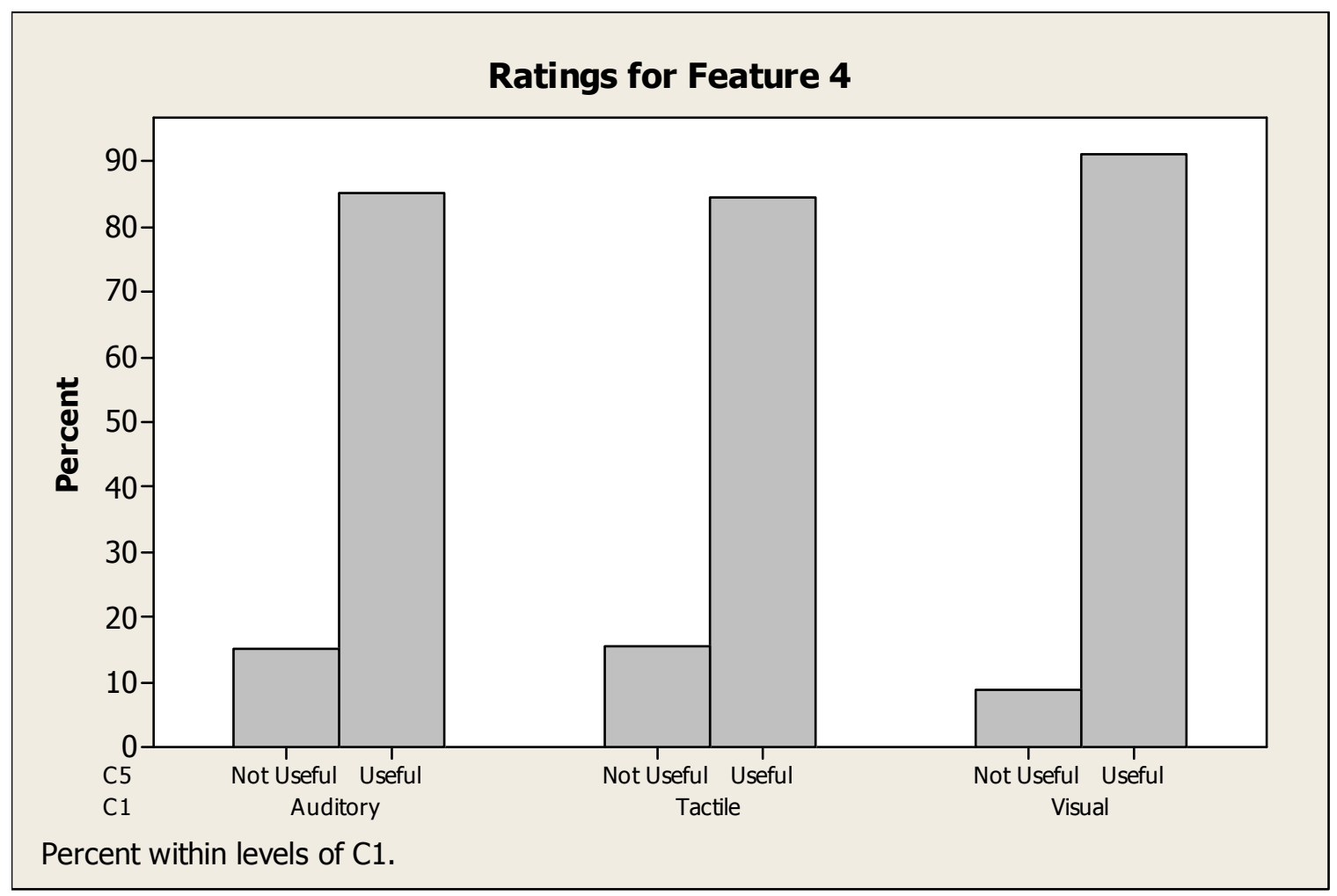

Figure 8: Feature 4 Ratings 


\subsubsection{Feature 5: Separate views for lecture notes with instructors' annotations and lecture notes with your own annotations}

Most auditory, tactile, and visual learners feel that having separate views to distinguish instructor annotations from student annotations is a useful feature. $31.25 \%$ of auditory, $37.93 \%$ of tactile, and $29.58 \%$ of visual learners feel that this feature is not useful to them. According to the chi-square test, the p-value for the Pearson Chi-Square test is 0.469 and the p-value for the Likelihood Ratio Chi-Square test is 0.478 . The pvalues show that there is no statistical significance in the association between learning styles and the ratings of Feature 5.

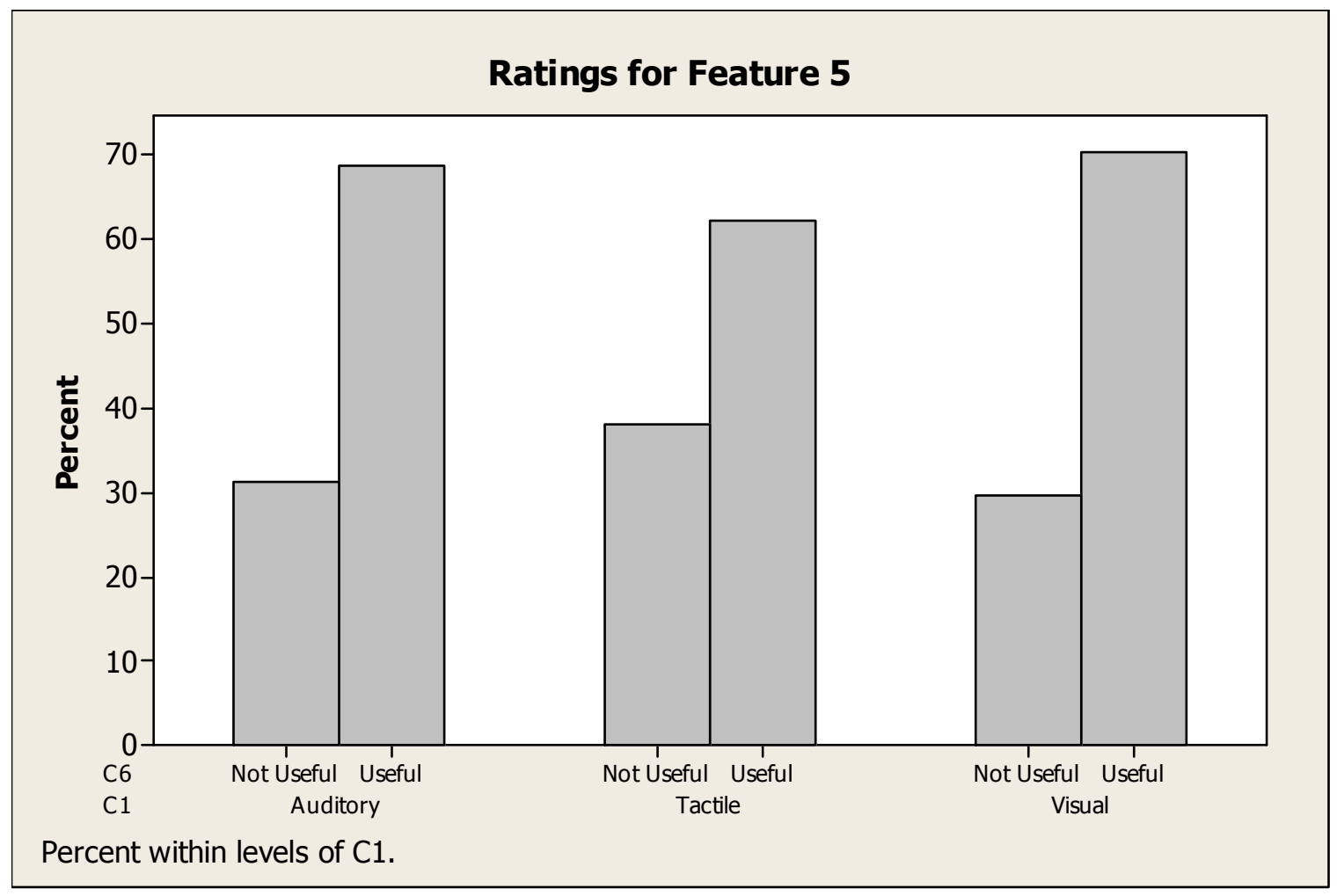

Figure 9: Feature 5 Ratings 


\subsubsection{Feature 6: Sending instant electronic questions to instructors during lecture}

Surprisingly, the majority of visual, auditory, and tactile learners feel that the ability to send questions to instructors is not useful. Of these learners, $35.00 \%$ of auditory, $39.66 \%$ of tactile, and $33.33 \%$ of visual learners feel that this feature is useful. According to the chi-square test, the p-value for the Pearson Chi-Square test is 0.660 and the p-value for the Likelihood Ratio Chi-Square test is 0.664 . The p-values show that there is no statistical significance in the association between learning styles and the ratings of Feature 6.

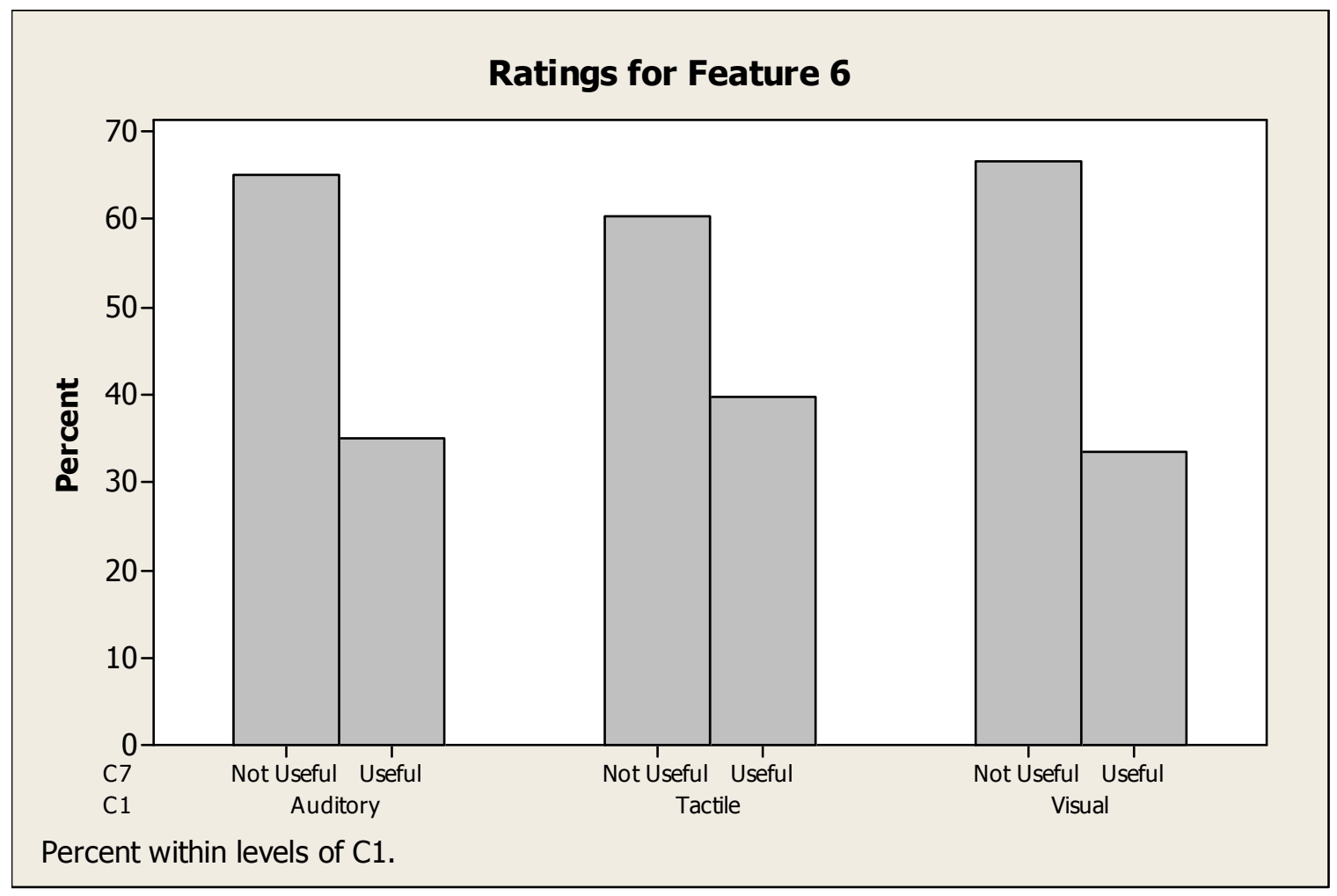

Figure 10: Feature 6 Ratings 


\subsubsection{Feature 7: Sending anonymous electronic questions to instructors during lecture}

Feature 7 is different from Feature 6 because it allows for anonymous submissions by students whereas Feature 6 does not. Despite the difference, most visual, auditory, and tactile learners also feel that sending anonymous feedback to instructors is not useful. $37.50 \%$ of auditory, $39.66 \%$ of tactile, and $37.08 \%$ of visual learners feel that this feature is useful to them. According to the chi-square test, the p-value for Pearson Chi-Square test is 0.936 and the p-value for the Likelihood Ratio Chi-Square test is 0.937. Statistically, there is no significance in the association between learning styles and the ratings of Feature 7.

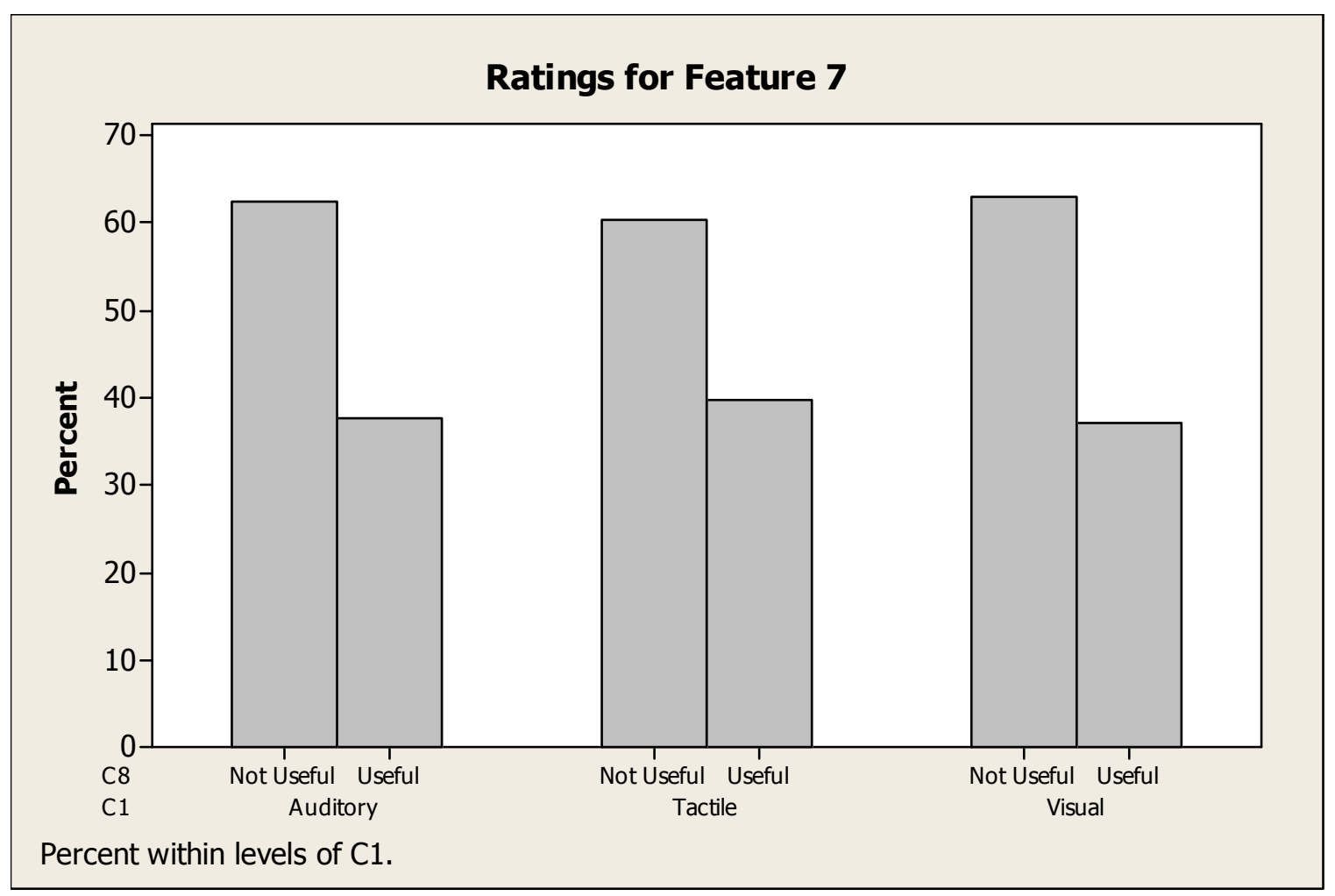

Figure 11: Feature 7 Ratings 


\subsubsection{Feature 8: Taking real-time quizzes or assessments on the tablet PC and submit them to the instructor electronically}

Most visual, auditory, and tactile learners feel that taking real-time quizzes during class time is a useful feature. Of these types of learners, $38.75 \%$ of auditory, $43.10 \%$ of tactile, and $42.08 \%$ of visual learners feel that this feature is useful to them. With such percentages, it seems like there is a split in preferences for tactile and visual learners. Auditory learners seem to feel more strongly about the usefulness of this feature. According to the chi-square test, the p-value for the Pearson Chi-Square test is 0.842 and the p-value for the Likelihood Ratio Chi-Square test is 0.841 . The p-values show that there is no statistical significance in the association between learning styles and the ratings of Feature 8.

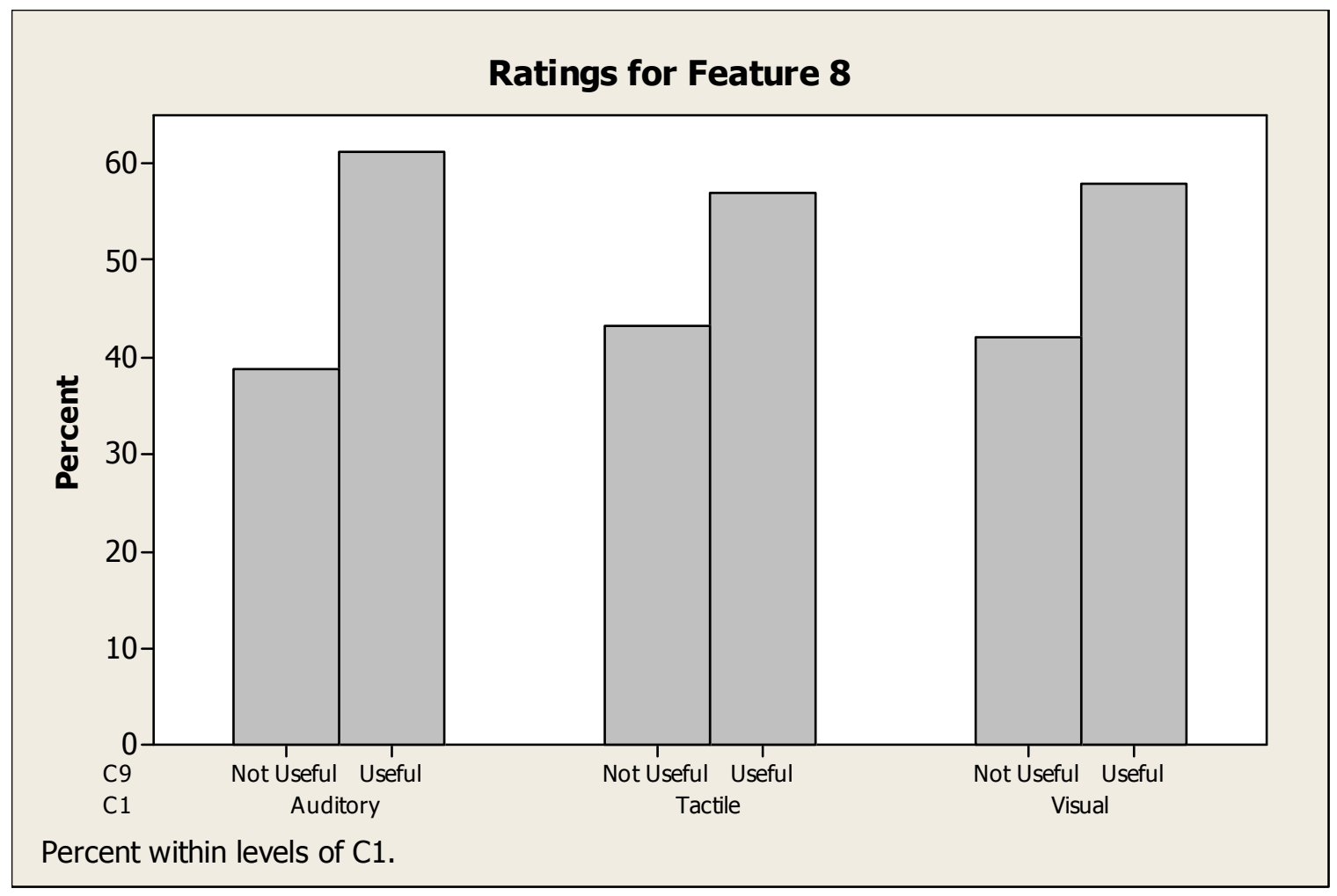

Figure 12: Feature 8 Ratings 


\subsubsection{Feature 9: Instructors share students' electronic submissions to the class via the tablet PC}

There are mixed results for the ratings of sharing students' electronic submissions to the class. Most tactile learners $(63.79 \%)$ feel that this feature is not useful to them. However, there seems to be a split in opinions for auditory and visual learners. $52.50 \%$ of auditory learners feel that the feature is useful whereas $47.50 \%$ feel that it is not useful. $54.58 \%$ of visual learners feel that the feature is useful whereas $45.42 \%$ feel that it is not useful. So it is hard to really conclude the preferences of auditory and visual learners for this feature. According to the chi-square test, the p-value for the Pearson Chi-Square test is 0.370 and the p-value for the Likelihood Ratio Chi-Square test is 0.365 . The p-values show that there is no statistical significance in the association between learning styles and the ratings of Feature 9.

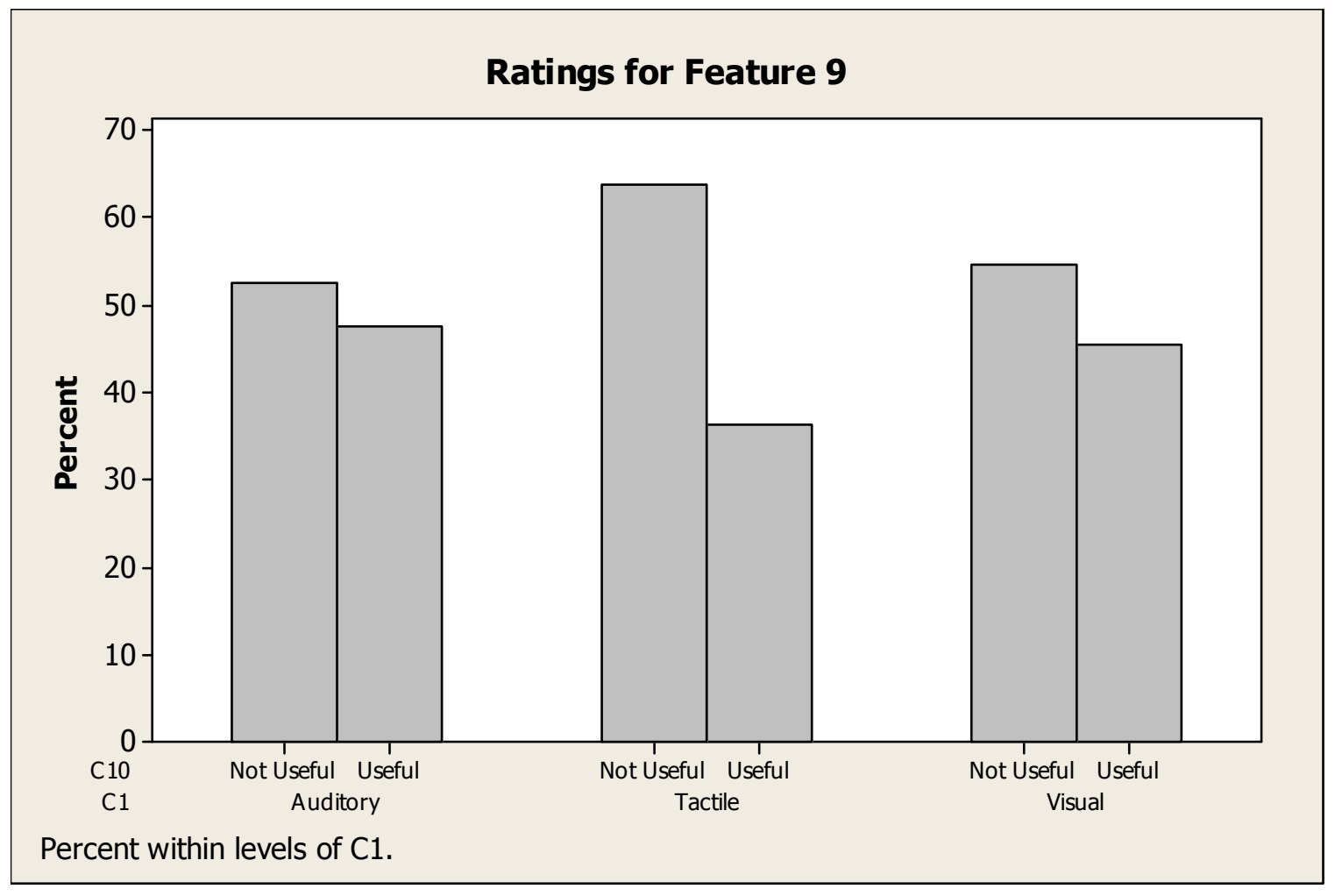

Figure 13: Feature 9 Ratings 


\subsubsection{Feature 10: Recording instructors' voices during lecture}

As shown in the graph, the majority of auditory and visual learners feel that it is useful to record instructor's voices during lecture. $37.5 \%$ of auditory and 38.75 of visual learners feel that this feature is not useful. However, it is hard to determine the preference of tactile learners for this feature. $55.17 \%$ of tactile learners feel that this feature is useful while $44.83 \%$ feel that it is not useful. The difference in percentage for tactile learners is not very much compared to auditory and visual learners. According to the chi-square test, the p-value for the Pearson Chi-Square test is 0.644 and the p-value for the Likelihood Ratio Chi-Square test is 0.647. Based on the p-values, there is no statistical significance in the association between learning styles and the ratings of Feature 10.

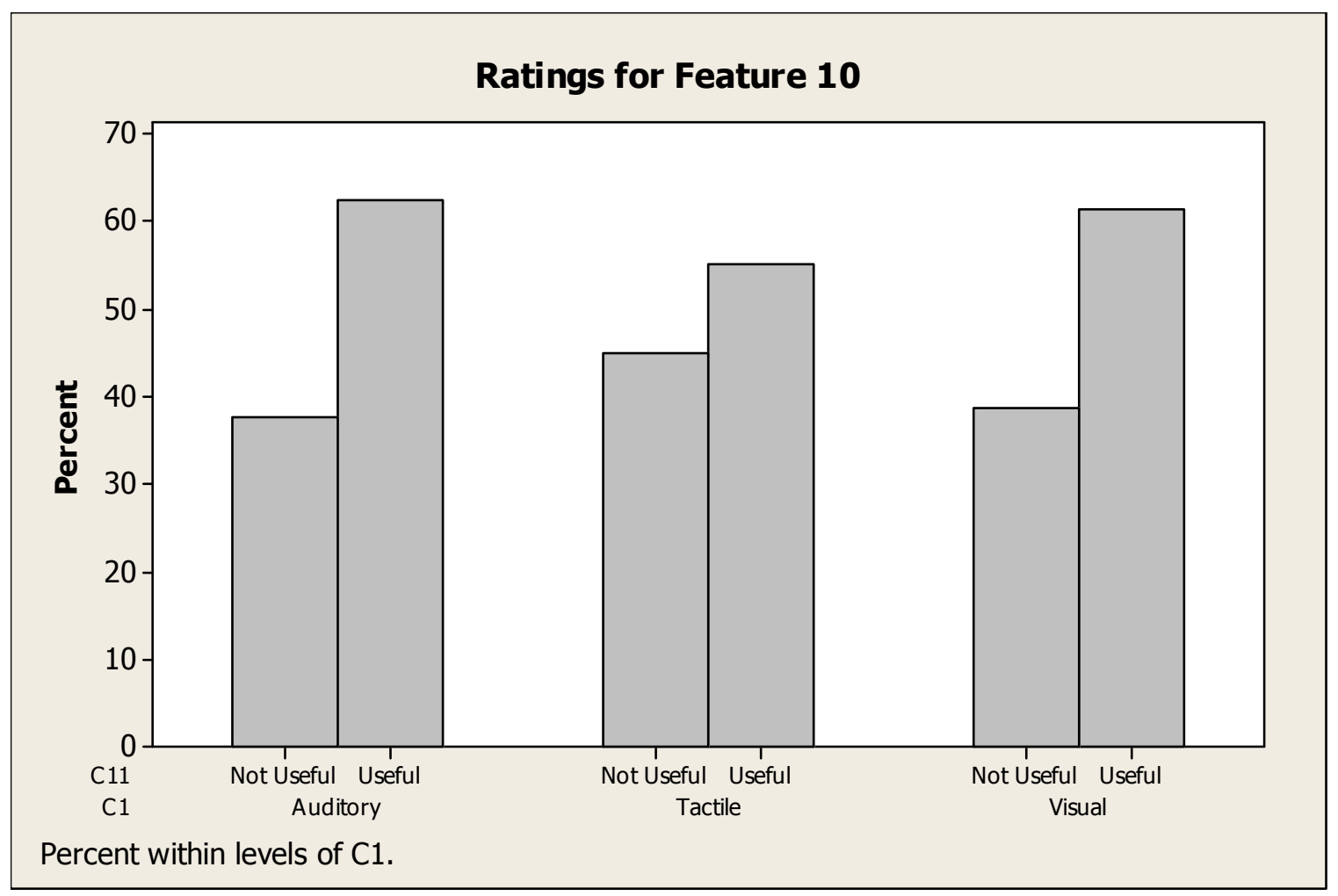

Figure 14: Feature 10 Ratings 
8.4.11. Feature 11: When reviewing lecture notes, recorded instructors' voices are synchronized with the slide you are on and the notes that you took during class

The majority of auditory, tactile, and visual learners feel that it is useful to have the recorded instructor's voice synchronized with the lecture notes. Of course, not all of the students feel that this feature is useful. $25.00 \%$ of auditory learners, $31.03 \%$ of tactile learners, and $27.08 \%$ of visual learners feel that this feature would not be useful to them. According to the chi-square test, the p-value for the Pearson Chi-Square test is 0.731 and the p-value for the Likelihood Ratio Chi-Square test is 0.734 . The p-values show that there is no statistical significance in the association between learning styles and the ratings of Feature 11.

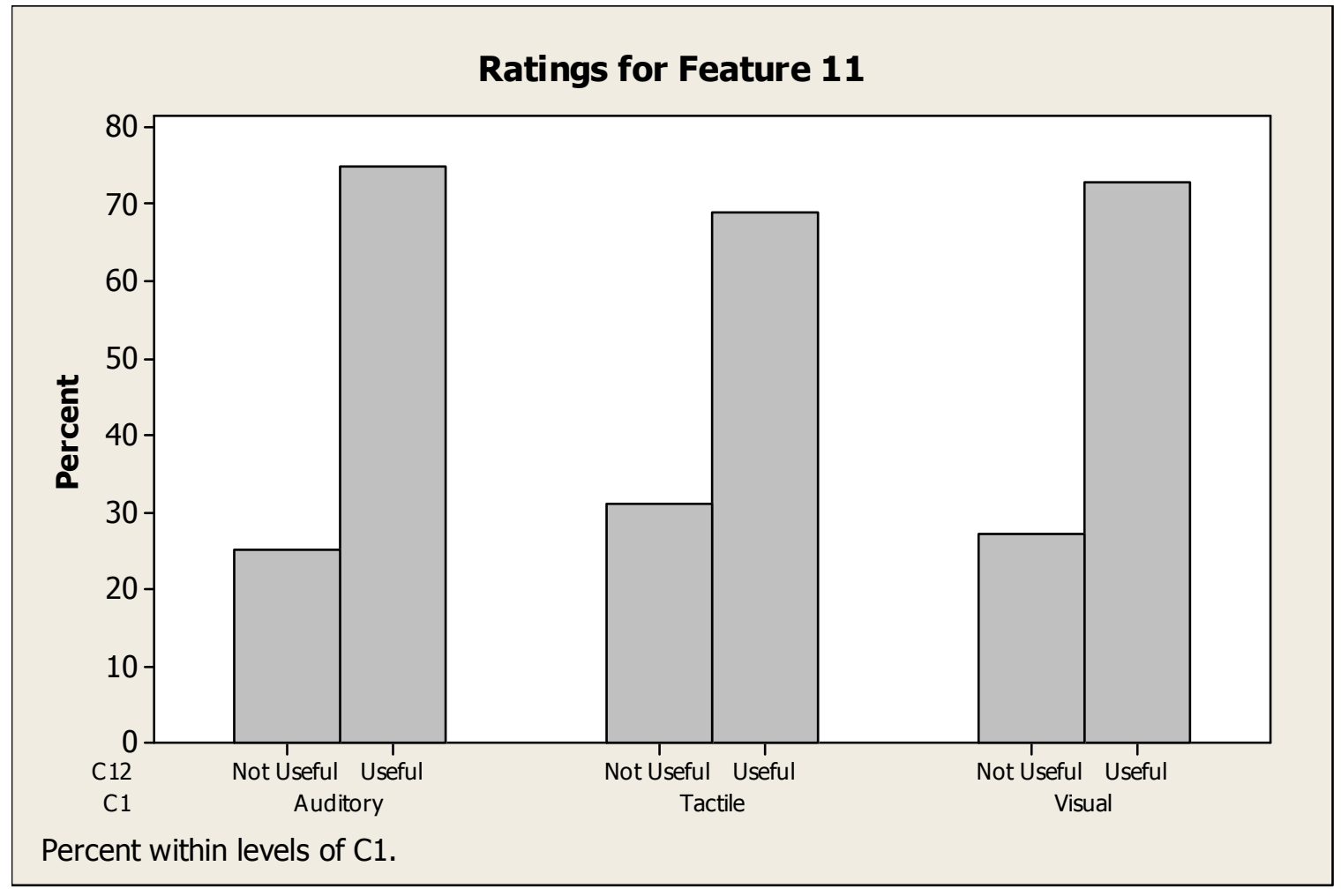

Figure 15: Feature 11 Ratings 


\subsubsection{Feature 12: Using speech recognition capabilities to convert instructors' voices to text}

The results for this feature are quite interesting since it is the first time that not all three learning styles have the same majority preference. As shown in the graph, most auditory learners feel that converting instructor's voice to text is a useful feature. However, the majority of tactile and visual learners feel that this is not a useful feature. It must be pointed out that $52.50 \%$ of auditory learners feel that this is useful while $47.50 \%$ feel that it is not useful. There is not a significant difference in preference for auditory learners. According to the chi-square test, the p-value for the Pearson Chi-Square test is 0.188 and the p-value for the Likelihood Ratio Chi-Square test is 0.190 . Statistically, there is no significance in the association between learning styles and the ratings of Feature 12.

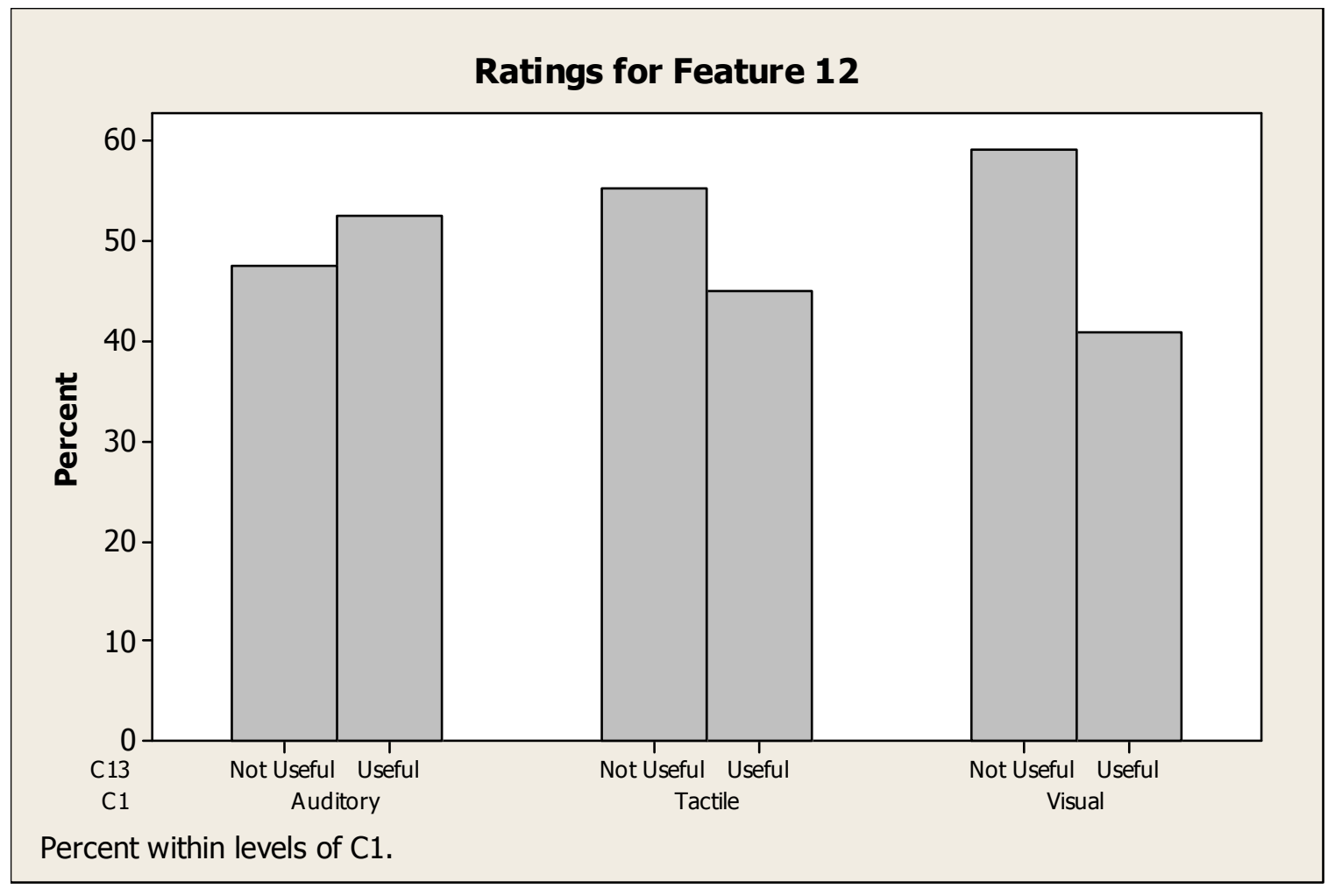

Figure 16: Feature 12 Ratings 


\subsubsection{Feature 13: Reviewing your notes in the order that you wrote them by using the tablet PC to replay the handwritten notes stroke- by-stroke}

The results show that the majority of auditory, tactile, and visual learners feel that it is not useful to be able to replay the notes stroke-by-stroke. However, the difference in preference is not very significant. $51.25 \%$ of auditory learners feel that this feature is not useful while $48.75 \%$ feel that it is useful. $56.90 \%$ of tactile learners feel that this feature is not useful while $43.10 \%$ feel that it is useful. Finally, $53.75 \%$ of visual learners feel that this feature is not useful while $46.25 \%$ feel that it is useful. According to the chisquare test, the p-value for the Pearson Chi-Square test is 0.806 and the p-value for the Likelihood Ratio Chi-Square test is 0.806 . The p-values show that there is no statistical significance in the association between learning styles and the ratings of Feature 13.

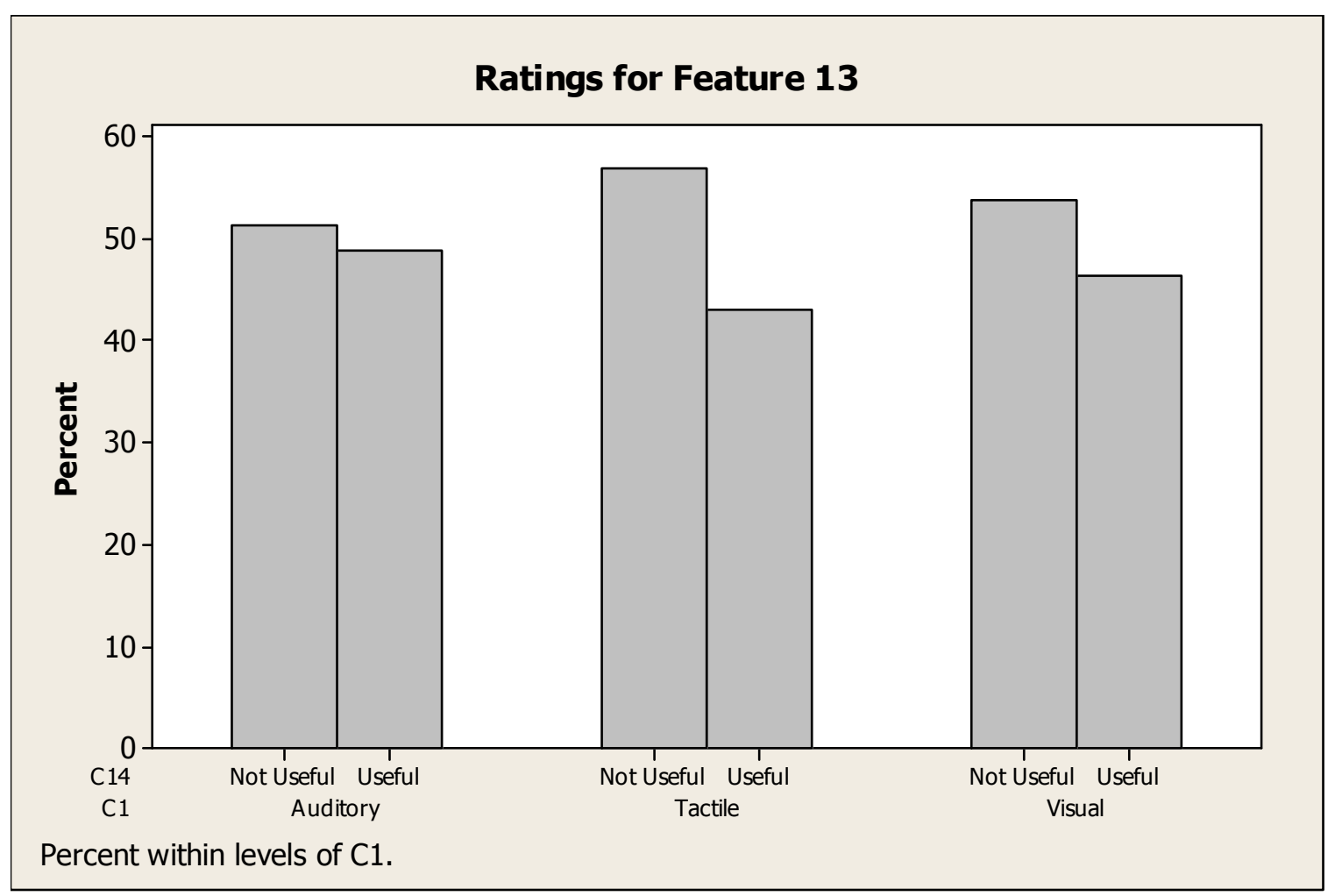

Figure 17: Feature 13 Ratings 


\subsubsection{Feature 14: Ink strokes change color over time to differentiate notes taken during different periods of the lecture}

The majority of auditory learners feel that having ink strokes change color over time is a useful feature with only $36.25 \%$ feeling that it is not useful. Even though the majority of tactile and visual learners also feel that this is a useful feature, there is almost a split in preference within these two groups. $46.55 \%$ of tactile learners actually feel that the feature is not useful and $46.25 \%$ of visual learners feel the same way. According to the chi-square test, the p-value for the Pearson Chi-Square test is 0.274 and the p-value for the Likelihood Ratio Chi-Square test is 0.269. Statistically, there is no significance in the association between learning styles and the ratings of Feature 14 .

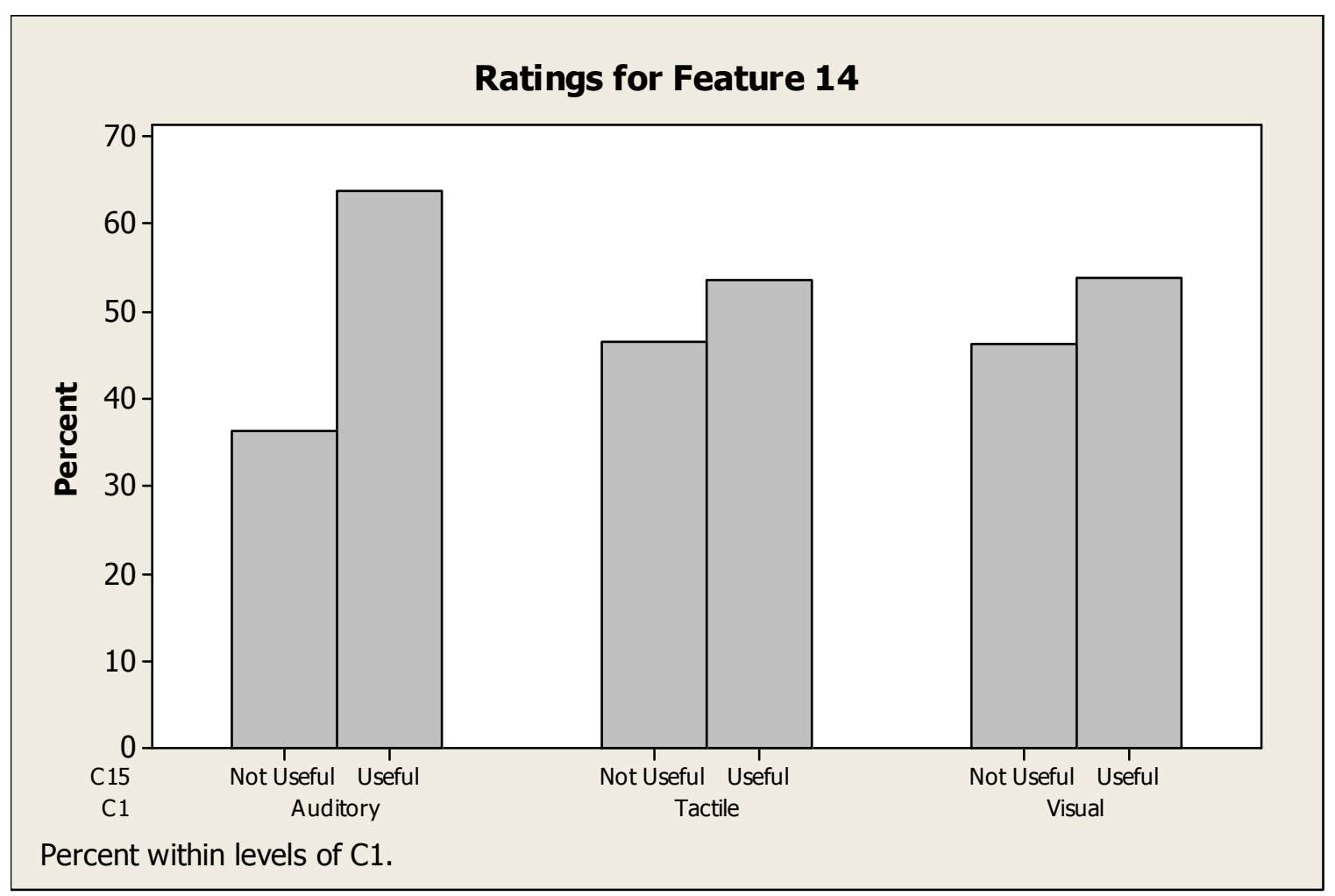

Figure 18: Feature 14 Ratings 


\subsubsection{Feature 15: Handwritten notes using the tablet PC are automatically converted to printed text}

The results for this feature are definitely interesting. $51.25 \%$ of auditory learners feel that having handwritten notes converted to text is useful while $48.75 \%$ feel that it is not. For tactile learners, there is a split with half feeling that the feature is useful while the other half does not. For visual learners, $54.17 \%$ feel that the feature is useful while $45.83 \%$ feel that it is not useful. All three learners have different preferences when it comes to this feature. According to the chi-square test, the p-value for the Pearson ChiSquare test is 0.650 and the p-value for the Likelihood Ratio Chi-Square test is 0.650 . The p-values show that there is no statistically significant association between learning styles and the ratings of Feature 15.

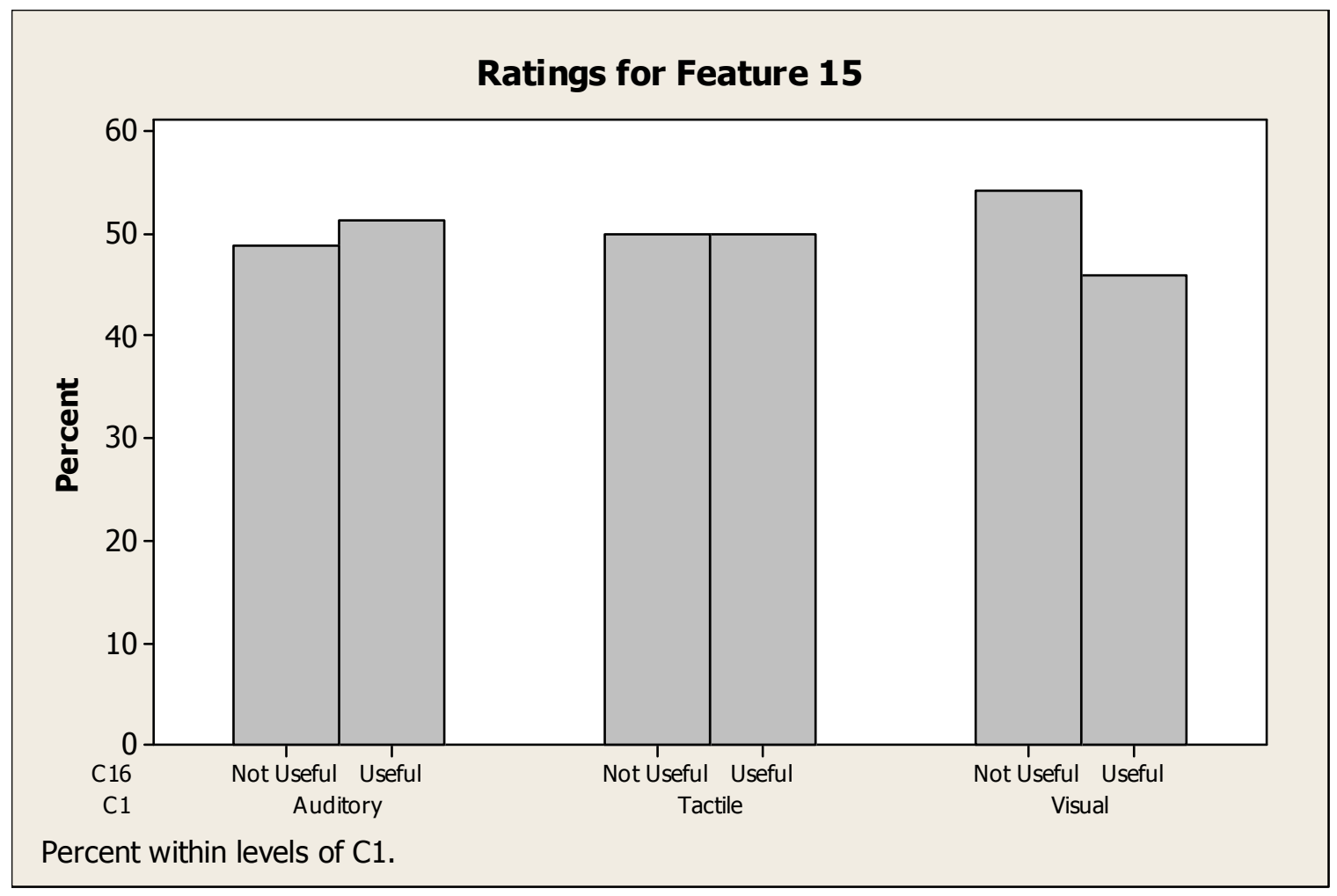

Figure 19: Feature 15 Ratings 


\subsubsection{Feature 16: Using the tablet PC to search through handwritten notes for keywords}

The majority of visual, auditory, and tactile learners agree that searching through handwritten notes is a useful feature. Only $30.00 \%$ of auditory learners, $29.31 \%$ of tactile learners, and $35.00 \%$ of visual learners feel that this feature is not useful. According to the chi-square test, the p-value for the Pearson Chi-Square test is 0.573 and the p-value for the Likelihood Ratio Chi-Square test is 0.570. Statistically, there is no significance in the association between learning styles and the ratings of Feature 16.

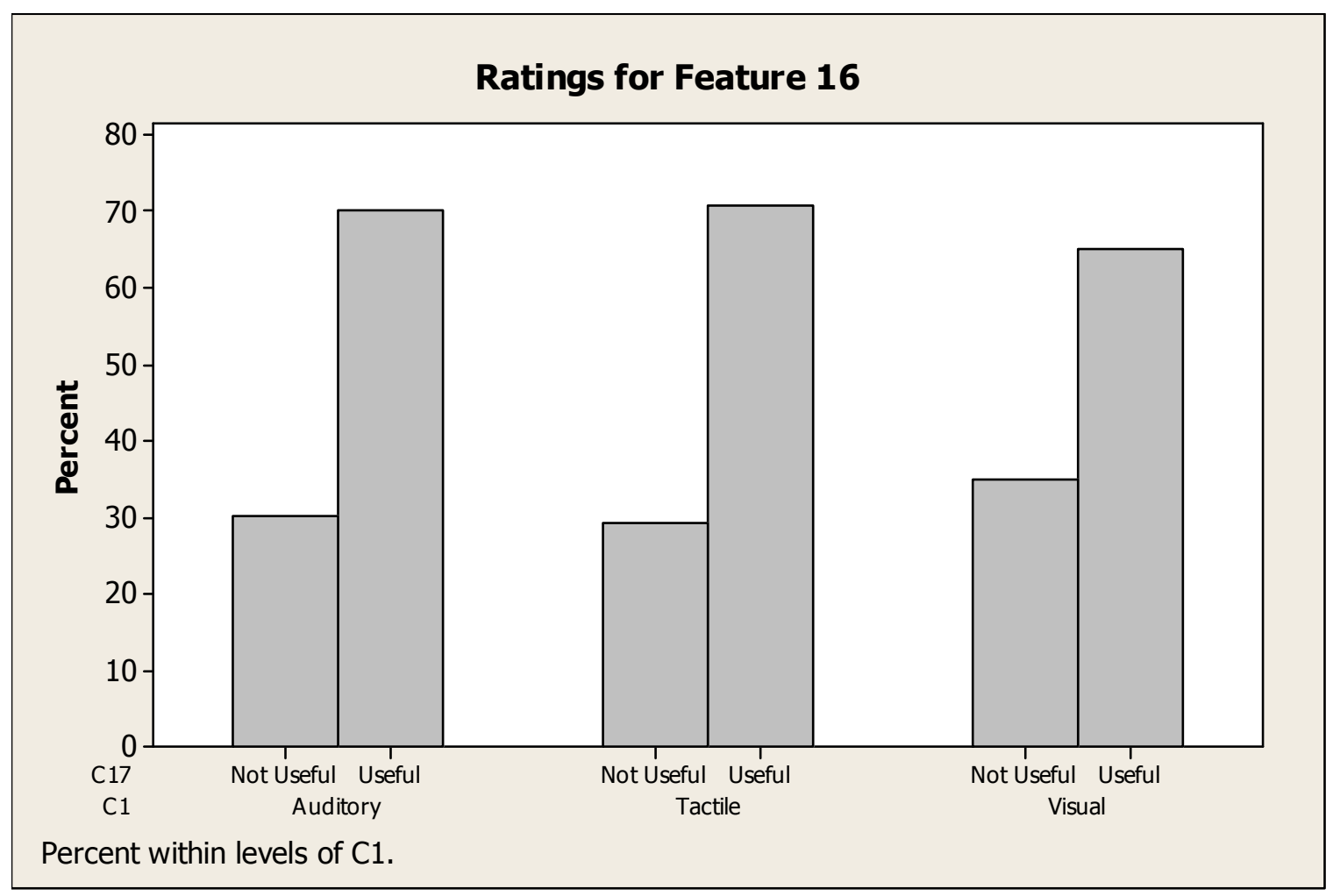

Figure 20: Feature 16 Ratings 


\subsubsection{Feature 17: Having access to blank slides to take additional notes}

Most auditory, visual, and tactile learners agree that having blank slides to take notes is a useful feature. In fact, only $11.25 \%$ of auditory learners, $18.97 \%$ of tactile learners, and $11.25 \%$ of visual learners feel that this feature is not useful. According to the chi-square test, the p-value for the Pearson Chi-Square test is 0.261 and the p-value for the Likelihood Ratio Chi-Square test is 0.297. The p-values show that there is no statistically significant association between learning styles and the ratings of Feature 17.

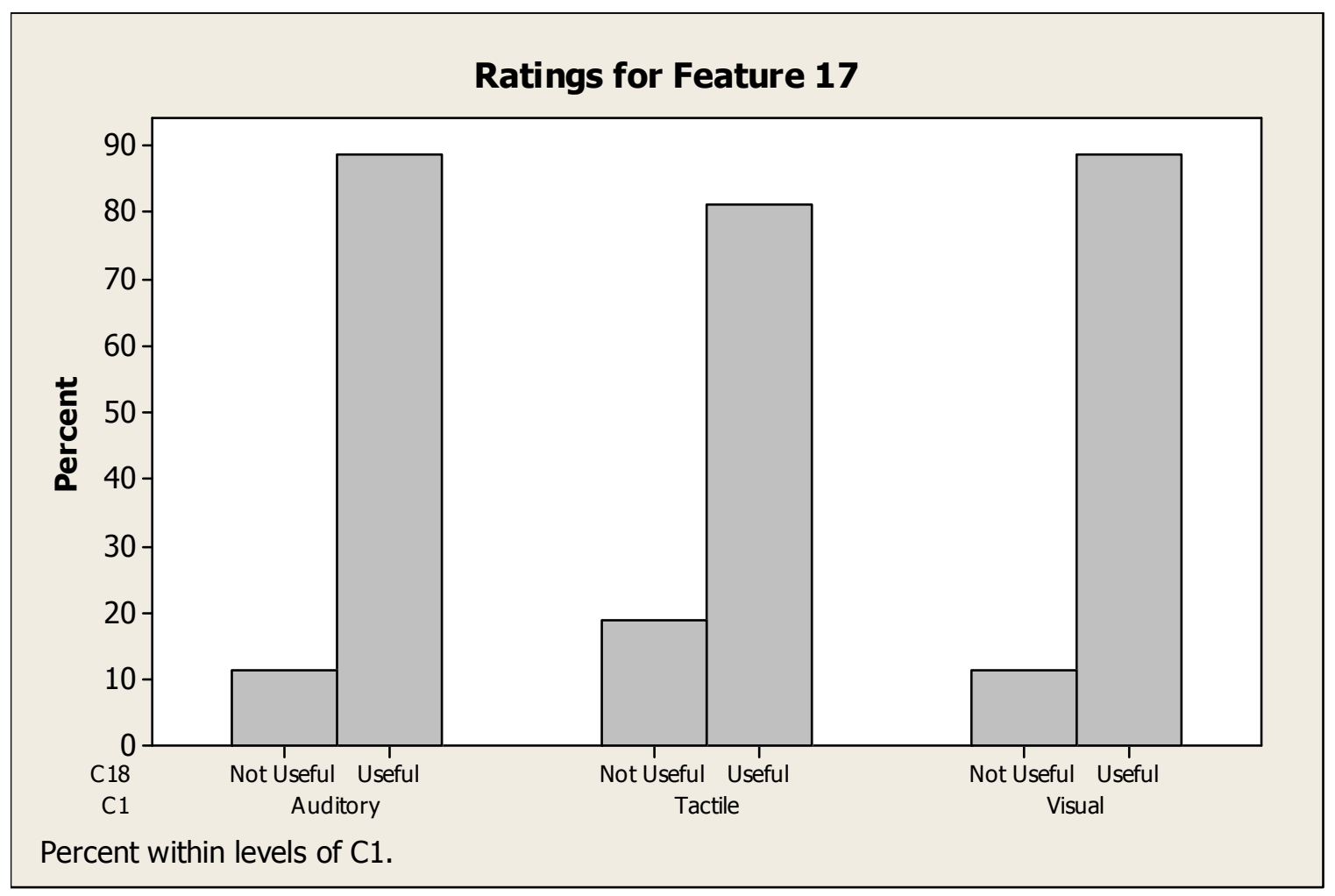

Figure 21: Feature 17 Ratings 


\subsubsection{Feature 18: Navigating through all lecture slides without being restricted to the slide that the instructor is lecturing on}

Navigating freely through lecture slides is a useful tool for most visual, auditory, and tactile learners. Only $18.75 \%$ of auditory learners, $20.69 \%$ of tactile learners, and $15.42 \%$ of visual learners feel that this feature is not useful. According to the chi-square test, the p-value for the Pearson Chi-Square test is 0.559 and the p-value for the Likelihood Ratio Chi-Square test is 0.567 . Statistically, there is no significant association between learning styles and the ratings of Feature 18.

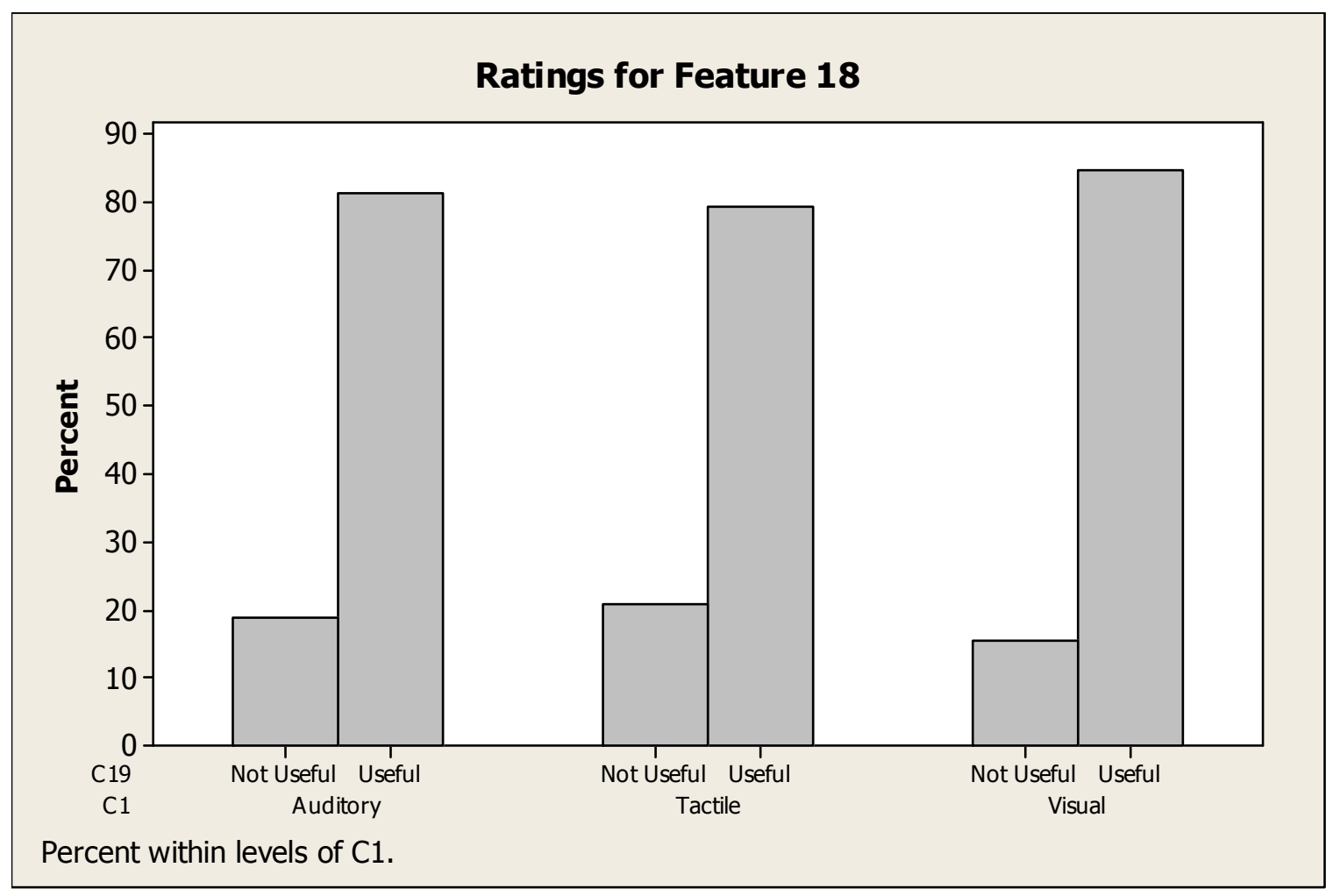

Figure 22: Feature 18 Ratings 


\subsubsection{Feature 19: Highlighting key words or ideas using the tablet PC}

Most auditory, tactile, and visual learners feel that the ability to highlight keywords is a useful feature. Only $11.25 \%$ of auditory learners, $12.07 \%$ of tactile learners, and $11.25 \%$ of visual learners feel that this feature is not useful. According to the chi-square test, the p-value for the Pearson Chi-Square test is 0.984 and the p-value for the Likelihood Ratio Chi-Square test is also 0.984. Based on the p-values, there is no statistical significance in the association between learning styles and the ratings of Feature 19.

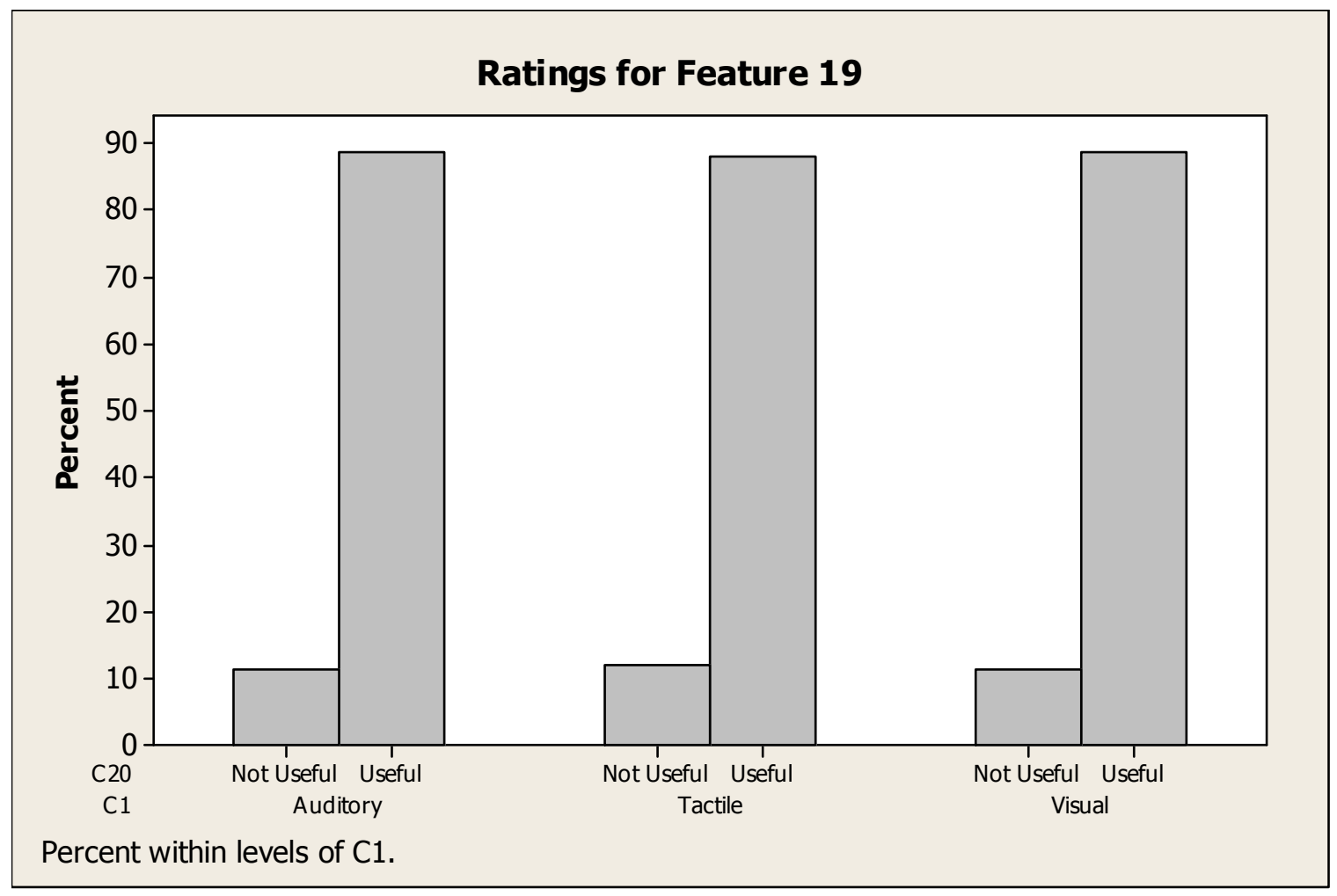

Figure 23: Feature 19 Ratings 


\subsubsection{Feature 20: Erasing ink marks or strokes written using the tablet pen}

For the ability to erase ink marks, most visual, auditory, and tactile learners found the feature to be useful. Only $6.25 \%$ of auditory learners, $13.79 \%$ of tactile learners, and $8.75 \%$ of visual learners feel that this feature is not useful. According to the chi-square test, the p-value for the Pearson Chi-Square test is 0.303 and the p-value for the Likelihood Ratio Chi-Square test is 0.323. Statistically, there is no significant association between learning styles and the ratings of Feature 20.

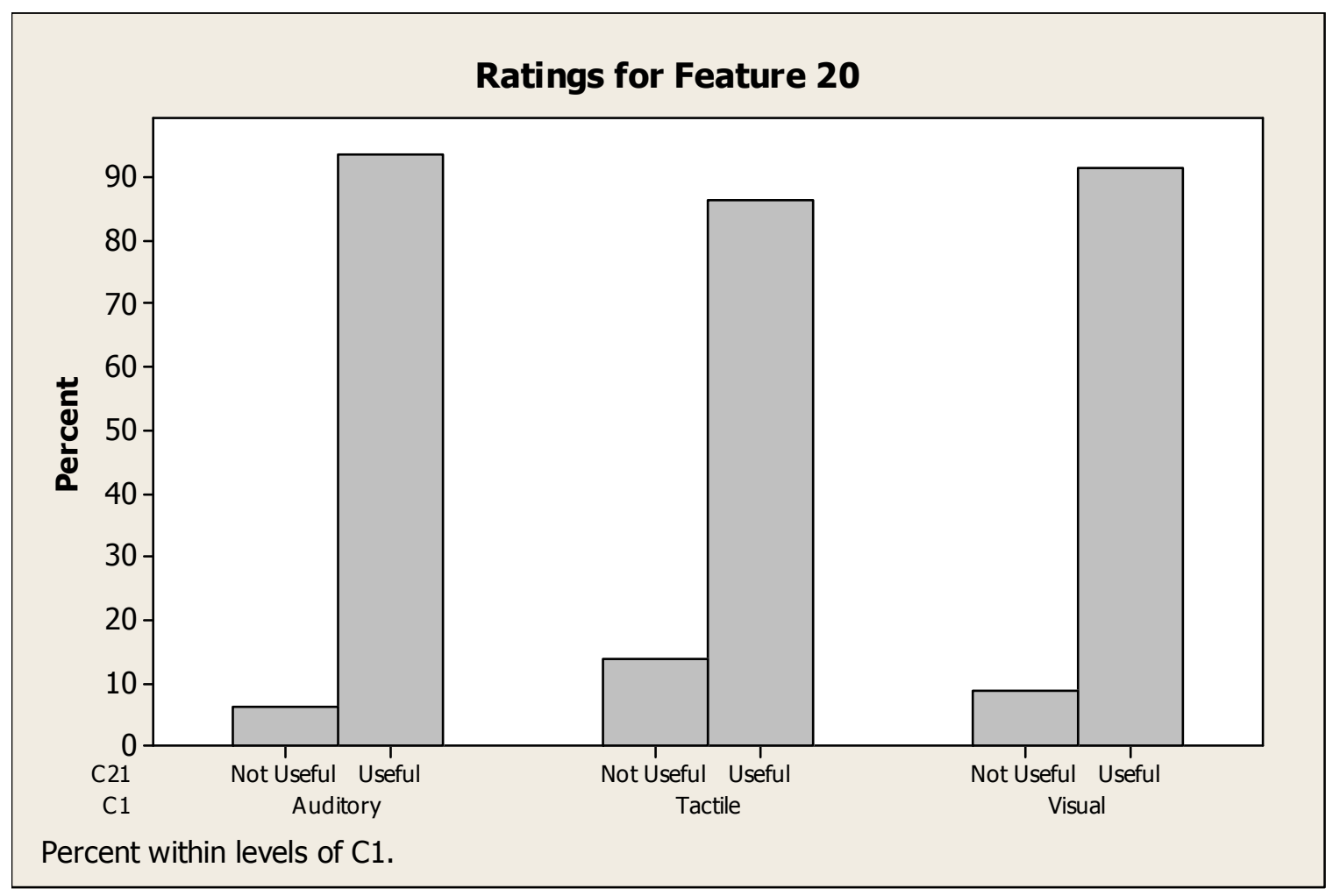

Figure 24: Feature 20 Ratings 


\subsubsection{Feature 21: Changing to different color ink when taking notes}

The majority of visual, auditory, and tactile learners agree that having access to different color ink is a useful feature. Only $7.50 \%$ of auditory learners, $12.07 \%$ of tactile learners, and $8.33 \%$ of visual learners think that this feature is not useful. According to the chi-square test, the p-value for the Pearson Chi-Square test is 0.603 and the p-value for the Likelihood Ratio Chi-Square test is 0.625 . The p-values show that there is no statistically significant association between learning styles and the ratings of Feature 21 .

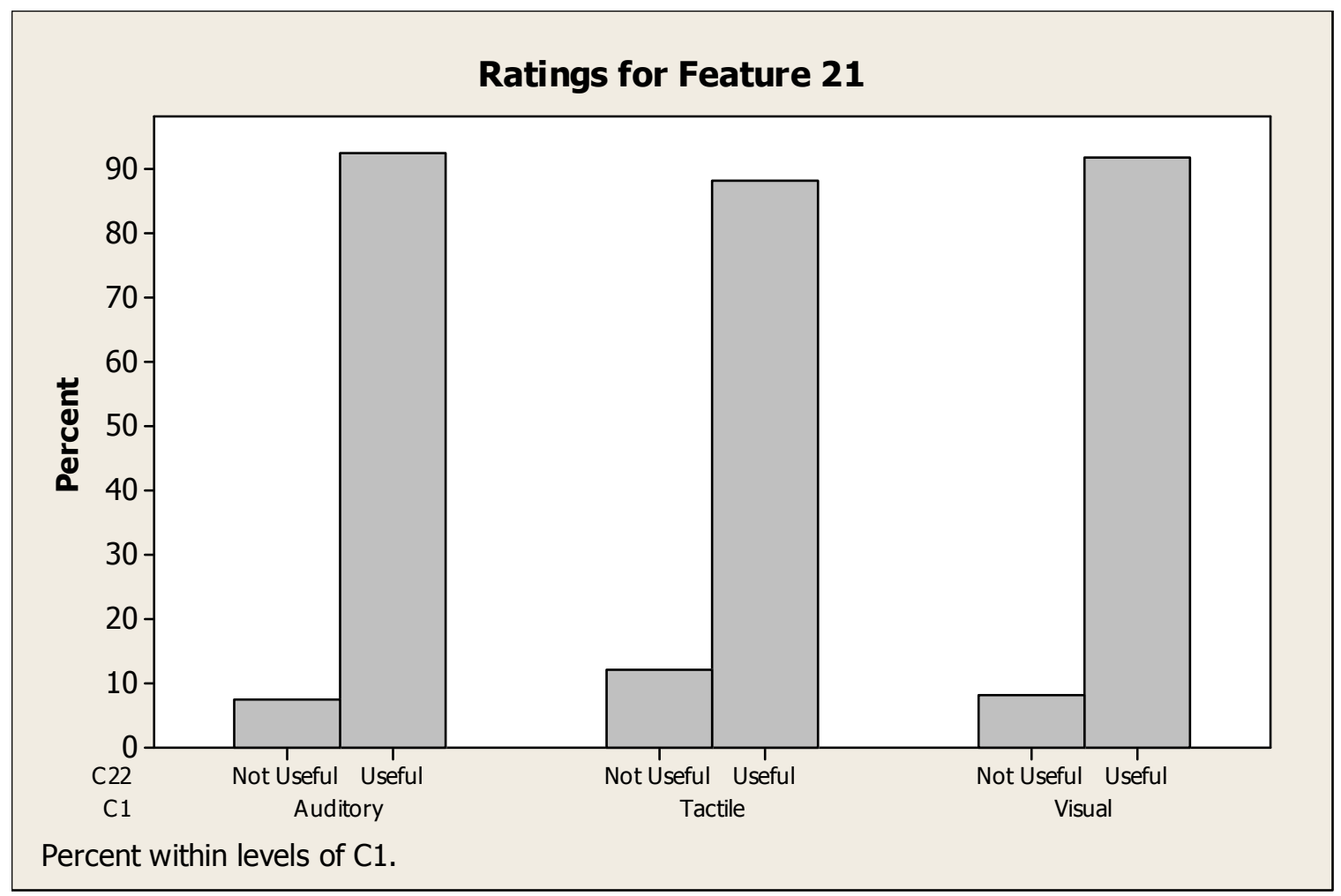

Figure 25: Feature 21 Ratings 


\subsubsection{Feature 22: Peer-to-peer networking of tablet PCs to allow you to share applications or chat with your instructors or other students}

Even though the majority of visual, auditory, and tactile learners feel that having a peer-to-peer network of tablet PCs is a useful feature, the difference in preference among the groups is not very much. $55.00 \%$ of auditory learners feel that the feature is useful while $45.00 \%$ think that it is not useful. $53.45 \%$ of tactile learners rate the feature to be useful while $46.55 \%$ think that it is not. $53.75 \%$ of visual learners agree that this feature is useful while $46.25 \%$ disagree. There is almost a split in opinions among the three learning styles. According to the chi-square test, the p-value for the Pearson Chi-Square test is 0.978 and the p-value for the Likelihood Ratio Chi-Square test is also 0.978. Statistically, there is no significant association between learning styles and the ratings of Feature 22.

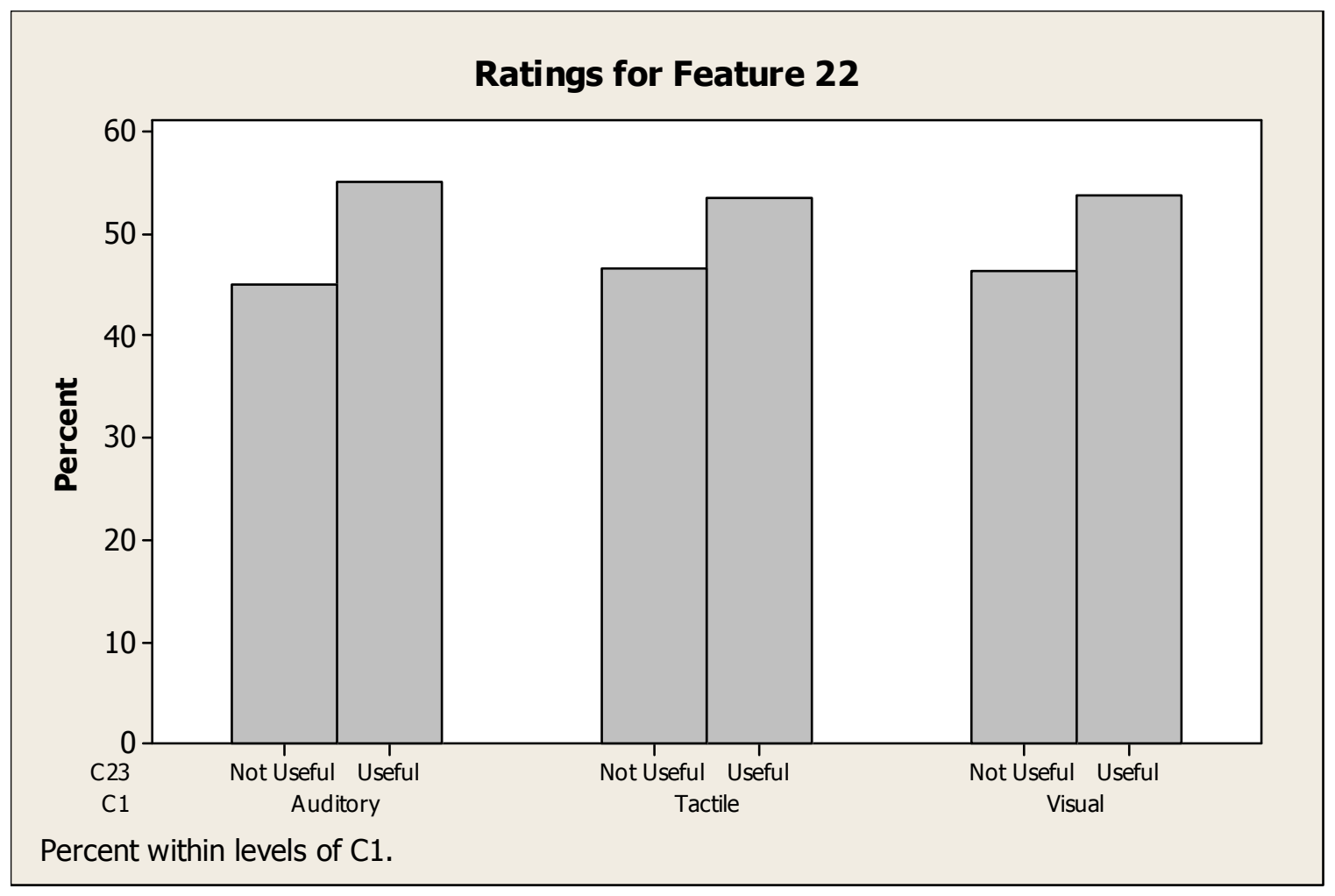

Figure 26: Feature 22 Ratings 


\subsubsection{Average Ratings for Visual}

Often times, it is useful to look at the data as a whole and evaluate the data using other statistical functions such as the mean, mode, median and standard deviation. The table that lists these measures for visual learners can be found in Appendix C. Figure 27 below shows the average rating of each feature for visual learners.

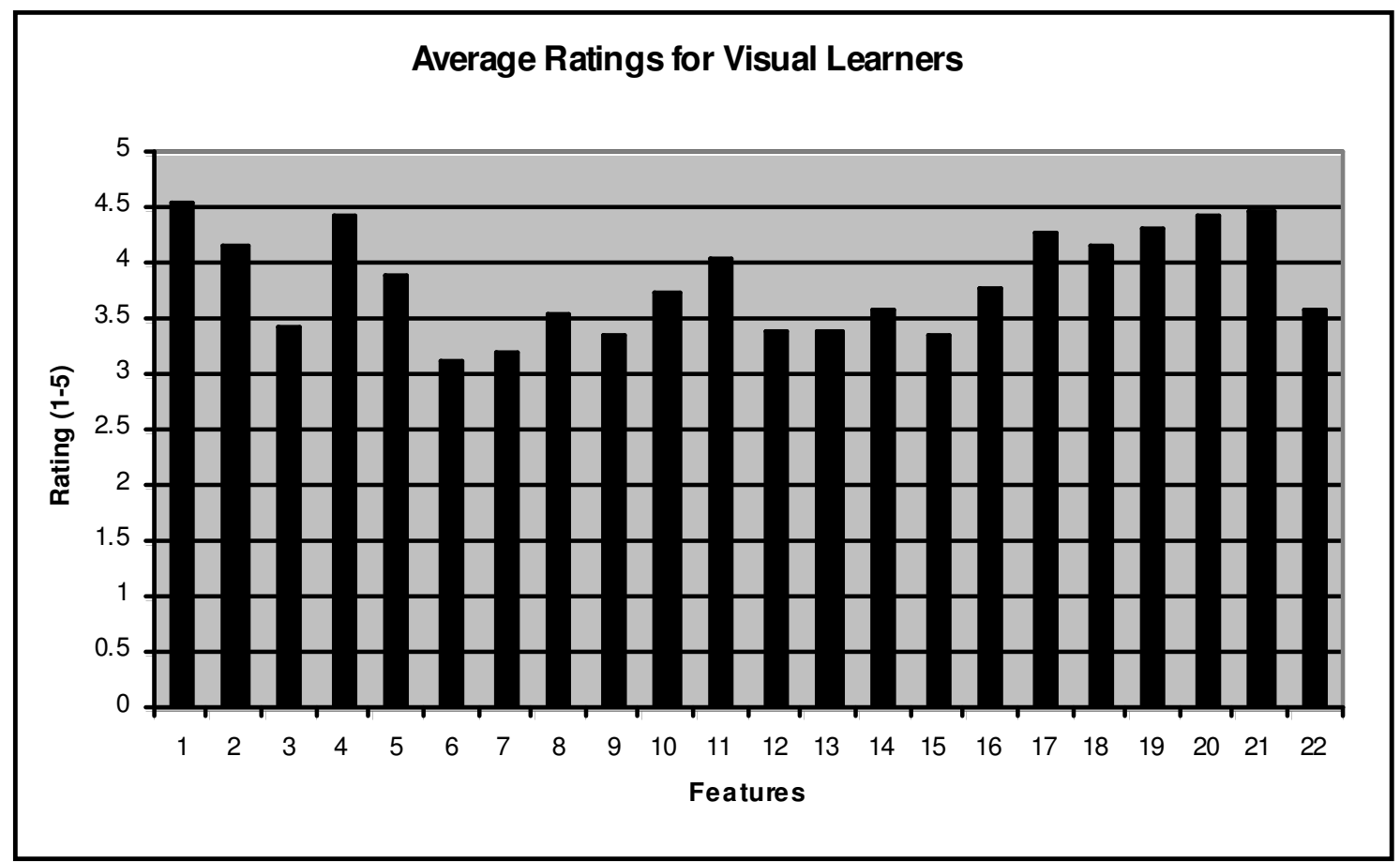

Figure 27: Average Ratings for Visual Learners

Because there are 22 features altogether, it is hard to extract any meaningful information if all of these features are considered. Therefore, the author only concentrates on the three highest-ranked features and the three lowest-ranked features for visual learners. When doing this, on average, the three highest-ranked features for visual learners are Feature 1, Feature 21, and Feature 4. The three lowest-ranked features are Feature 6, Feature 7, and Feature 15. 


\subsubsection{Average Ratings for Auditory}

The mean, mode, median, and standard deviation are also applied to auditory learners. The table for these measures can be found in Appendix C. Figure 28 shows the average rating of each feature for auditory learners.

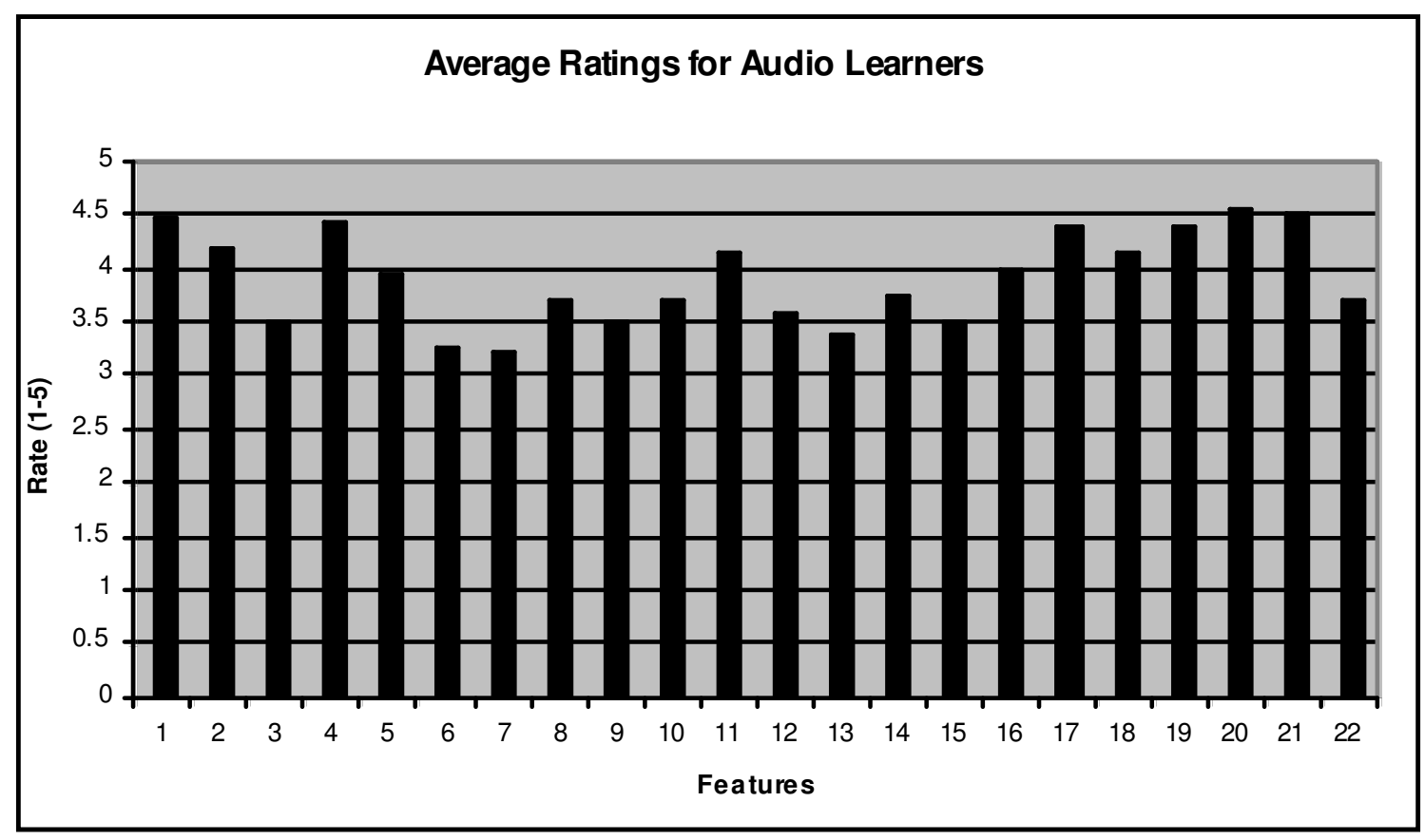

Figure 28: Average Ratings for Auditory Learners

From looking at the data, on average, the three highest-ranked features for auditory learners are Feature 20, Feature 21, and Feature 1. The three lowest-ranked features are Feature 7, Feature 6, and Feature 13. 


\subsubsection{Average Ratings for Tactile/Kinesthetic}

Like that of visual and auditory learners, the mean, mode, median, and standard deviation were also calculated for tactile learners. The table of these measures can be found in Appendix C. Figure 29 shows the average ratings of each feature for tactile learners.

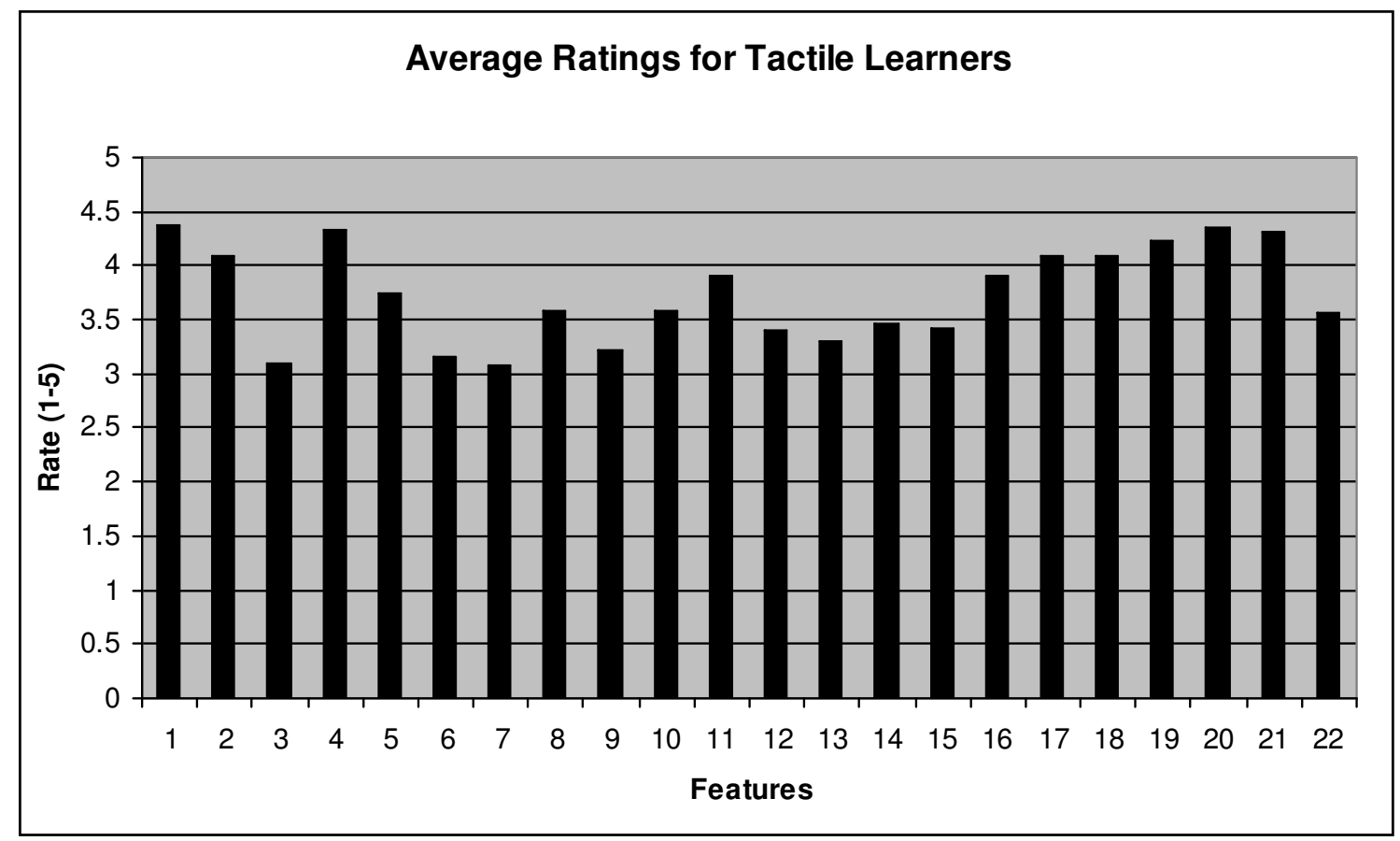

Figure 29: Average Ratings for Tactile Learners

On average, the highest-ranked features for tactile learners are Feature 1, Feature

20, and Feature 4. The three lowest-ranked features are Feature 7, Feature 3, and Feature 6. 


\subsection{Analysis}

The results from the previous section reveal that there is no statistical significant association between learning styles and all features listed for tablet-based presentation systems. Most participants have the same rating for the majority of the features despite learning style differences. A summary of these results can be seen in Table 4 below. There are only two features where the three learning types disagree on the ratings: Feature 12 and 15. For Feature 12, which is using speech recognition capabilities to convert instructor's voice to text, auditory learners find this to be a useful feature; however, tactile and visual learners feel that this feature is not useful. As for Feature 15, which is the automatic conversion of handwritten notes to printed text, auditory learners find this feature to be useful. Tactile learners are torn between the two ratings with half finding it to be useful and the other half rates it as not useful. And finally, visual learners rate Feature 15 to be not useful for their needs. 


\begin{tabular}{|c|c|}
\hline Rating & Features \\
\hline \multirow{15}{*}{ Useful } & $\begin{array}{l}\text { Feature 1: Using the tablet PC, instructors can handwrite additional notes on top of } \\
\text { slides to illustrate difficult concepts or to give explanations of important ideas }\end{array}$ \\
\hline & $\begin{array}{l}\text { Feature 2: Capturing instructors' handwritten notes during lecture using the tablet } \\
\text { PC }\end{array}$ \\
\hline & $\begin{array}{l}\text { Feature 4: Handwriting student digital notes on top of lecture slides using the } \\
\text { tablet PC }\end{array}$ \\
\hline & $\begin{array}{l}\text { Feature 5: Separate views for lecture notes with instructors' annotations and } \\
\text { lecture notes with student annotations }\end{array}$ \\
\hline & $\begin{array}{l}\text { Feature 8: Taking real-time quizzes or assessments on the tablet PC and submit } \\
\text { them to the instructor electronically }\end{array}$ \\
\hline & Feature 10: Recording instructor's voice during lecture \\
\hline & $\begin{array}{l}\text { Feature 11: When reviewing lecture notes, recorded instructor's voice are } \\
\text { synchronized with the slide you are on and the notes that you took during class }\end{array}$ \\
\hline & $\begin{array}{l}\text { Feature 14: Ink strokes change color over time to differentiate notes taken during } \\
\text { different periods of the lecture }\end{array}$ \\
\hline & Feature 16: Using the tablet PC to search through handwritten notes for key words \\
\hline & Feature 17: Having access to blank slides to take additional notes \\
\hline & $\begin{array}{l}\text { Feature 18: Navigating through all lecture slides without being restricted to the } \\
\text { slide that the instructor is lecturing on }\end{array}$ \\
\hline & Feature 19: Highlighting key words or ideas using the tablet PC \\
\hline & Feature 20: Erasing ink marks or strokes written using the tablet pen \\
\hline & Feature 21: Changing to different color ink when taking notes \\
\hline & $\begin{array}{l}\text { Feature 22: Peer-to-peer networking of tablet PCs to allow you to share } \\
\text { applications or chat with your instructors or other students }\end{array}$ \\
\hline \multirow{5}{*}{ Not Useful } & $\begin{array}{l}\text { Feature 3: Sending instant electronic responses to students' questions or comments } \\
\text { during lecture }\end{array}$ \\
\hline & Feature 6: Sending instant electronic questions to the instructor during lecture \\
\hline & Feature 7: Sending anonymous electronic questions to the instructor during lecture \\
\hline & $\begin{array}{l}\text { Feature 9: Instructor shares students' electronic submissions to the class via the } \\
\text { tablet PC }\end{array}$ \\
\hline & $\begin{array}{l}\text { Feature 13: Reviewing the notes in the order that instructor/students wrote them by } \\
\text { using the tablet PC to replay the handwritten notes stroke-by-stroke }\end{array}$ \\
\hline
\end{tabular}

Table 4: Overall Ratings of Features

When looking at the average ratings of different learners, all learners agree that the most important feature for tablet-based presentation systems is Feature 1 (instructors writing additional notes on top of slides). In addition, all three types of learners agree that Feature 6 (sending electronic questions to instructors) and Feature 7 (sending anonymous submissions to instructors) are not useful and have the lowest ratings compared to all other features offered by tablet-based presentation systems. It is also interesting to note that of the five features that participants found to be not useful in Table 4, four of those 
features have to deal with electronic communication between instructor and students in the classroom. It seems like students tend to stick to what they are used to. Electronic communication during class time seems to require extra effort and time to adapt; therefore, students seem to be resistant to such change. Furthermore, some informal reports from users showed that users often have a difficult time setting up the necessary network for classroom communication. So this feature is simply not used in various cases. 


\section{CONTRIBUTIONS}

In summary, the pilot study shows that participants with different learning styles do not have significantly different preferences when using tablet-based presentation systems. There were only 5 features that exhibited the greatest difference ( $7 \%$ and above) in preferences among different learning styles. These observations are further supported with the distribution of the survey. The chi-square test shows that the ratings for all of the listed features for tablet-based presentation systems have no statistical significant association with participants' learning styles. Hence, based on the findings of this research, the author concludes that there is no correlation between learning styles and tablet-based presentation systems. Students using these systems have approximately the same preferences despite learning style differences.

Since participants have similar preferences despite differences in learning styles, the research reveals some findings for students' overall preferences when using tabletbased presentation systems. According to the pilot study, all participants agree that on average, the most useful features are the following:

- Feature 15: Handwritten notes using the tablet PC are automatically converted to printed text

- Feature 16: Using the tablet PC to search through handwritten notes for key words

- Feature 18: Navigating through all lecture slides without being restricted to the slide that the instructor is lecturing on 
The features that participants found to be not useful on average are:

- Feature 8: Taking real-time quizzes or assessments on the tablet PC and submit them to the instructor electronically

- Feature 9: Instructors share students' electronic submissions to the class via the tablet PC

According to the results from the survey, all learners agree that on average, the most useful feature is Feature 1 (Using the tablet PC, instructors can handwrite additional notes on top of slides to illustrate difficult concepts or to give explanations of important ideas). Also, all participants, despite learning styles, agree on average that the two following features are not useful in the classroom:

- Feature 6: Sending instant electronic questions to instructors during lecture - Feature 7: Sending anonymous electronic questions to instructors during lecture

Table 4 also groups participants' ratings for each of the features into two categories: useful and not useful. This table shows participants' overall preferences when using tablet-based presentation systems despite learning styles. 


\section{RESEARCH VALIDATION}

Even though the research was performed with careful organization and planning, there are a few weaknesses that must be addressed. The main concern is the validity of the learning styles assessment tools that were used in this study. The question is the following: how accurate are these tools in assessing learning styles? The Memletics Learning Styles Inventory was taken from a website online that offers free assessments. As the site claims, there are over 180,000 people who have done the test and the test seems to be helpful to these people.

Marcia Conner's learning styles test was also taken from a website for the Ageless Learner Corporation. Conner has published various books on learning, such as [13] which describes the learning styles model used in this research. Background information on Conner is provided below:

Marcia L. Conner is Managing Director of Ageless Learner and an advisor to schools, corporations, associations, and busy people throughout the world. She was a Senior Manager at Microsoft, where she developed groundbreaking training practices, and was the Information Futurist at PeopleSoft, where she led programs for individual and organizational effectiveness [13].

Even though Conner seems to have much knowledge in learning, many participants from the survey have commented that the questions in the learning styles test were confusing and hard to answer based on the choices that were provided. 
Other than the validity of the learning styles assessment tools, the pilot study has some obvious problems. Because the sample size of the study was so small, it is very hard to take any conclusions yielded from the study to be valid. Also, participants involved in the study did not have enough time to fully experience the classroom environment with the use of tablet-based presentation systems. The mock lectures only lasted 30 minutes and most students had never used a tablet PC before taking part in the experiment. Studies that involve students experiencing tablet-based presentation systems in the classroom for a longer period of time could potentially provide more insights. However, it must be noted that the knowledge gained from carrying out the pilot study has aided the author in correcting some of its issues in the survey approach.

Finally, there are a couple of issues with the survey approach as well. In order to have enough data to perform the chi-square test, ratings with a 3 or below are grouped into the category "Not Useful." Ratings with a 4 or 5 are grouped into the category "Useful." One obvious problem with this approach is labeling the rating of 3 to be not useful. According to the distributed survey, the rating of 3 signifies no preference. By labeling this rating as not useful, it is not staying true to participants' intentions when they rated these features. Another issue to address is that participants involved in the survey were given the incentive of earning extra credit for class. Perhaps this could cause a certain bias in the sample or not. There are two types of students who would want to earn extra credit: over-achievers who are trying to stay ahead and under-achievers who are trying to pass the class. By offering extra credit to participants, this could have actually helped the survey sample to be more diverse. In addition, the survey result is a 
product of student's opinions of their own preferences and does not objectively evaluate the usefulness tablet-based presentation system features. Subjective ratings can suffer from biases and inaccurate assumptions from the participants giving them. Lastly, the tablet-based presentation system features chosen to be tested in this study were picked due to their popularity and commonality in most general presentation systems. This could cause this study to be incomprehensive and lacking some potentially important aspects of tablet-based presentation systems. 


\section{FUTURE WORK}

There is some future work that could be done within this area of research. As shown in the previous chapter, there are various flaws that the current research has. A possible solution to these problems is to administer a similar survey with a larger sample size. By having a larger sample size, the ratings do not have to be grouped into two categories and they can have enough data to serve as individual categories themselves. Also, a different learning styles test could be used instead of the one used by this study. As mentioned, Marcia Conner's learning styles test is too narrow in scope and participants have mentioned that the questions are confusing and hard to answer. In addition, instead of asking participants to rate the "usefulness" of features, participants could rate based on whether or not they think tablets would help them perform better in the classroom. Explicitly stating the outcome can help frame the question being asked better and could potentially yield less abstract assumptions from the participants. Furthermore, researchers could track actual student performance when using different tablet features in the classroom. Performance tracking can eliminate subjective ratings of students and offer pure objective results. With these mentioned changes, perhaps more findings can be found and different conclusions can be reached.

If the flaws from this research are far less significant compared to the actual findings yielded by the pilot study and the survey, then it can be concluded that students of all learning styles have the same preferences when using tablet-based presentation systems. From here, more research can be done to explore what other features besides the ones covered by this paper can be useful to students in general. These features can be 
features that are already available or possible features to be implemented in future tabletbased presentation systems.

Another research route that could be taken is to explore the correlation between personality types and tablet-based presentation systems. As mentioned earlier, understanding differences in students' personality can help instructors create a more balanced learning environment. Even though this paper has found that there is no correlation between learning styles and tablet-based presentation systems, perhaps personality types can offer different results and conclusions. 


\section{CONCLUSION}

To reiterate the words of Felder, "understanding learning style differences is thus an important step in designing balanced instruction that is effective for all students [22]." For this reason, the purpose of this paper is to explore the correlation between tabletbased presentation systems and learning styles.

Two approaches were taken: the pilot study and the survey. As shown previously, the pilot study reveals that there is no significant difference in preferences for various learning styles when using tablet-based presentation systems. These results are not statistically valid due to the small sample size. Hence, the survey was conducted and distributed to numerous students. The survey shows that all listed tablet-based presentation system features have no statistically significant association with learning styles based on the chi-square test.

By combining all of the results yielded from the pilot study and the survey, this paper tentatively concludes that there is no correlation between tablet-based presentation systems and learning styles. In general, students have approximately the same preferences when using tablet-based presentation systems regardless of learning style differences. Even though the results prove a negative effect to the efforts of this paper, the research is still valid and very important. There is an ongoing belief that education should address all learning styles in order to create a well-balanced learning environment for students. However, there are times when learning styles are not as crucial and do not have to be considered in the classroom. As evidence, the results from this paper reveal that there is no correlation between students' learning style differences and their 
preferences when using tablet-based presentation systems in the classroom. With this knowledge, effort can be spent on exploring various ways to effectively use tablet-based presentation systems in the classroom without having to place much emphasis on learning style differences. 


\section{APPENDIX A: Survey on Tablet PCs and Learning Styles}

\section{Survey on Tablet PCs and Learning Styles}

The purpose of this survey is to explore how useful tablet-based presentation systems are to address the needs of students with different learning styles. Examples of tablet-based presentation systems include Classroom Presenter, Ubiquitous Presenter, and OneNote. Therefore, the first 12 questions are used to determine your learning style (I apologize if the questions seem confusing. Just try your best!). The rest of the questions focuses on the different features that tablet-based presentation systems have to offer. Please answer these questions based on either your personal experience with using the tablet PC or your preference if you were to use a tablet PC.

Please note that the information you provide will be shared with the public for the sole purpose of data analysis and educational research. Your identity will remain anonymous and your privacy will not be violated in any way.

The learning styles test is used with permission from (C) Marcia L. Conner, 1993-2005. All rights reserved View this assessment online at http://www.agelesslearner.com/assess/learningstyle.html

1) When I try to concentrate...

C I grow distracted by clutter or movement, and I notice things around me other people don't notice.

C I get distracted by sounds, and I attempt to control the amount and type of noise around me.

C I become distracted by commotion, and I tend to retreat inside myself.

2) When I visualize...

I see vivid, detailed pictures in my thoughts.

[ I think in voices and sounds.

C I see images in my thoughts that involve movement.

3) When I talk with others...

C I find it difficult to listen for very long.

C I enjoy listening, or I get impatient to talk myself.

C I gesture and communicate with my hands.

4) When I contact people...

C I prefer face-to-face meetings.

[ I prefer speaking by telephone for serious conversations. 
C I prefer to interact while walking or participating in some activity.

5) When I see an acquaintance...

C I forget names but remember faces, and I tend to replay where we met for the first time.

[ I know people's names and I can usually quote what we discussed.

C I remember what we did together and I may almost "feel" our time together.

6) When I relax...

C I watch TV, see a play, visit an exhibit, or go to a movie.

C I listen to the radio, play music, read, or talk with a friend.

C I play sports, make crafts, or build something with my hands.

7) When I read...

C I like descriptive examples and I may pause to imagine the scene.

C I enjoy the narrative most and I can almost "hear" the characters talk.

C I prefer action-oriented stories, but I do not often read for pleasure.

8) When I spell...

C I envision the word in my mind or imagine what the word looks like when written.

C I sound out the word, sometimes aloud, and tend to recall rules about letter order.

C I get a feel for the word by writing it out or pretending to type it.

9) When I do something new...

[ I seek out demonstrations, pictures, or diagrams.

C I want verbal and written instructions, and to talk it over with someone else.

C I jump right in to try it, keep trying, and try different approaches.

10) When I assemble an object...

I I look at the picture first and then, maybe, read the directions.

C I read the directions, or I talk aloud as I work.

C I usually ignore the directions and figure it out as I go along.

11) When I interpret someone's mood...

C I examine facial expressions.

C I rely on listening to tone of voice. 
C I focus on body language.

12) When I teach other people...

C I show them.

[ I tell them, write it out, or I ask them a series of questions.

C I demonstrate how it is done and then ask them to try.

Next Page

13) Have you had experience with using a tablet PC in the classroom? If No, please skip the next 3 questions
C Yes
D No

14) What version of the tablet PC are you using?

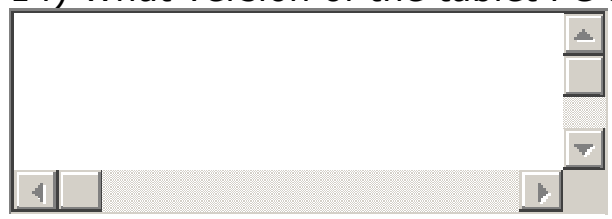

15) What type of courses are you using the tablet PC for?

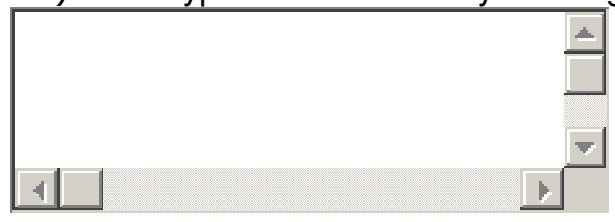

16) What software do you use to capture notes in the classroom?

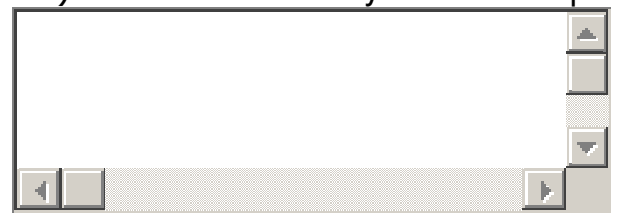

17) Please rate the following features based on your preference when using the tablet PC in the classroom lecture environment. If you've never had experience with using a tablet PC before, please answer these questions based on what you would want if you were to use one in the future.

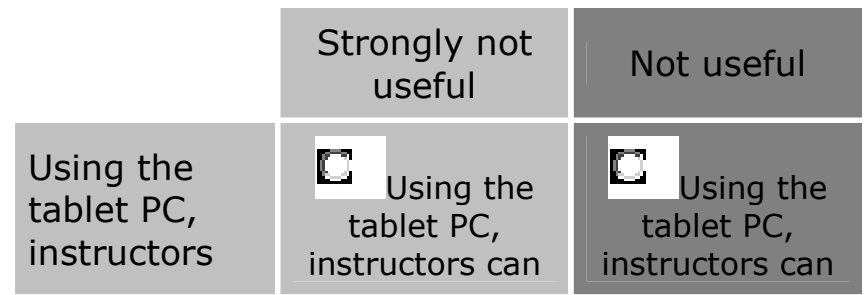

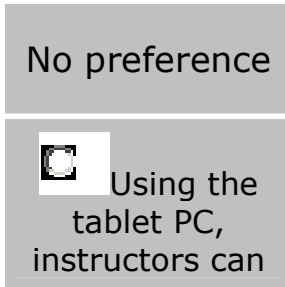

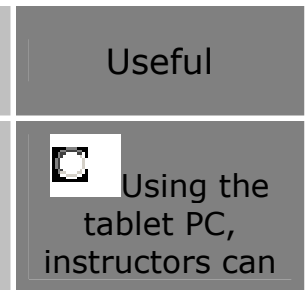

Strongly useful

C Using the tablet PC, instructors can 


\begin{tabular}{|c|c|c|c|c|c|}
\hline $\begin{array}{l}\text { can } \\
\text { handwrite } \\
\text { additional } \\
\text { notes on top } \\
\text { of slides to } \\
\text { illustrate } \\
\text { difficult } \\
\text { concepts or } \\
\text { to give } \\
\text { explanations } \\
\text { of important } \\
\text { ideas }\end{array}$ & $\begin{array}{c}\text { handwrite } \\
\text { additional notes } \\
\text { on top of slides } \\
\text { to illustrate } \\
\text { difficult } \\
\text { concepts or to } \\
\text { give } \\
\text { explanations of } \\
\text { important ideas } \\
\text { Strongly not } \\
\text { useful }\end{array}$ & $\begin{array}{c}\text { handwrite } \\
\text { additional notes } \\
\text { on top of slides } \\
\text { to illustrate } \\
\text { difficult } \\
\text { concepts or to } \\
\text { give } \\
\text { explanations of } \\
\text { important ideas } \\
\text { Not useful }\end{array}$ & $\begin{array}{c}\text { handwrite } \\
\text { additional notes } \\
\text { on top of slides } \\
\text { to illustrate } \\
\text { difficult } \\
\text { concepts or to } \\
\text { give } \\
\text { explanations of } \\
\text { important ideas } \\
\text { No preference }\end{array}$ & $\begin{array}{c}\text { handwrite } \\
\text { additional notes } \\
\text { on top of slides } \\
\text { to illustrate } \\
\text { difficult } \\
\text { concepts or to } \\
\text { give } \\
\text { explanations of } \\
\text { important ideas } \\
\text { Useful }\end{array}$ & $\begin{array}{l}\text { handwrite } \\
\text { additional notes } \\
\text { on top of slides } \\
\text { to illustrate } \\
\text { difficult } \\
\text { concepts or to } \\
\text { give } \\
\text { explanations of } \\
\text { important ideas } \\
\text { Strongly useful }\end{array}$ \\
\hline $\begin{array}{l}\text { Capturing } \\
\text { instructors' } \\
\text { handwritten } \\
\text { notes during } \\
\text { lecture using } \\
\text { the tablet PC }\end{array}$ & $\begin{array}{l}\text { Capturing } \\
\text { instructors' } \\
\text { handwritten } \\
\text { notes during } \\
\text { lecture using } \\
\text { the tablet PC } \\
\text { Strongly not } \\
\text { useful }\end{array}$ & $\begin{array}{l}\text { C Capturing } \\
\text { instructors' } \\
\text { handwritten } \\
\text { notes during } \\
\text { lecture using } \\
\text { the tablet PC } \\
\text { Not useful }\end{array}$ & $\begin{array}{l}\text { C Capturing } \\
\text { instructors' } \\
\text { handwritten } \\
\text { notes during } \\
\text { lecture using } \\
\text { the tablet PC No } \\
\text { preference }\end{array}$ & $\begin{array}{c}\text { C Capturing } \\
\text { instructors' } \\
\text { handwritten } \\
\text { notes during } \\
\text { lecture using } \\
\text { the tablet PC } \\
\text { Useful }\end{array}$ & $\begin{array}{l}\text { C Capturing } \\
\text { instructors' } \\
\text { handwritten } \\
\text { notes during } \\
\text { lecture using } \\
\text { the tablet PC } \\
\text { Strongly useful }\end{array}$ \\
\hline $\begin{array}{l}\text { Sending } \\
\text { instant } \\
\text { electronic } \\
\text { responses to } \\
\text { students' } \\
\text { questions or } \\
\text { comments } \\
\text { during } \\
\text { lecture }\end{array}$ & $\begin{array}{l}\text { Cending } \\
\text { instant } \\
\text { electronic } \\
\text { responses to } \\
\text { students' } \\
\text { questions or } \\
\text { comments } \\
\text { during lecture } \\
\text { Strongly not } \\
\text { useful }\end{array}$ & $\begin{array}{c}\text { C Sending } \\
\text { instant } \\
\text { electronic } \\
\text { responses to } \\
\text { students' } \\
\text { questions or } \\
\text { comments } \\
\text { during lecture } \\
\text { Not useful }\end{array}$ & $\begin{array}{c}\text { C Sending } \\
\text { instant } \\
\text { electronic } \\
\text { responses to } \\
\text { students' } \\
\text { questions or } \\
\text { comments } \\
\text { during lecture } \\
\text { No preference }\end{array}$ & $\begin{array}{c}\text { C Sending } \\
\text { instant } \\
\text { electronic } \\
\text { responses to } \\
\text { students' } \\
\text { questions or } \\
\text { comments } \\
\text { during lecture } \\
\text { Useful }\end{array}$ & $\begin{array}{c}\text { C Sending } \\
\text { instant } \\
\text { electronic } \\
\text { responses to } \\
\text { students' } \\
\text { questions or } \\
\text { comments } \\
\text { during lecture } \\
\text { Strongly useful }\end{array}$ \\
\hline $\begin{array}{l}\text { Handwriting } \\
\text { your own } \\
\text { digital notes } \\
\text { on top of } \\
\text { lecture slides } \\
\text { using the } \\
\text { tablet PC }\end{array}$ & $\begin{array}{c}\text { C Handwriting } \\
\text { your own digital } \\
\text { notes on top of } \\
\text { lecture slides } \\
\text { using the tablet } \\
\text { PC Strongly not } \\
\text { useful }\end{array}$ & $\begin{array}{l}\text { C Handwriting } \\
\text { your own digital } \\
\text { notes on top of } \\
\text { lecture slides } \\
\text { using the tablet } \\
\text { PC Not useful }\end{array}$ & $\begin{array}{c}\text { C Handwriting } \\
\text { your own digital } \\
\text { notes on top of } \\
\text { lecture slides } \\
\text { using the tablet } \\
\text { PC No } \\
\text { preference }\end{array}$ & $\begin{array}{c}\text { C Handwriting } \\
\text { your own digital } \\
\text { notes on top of } \\
\text { lecture slides } \\
\text { using the tablet } \\
\text { PC Useful }\end{array}$ & $\begin{array}{c}\text { C Handwriting } \\
\text { your own digital } \\
\text { notes on top of } \\
\text { lecture slides } \\
\text { using the tablet } \\
\text { PC Strongly } \\
\text { useful }\end{array}$ \\
\hline $\begin{array}{l}\text { Separate } \\
\text { views for } \\
\text { lecture notes } \\
\text { with } \\
\text { instructors' } \\
\text { annotations } \\
\text { and lecture } \\
\text { notes with } \\
\text { your own } \\
\text { annotations }\end{array}$ & $\begin{array}{c}\text { Separate } \\
\text { views for lecture } \\
\text { notes with } \\
\text { instructors' } \\
\text { annotations and } \\
\text { lecture notes } \\
\text { with your own } \\
\text { annotations } \\
\text { Strongly not } \\
\text { useful }\end{array}$ & $\begin{array}{c}\text { C Separate } \\
\text { views for lecture } \\
\text { notes with } \\
\text { instructors' } \\
\text { annotations and } \\
\text { lecture notes } \\
\text { with your own } \\
\text { annotations Not } \\
\text { useful }\end{array}$ & $\begin{array}{c}\text { C Separate } \\
\text { views for lecture } \\
\text { notes with } \\
\text { instructors' } \\
\text { annotations and } \\
\text { lecture notes } \\
\text { with your own } \\
\text { annotations No } \\
\text { preference }\end{array}$ & $\begin{array}{c}\text { C Separate } \\
\text { views for lecture } \\
\text { notes with } \\
\text { instructors' } \\
\text { annotations and } \\
\text { lecture notes } \\
\text { with your own } \\
\text { annotations } \\
\text { Useful }\end{array}$ & $\begin{array}{c}\text { C Separate } \\
\text { views for lecture } \\
\text { notes with } \\
\text { instructors' } \\
\text { annotations and } \\
\text { lecture notes } \\
\text { with your own } \\
\text { annotations } \\
\text { Strongly useful }\end{array}$ \\
\hline $\begin{array}{l}\text { Sending } \\
\text { instant }\end{array}$ & C Sending & C Sending & C Sending & C Sending & C Sending \\
\hline
\end{tabular}




\begin{tabular}{|c|c|c|c|c|c|}
\hline $\begin{array}{l}\text { electronic } \\
\text { questions to } \\
\text { instructors } \\
\text { during } \\
\text { lecture }\end{array}$ & $\begin{array}{c}\text { instant } \\
\text { electronic } \\
\text { questions to } \\
\text { instructors } \\
\text { during lecture } \\
\text { Strongly not } \\
\text { useful }\end{array}$ & $\begin{array}{l}\text { instant } \\
\text { electronic } \\
\text { questions to } \\
\text { instructors } \\
\text { during lecture } \\
\text { Not useful }\end{array}$ & $\begin{array}{l}\text { instant } \\
\text { electronic } \\
\text { questions to } \\
\text { instructors } \\
\text { during lecture } \\
\text { No preference }\end{array}$ & $\begin{array}{c}\text { instant } \\
\text { electronic } \\
\text { questions to } \\
\text { instructors } \\
\text { during lecture } \\
\text { Useful }\end{array}$ & $\begin{array}{l}\text { instant } \\
\text { electronic } \\
\text { questions to } \\
\text { instructors } \\
\text { during lecture } \\
\text { Strongly useful }\end{array}$ \\
\hline $\begin{array}{l}\text { Sending } \\
\text { anonymous } \\
\text { electronic } \\
\text { questions to } \\
\text { instructors } \\
\text { during } \\
\text { lecture }\end{array}$ & $\begin{array}{c}\text { C Sending } \\
\text { anonymous } \\
\text { electronic } \\
\text { questions to } \\
\text { instructors } \\
\text { during lecture } \\
\text { Strongly not } \\
\text { useful }\end{array}$ & $\begin{array}{l}\text { C Sending } \\
\text { anonymous } \\
\text { electronic } \\
\text { questions to } \\
\text { instructors } \\
\text { during lecture } \\
\text { Not useful }\end{array}$ & $\begin{array}{l}\text { C Sending } \\
\text { anonymous } \\
\text { electronic } \\
\text { questions to } \\
\text { instructors } \\
\text { during lecture } \\
\text { No preference }\end{array}$ & $\begin{array}{c}\text { Cending } \\
\text { anonymous } \\
\text { electronic } \\
\text { questions to } \\
\text { instructors } \\
\text { during lecture } \\
\text { Useful }\end{array}$ & $\begin{array}{l}\mathrm{C} \text { Sending } \\
\text { anonymous } \\
\text { electronic } \\
\text { questions to } \\
\text { instructors } \\
\text { during lecture } \\
\text { Strongly useful }\end{array}$ \\
\hline $\begin{array}{l}\text { Taking real- } \\
\text { time quizzes } \\
\text { or } \\
\text { assessments } \\
\text { on the tablet } \\
\text { PC and } \\
\text { submit them } \\
\text { to the } \\
\text { instructor } \\
\text { electronically }\end{array}$ & $\begin{array}{l}\text { C Taking real- } \\
\text { time quizzes or } \\
\text { assessments on } \\
\text { the tablet PC } \\
\text { and submit } \\
\text { them to the } \\
\text { instructor } \\
\text { electronically } \\
\text { Strongly not } \\
\text { useful }\end{array}$ & $\begin{array}{l}\text { Taking real- } \\
\text { time quizzes or } \\
\text { assessments on } \\
\text { the tablet PC } \\
\text { and submit } \\
\text { them to the } \\
\text { instructor } \\
\text { electronically } \\
\text { Not useful }\end{array}$ & $\begin{array}{l}\text { C Taking real- } \\
\text { time quizzes or } \\
\text { assessments on } \\
\text { the tablet PC } \\
\text { and submit } \\
\text { them to the } \\
\text { instructor } \\
\text { electronically No } \\
\text { preference }\end{array}$ & $\begin{array}{l}\text { C Taking real- } \\
\text { time quizzes or } \\
\text { assessments on } \\
\text { the tablet PC } \\
\text { and submit } \\
\text { them to the } \\
\text { instructor } \\
\text { electronically } \\
\text { Useful }\end{array}$ & $\begin{array}{l}\text { C Taking real- } \\
\text { time quizzes or } \\
\text { assessments on } \\
\text { the tablet PC } \\
\text { and submit } \\
\text { them to the } \\
\text { instructor } \\
\text { electronically } \\
\text { Strongly useful }\end{array}$ \\
\hline $\begin{array}{l}\text { Instructors } \\
\text { share } \\
\text { students' } \\
\text { electronic } \\
\text { submissions } \\
\text { to the class } \\
\text { via the tablet } \\
\text { PC }\end{array}$ & $\begin{array}{l}\text { Instructors } \\
\text { share students' } \\
\text { electronic } \\
\text { submissions to } \\
\text { the class via the } \\
\text { tablet PC } \\
\text { Strongly not } \\
\text { useful }\end{array}$ & $\begin{array}{c}\text { C Instructors } \\
\text { share students' } \\
\text { electronic } \\
\text { submissions to } \\
\text { the class via the } \\
\text { tablet PC Not } \\
\text { useful }\end{array}$ & $\begin{array}{l}\text { Instructors } \\
\text { share students' } \\
\text { electronic } \\
\text { submissions to } \\
\text { the class via the } \\
\text { tablet PC No } \\
\text { preference }\end{array}$ & $\begin{array}{c}\mathrm{C} \text { Instructors } \\
\text { share students' } \\
\text { electronic } \\
\text { submissions to } \\
\text { the class via the } \\
\text { tablet PC Useful }\end{array}$ & $\begin{array}{l}\text { Instructors } \\
\text { share students' } \\
\text { electronic } \\
\text { submissions to } \\
\text { the class via the } \\
\text { tablet PC } \\
\text { Strongly useful }\end{array}$ \\
\hline $\begin{array}{l}\text { Recording } \\
\text { instructors' } \\
\text { voices during } \\
\text { lecture }\end{array}$ & $\begin{array}{c}\text { C Recording } \\
\text { instructors' } \\
\text { voices during } \\
\text { lecture Strongly } \\
\text { not useful }\end{array}$ & $\begin{array}{c}\text { C Recording } \\
\text { instructors' } \\
\text { voices during } \\
\text { lecture Not } \\
\text { useful }\end{array}$ & $\begin{array}{c}\text { C Recording } \\
\text { instructors' } \\
\text { voices during } \\
\text { lecture No } \\
\text { preference }\end{array}$ & $\begin{array}{c}\text { Recording } \\
\text { instructors' } \\
\text { voices during } \\
\text { lecture Useful }\end{array}$ & $\begin{array}{c}\text { Recording } \\
\text { instructors' } \\
\text { voices during } \\
\text { lecture Strongly } \\
\text { useful }\end{array}$ \\
\hline $\begin{array}{l}\text { When } \\
\text { reviewing } \\
\text { lecture } \\
\text { notes, } \\
\text { recorded } \\
\text { instructors' } \\
\text { voices are } \\
\text { synchronized } \\
\text { with the slide } \\
\text { you are on } \\
\text { and the }\end{array}$ & $\begin{array}{l}\text { When } \\
\text { reviewing } \\
\text { lecture notes, } \\
\text { recorded } \\
\text { instructors' } \\
\text { voices are } \\
\text { synchronized } \\
\text { with the slide } \\
\text { you are on and } \\
\text { the notes that } \\
\text { you took during }\end{array}$ & $\begin{array}{c}\text { When } \\
\text { reviewing } \\
\text { lecture notes, } \\
\text { recorded } \\
\text { instructors' } \\
\text { voices are } \\
\text { synchronized } \\
\text { with the slide } \\
\text { you are on and } \\
\text { the notes that } \\
\text { you took during }\end{array}$ & $\begin{array}{c}\text { C When } \\
\text { reviewing } \\
\text { lecture notes, } \\
\text { recorded } \\
\text { instructors' } \\
\text { voices are } \\
\text { synchronized } \\
\text { with the slide } \\
\text { you are on and } \\
\text { the notes that } \\
\text { you took during }\end{array}$ & $\begin{array}{l}\text { C When } \\
\text { reviewing } \\
\text { lecture notes, } \\
\text { recorded } \\
\text { instructors' } \\
\text { voices are } \\
\text { synchronized } \\
\text { with the slide } \\
\text { you are on and } \\
\text { the notes that } \\
\text { you took during }\end{array}$ & $\begin{array}{l}\text { C When } \\
\text { reviewing } \\
\text { lecture notes, } \\
\text { recorded } \\
\text { instructors' } \\
\text { voices are } \\
\text { synchronized } \\
\text { with the slide } \\
\text { you are on and } \\
\text { the notes that } \\
\text { you took during }\end{array}$ \\
\hline
\end{tabular}




\begin{tabular}{|c|c|c|c|c|c|}
\hline $\begin{array}{l}\text { notes that } \\
\text { you took } \\
\text { during class }\end{array}$ & $\begin{array}{c}\text { class Strongly } \\
\text { not useful }\end{array}$ & class Not useful & $\begin{array}{l}\text { class No } \\
\text { preference }\end{array}$ & class Useful & $\begin{array}{c}\text { class Strongly } \\
\text { useful }\end{array}$ \\
\hline $\begin{array}{l}\text { Using speech } \\
\text { recognition } \\
\text { capabilities } \\
\text { to convert } \\
\text { instructors' } \\
\text { voices to } \\
\text { text }\end{array}$ & $\begin{array}{l}\text { Using } \\
\text { speech } \\
\text { recognition } \\
\text { capabilities to } \\
\text { convert } \\
\text { instructors' } \\
\text { voices to text } \\
\text { Strongly not } \\
\text { useful }\end{array}$ & $\begin{array}{l}\text { C Using } \\
\text { speech } \\
\text { recognition } \\
\text { capabilities to } \\
\text { convert } \\
\text { instructors' } \\
\text { voices to text } \\
\text { Not useful }\end{array}$ & $\begin{array}{c}\mathbf{C} \text { Using } \\
\text { speech } \\
\text { recognition } \\
\text { capabilities to } \\
\text { convert } \\
\text { instructors' } \\
\text { voices to text } \\
\text { No preference }\end{array}$ & $\begin{array}{l}\text { C Using } \\
\text { speech } \\
\text { recognition } \\
\text { capabilities to } \\
\text { convert } \\
\text { instructors' } \\
\text { voices to text } \\
\text { Useful }\end{array}$ & $\begin{array}{l}\mathbf{C} \text { Using } \\
\text { speech } \\
\text { recognition } \\
\text { capabilities to } \\
\text { convert } \\
\text { instructors' } \\
\text { voices to text } \\
\text { Strongly useful }\end{array}$ \\
\hline $\begin{array}{l}\text { Reviewing } \\
\text { your notes in } \\
\text { the order } \\
\text { that you } \\
\text { wrote them } \\
\text { by using the } \\
\text { tablet PC to } \\
\text { replay the } \\
\text { handwritten } \\
\text { notes stroke- } \\
\text { by-stroke }\end{array}$ & $\begin{array}{l}\text { C Reviewing } \\
\text { your notes in } \\
\text { the order that } \\
\text { you wrote them } \\
\text { by using the } \\
\text { tablet PC to } \\
\text { replay the } \\
\text { handwritten } \\
\text { notes stroke-by- } \\
\text { stroke Strongly } \\
\text { not useful }\end{array}$ & $\begin{array}{l}\text { Reviewing } \\
\text { your notes in } \\
\text { the order that } \\
\text { you wrote them } \\
\text { by using the } \\
\text { tablet PC to } \\
\text { replay the } \\
\text { handwritten } \\
\text { notes stroke-by- } \\
\text { stroke Not } \\
\text { useful }\end{array}$ & $\begin{array}{l}\text { R Reviewing } \\
\text { your notes in } \\
\text { the order that } \\
\text { you wrote them } \\
\text { by using the } \\
\text { tablet PC to } \\
\text { replay the } \\
\text { handwritten } \\
\text { notes stroke-by- } \\
\text { stroke No } \\
\text { preference }\end{array}$ & $\begin{array}{l}\mathrm{C} \text { Reviewing } \\
\text { your notes in } \\
\text { the order that } \\
\text { you wrote them } \\
\text { by using the } \\
\text { tablet PC to } \\
\text { replay the } \\
\text { handwritten } \\
\text { notes stroke-by- } \\
\text { stroke Useful }\end{array}$ & $\begin{array}{l}\text { Reviewing } \\
\text { your notes in } \\
\text { the order that } \\
\text { you wrote them } \\
\text { by using the } \\
\text { tablet PC to } \\
\text { replay the } \\
\text { handwritten } \\
\text { notes stroke-by- } \\
\text { stroke Strongly } \\
\text { useful }\end{array}$ \\
\hline $\begin{array}{l}\text { Ink strokes } \\
\text { change color } \\
\text { over time to } \\
\text { differentiate } \\
\text { notes taken } \\
\text { during } \\
\text { different } \\
\text { periods of } \\
\text { the lecture }\end{array}$ & $\begin{array}{c}\text { Ink strokes } \\
\text { change color } \\
\text { over time to } \\
\text { differentiate } \\
\text { notes taken } \\
\text { during different } \\
\text { periods of the } \\
\text { lecture Strongly } \\
\text { not useful }\end{array}$ & $\begin{array}{c}\text { Ink strokes } \\
\text { change color } \\
\text { over time to } \\
\text { differentiate } \\
\text { notes taken } \\
\text { during different } \\
\text { periods of the } \\
\text { lecture Not } \\
\text { useful }\end{array}$ & $\begin{array}{c}\text { Ink strokes } \\
\text { change color } \\
\text { over time to } \\
\text { differentiate } \\
\text { notes taken } \\
\text { during different } \\
\text { periods of the } \\
\text { lecture No } \\
\text { preference }\end{array}$ & $\begin{array}{c}\text { Ink strokes } \\
\text { change color } \\
\text { over time to } \\
\text { differentiate } \\
\text { notes taken } \\
\text { during different } \\
\text { periods of the } \\
\text { lecture Useful }\end{array}$ & $\begin{array}{c}\text { Ink strokes } \\
\text { change color } \\
\text { over time to } \\
\text { differentiate } \\
\text { notes taken } \\
\text { during different } \\
\text { periods of the } \\
\text { lecture Strongly } \\
\text { useful }\end{array}$ \\
\hline $\begin{array}{l}\text { Handwritten } \\
\text { notes using } \\
\text { the tablet PC } \\
\text { are } \\
\text { automatically } \\
\text { converted to } \\
\text { printed text }\end{array}$ & $\begin{array}{c}\text { C Handwritten } \\
\text { notes using the } \\
\text { tablet PC are } \\
\text { automatically } \\
\text { converted to } \\
\text { printed text } \\
\text { Strongly not } \\
\text { useful }\end{array}$ & $\begin{array}{c}\text { C Handwritten } \\
\text { notes using the } \\
\text { tablet PC are } \\
\text { automatically } \\
\text { converted to } \\
\text { printed text Not } \\
\text { useful }\end{array}$ & $\begin{array}{l}\text { Handwritten } \\
\text { notes using the } \\
\text { tablet PC are } \\
\text { automatically } \\
\text { converted to } \\
\text { printed text No } \\
\text { preference }\end{array}$ & $\begin{array}{c}\text { C Handwritten } \\
\text { notes using the } \\
\text { tablet PC are } \\
\text { automatically } \\
\text { converted to } \\
\text { printed text } \\
\text { Useful }\end{array}$ & $\begin{array}{l}\text { Handwritten } \\
\text { notes using the } \\
\text { tablet PC are } \\
\text { automatically } \\
\text { converted to } \\
\text { printed text } \\
\text { Strongly useful }\end{array}$ \\
\hline $\begin{array}{l}\text { Using the } \\
\text { tablet PC to } \\
\text { search } \\
\text { through } \\
\text { handwritten } \\
\text { notes for key } \\
\text { words }\end{array}$ & $\begin{array}{l}\text { C Using the } \\
\text { tablet PC to } \\
\text { search through } \\
\text { handwritten } \\
\text { notes for key } \\
\text { words Strongly } \\
\text { not useful }\end{array}$ & $\begin{array}{l}\text { C Using the } \\
\text { tablet PC to } \\
\text { search through } \\
\text { handwritten } \\
\text { notes for key } \\
\text { words Not } \\
\text { useful }\end{array}$ & $\begin{array}{l}\text { C Using the } \\
\text { tablet PC to } \\
\text { search through } \\
\text { handwritten } \\
\text { notes for key } \\
\text { words No } \\
\text { preference }\end{array}$ & $\begin{array}{l}\mathrm{C} \text { Using the } \\
\text { tablet PC to } \\
\text { search through } \\
\text { handwritten } \\
\text { notes for key } \\
\text { words Useful }\end{array}$ & $\begin{array}{l}\text { C Using the } \\
\text { tablet PC to } \\
\text { search through } \\
\text { handwritten } \\
\text { notes for key } \\
\text { words Strongly } \\
\text { useful }\end{array}$ \\
\hline
\end{tabular}




\begin{tabular}{|c|c|c|c|c|c|}
\hline $\begin{array}{l}\text { Having } \\
\text { access to } \\
\text { blank slides } \\
\text { to take } \\
\text { additional } \\
\text { notes }\end{array}$ & $\begin{array}{c}\text { Having } \\
\text { access to blank } \\
\text { slides to take } \\
\text { additional notes } \\
\text { Strongly not } \\
\text { useful }\end{array}$ & $\begin{array}{c}\text { C Having } \\
\text { access to blank } \\
\text { slides to take } \\
\text { additional notes } \\
\text { Not useful }\end{array}$ & $\begin{array}{c}\text { C Having } \\
\text { access to blank } \\
\text { slides to take } \\
\text { additional notes } \\
\text { No preference }\end{array}$ & $\begin{array}{c}\text { C Having } \\
\text { access to blank } \\
\text { slides to take } \\
\text { additional notes } \\
\text { Useful }\end{array}$ & $\begin{array}{c}\text { Having } \\
\text { access to blank } \\
\text { slides to take } \\
\text { additional notes } \\
\text { Strongly useful }\end{array}$ \\
\hline $\begin{array}{l}\text { Navigating } \\
\text { through all } \\
\text { lecture slides } \\
\text { without } \\
\text { being } \\
\text { restricted to } \\
\text { the slide that } \\
\text { the } \\
\text { instructor is } \\
\text { lecturing on }\end{array}$ & $\begin{array}{l}\text { Navigating } \\
\text { through all } \\
\text { lecture slides } \\
\text { without being } \\
\text { restricted to the } \\
\text { slide that the } \\
\text { instructor is } \\
\text { lecturing on } \\
\text { Strongly not } \\
\text { useful }\end{array}$ & $\begin{array}{l}\text { Navigating } \\
\text { through all } \\
\text { lecture slides } \\
\text { without being } \\
\text { restricted to the } \\
\text { slide that the } \\
\text { instructor is } \\
\text { lecturing on Not } \\
\text { useful }\end{array}$ & $\begin{array}{l}\text { Navigating } \\
\text { through all } \\
\text { lecture slides } \\
\text { without being } \\
\text { restricted to the } \\
\text { slide that the } \\
\text { instructor is } \\
\text { lecturing on No } \\
\text { preference }\end{array}$ & $\begin{array}{l}\text { Navigating } \\
\text { through all } \\
\text { lecture slides } \\
\text { without being } \\
\text { restricted to the } \\
\text { slide that the } \\
\text { instructor is } \\
\text { lecturing on } \\
\text { Useful }\end{array}$ & $\begin{array}{l}\text { Navigating } \\
\text { through all } \\
\text { lecture slides } \\
\text { without being } \\
\text { restricted to the } \\
\text { slide that the } \\
\text { instructor is } \\
\text { lecturing on } \\
\text { Strongly useful }\end{array}$ \\
\hline $\begin{array}{l}\text { Highlighting } \\
\text { key words or } \\
\text { ideas using } \\
\text { the tablet PC }\end{array}$ & $\begin{array}{l}\text { Highlighting } \\
\text { key words or } \\
\text { ideas using the } \\
\text { tablet PC } \\
\text { Strongly not } \\
\text { useful }\end{array}$ & $\begin{array}{c}\text { C Highlighting } \\
\text { key words or } \\
\text { ideas using the } \\
\text { tablet PC Not } \\
\text { useful }\end{array}$ & $\begin{array}{l}\text { C Highlighting } \\
\text { key words or } \\
\text { ideas using the } \\
\text { tablet PC No } \\
\text { preference }\end{array}$ & $\begin{array}{l}\text { Hey Highlighting } \\
\text { key words or } \\
\text { ideas using the } \\
\text { tablet PC Useful }\end{array}$ & $\begin{array}{l}\text { Highlighting } \\
\text { key words or } \\
\text { ideas using the } \\
\text { tablet PC } \\
\text { Strongly useful }\end{array}$ \\
\hline $\begin{array}{l}\text { Erasing ink } \\
\text { marks or } \\
\text { strokes } \\
\text { written using } \\
\text { the tablet } \\
\text { pen }\end{array}$ & $\begin{array}{l}\text { E Erasing ink } \\
\text { marks or } \\
\text { strokes written } \\
\text { using the tablet } \\
\text { pen Strongly } \\
\text { not useful }\end{array}$ & $\begin{array}{c}\text { E Erasing ink } \\
\text { marks or } \\
\text { strokes written } \\
\text { using the tablet } \\
\text { pen Not useful }\end{array}$ & $\begin{array}{c}\text { Erasing ink } \\
\text { marks or } \\
\text { strokes written } \\
\text { using the tablet } \\
\text { pen No } \\
\text { preference }\end{array}$ & $\begin{array}{c}\text { Erasing ink } \\
\text { marks or } \\
\text { strokes written } \\
\text { using the tablet } \\
\text { pen Useful }\end{array}$ & $\begin{array}{c}\text { C Erasing ink } \\
\text { marks or } \\
\text { strokes written } \\
\text { using the tablet } \\
\text { pen Strongly } \\
\text { useful }\end{array}$ \\
\hline $\begin{array}{l}\text { Changing to } \\
\text { different } \\
\text { color ink } \\
\text { when taking } \\
\text { notes }\end{array}$ & $\begin{array}{c}\text { C Changing to } \\
\text { different color } \\
\text { ink when taking } \\
\text { notes Strongly } \\
\text { not useful }\end{array}$ & $\begin{array}{c}\text { C Changing to } \\
\text { different color } \\
\text { ink when taking } \\
\text { notes Not useful }\end{array}$ & $\begin{array}{l}\text { Changing to } \\
\text { different color } \\
\text { ink when taking } \\
\text { notes No } \\
\text { preference }\end{array}$ & $\begin{array}{c}\text { C Changing to } \\
\text { different color } \\
\text { ink when taking } \\
\text { notes Useful }\end{array}$ & $\begin{array}{c}\text { C Changing to } \\
\text { different color } \\
\text { ink when taking } \\
\text { notes Strongly } \\
\text { useful }\end{array}$ \\
\hline $\begin{array}{l}\text { Peer-to-peer } \\
\text { networking } \\
\text { of tablet PCs } \\
\text { to allow you } \\
\text { to share } \\
\text { applications } \\
\text { or chat with } \\
\text { your } \\
\text { instructors or } \\
\text { other } \\
\text { students }\end{array}$ & $\begin{array}{l}\text { C Peer-to- } \\
\text { peer networking } \\
\text { of tablet PCs to } \\
\text { allow you to } \\
\text { share } \\
\text { applications or } \\
\text { chat with your } \\
\text { instructors or } \\
\text { other students } \\
\text { Strongly not } \\
\text { useful }\end{array}$ & $\begin{array}{l}\text { Peer-to- } \\
\text { peer networking } \\
\text { of tablet PCs to } \\
\text { allow you to } \\
\text { share } \\
\text { applications or } \\
\text { chat with your } \\
\text { instructors or } \\
\text { other students } \\
\text { Not useful }\end{array}$ & $\begin{array}{l}\text { Peer-to- } \\
\text { peer networking } \\
\text { of tablet PCs to } \\
\text { allow you to } \\
\text { share } \\
\text { applications or } \\
\text { chat with your } \\
\text { instructors or } \\
\text { other students } \\
\text { No preference }\end{array}$ & $\begin{array}{l}\text { C Peer-to- } \\
\text { peer networking } \\
\text { of tablet PCs to } \\
\text { allow you to } \\
\text { share } \\
\text { applications or } \\
\text { chat with your } \\
\text { instructors or } \\
\text { other students } \\
\text { Useful }\end{array}$ & $\begin{array}{l}\text { D Peer-to- } \\
\text { peer networking } \\
\text { of tablet PCs to } \\
\text { allow you to } \\
\text { share } \\
\text { applications or } \\
\text { chat with your } \\
\text { instructors or } \\
\text { other students } \\
\text { Strongly useful }\end{array}$ \\
\hline
\end{tabular}

\section{Additional comments:}


By submitting this survey, I acknowledge that the information I have provided will be shared with the public for the sole purpose of data analysis and educational research. My identity will remain anonymous and my privacy will not be violated in any way.

Submit Survey 


\section{APPENDIX B: Minitab Output for Survey}

Feature 1: Using the tablet PC, instructors can handwrite additional notes on top of slides to illustrate difficult concepts or to give explanations of important ideas

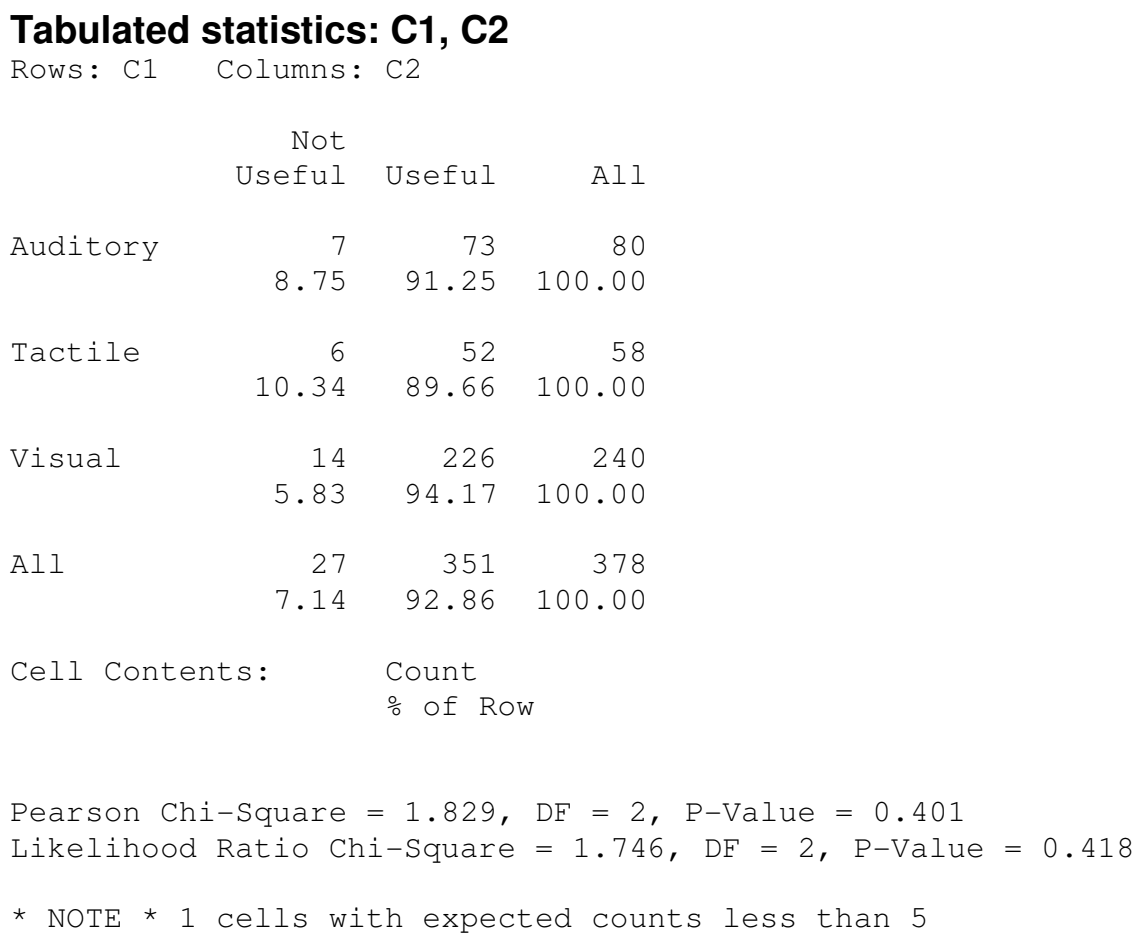

Feature 2: Capturing instructors' handwritten notes during lecture using the tablet PC

$\begin{array}{lrrr}\text { Tabulated statistics: C1, C3 } & \\ \text { Rows: C1 } & \text { Columns: C3 } & \\ & \begin{array}{r}\text { Not } \\ \text { Useful }\end{array} & \text { Useful } & \text { All } \\ & & & \\ & 11 & 69 & 80 \\ \text { Auditory } & 13.75 & 86.25 & 100.00 \\ \text { Tactile } & & & 48 \\ & 17.24 & 82.76 & 100.00 \\ \text { Visual } & & & 58 \\ & 15.83 & 84.17 & 100.00 \\ \text { All } & & & 240 \\ & 15.61 & 84.39 & 100.00 \\ \text { Cell Contents : } & \text { Count } & \end{array}$

\% of Row 
Feature 3: Sending instant electronic responses to students' questions or comments during lecture

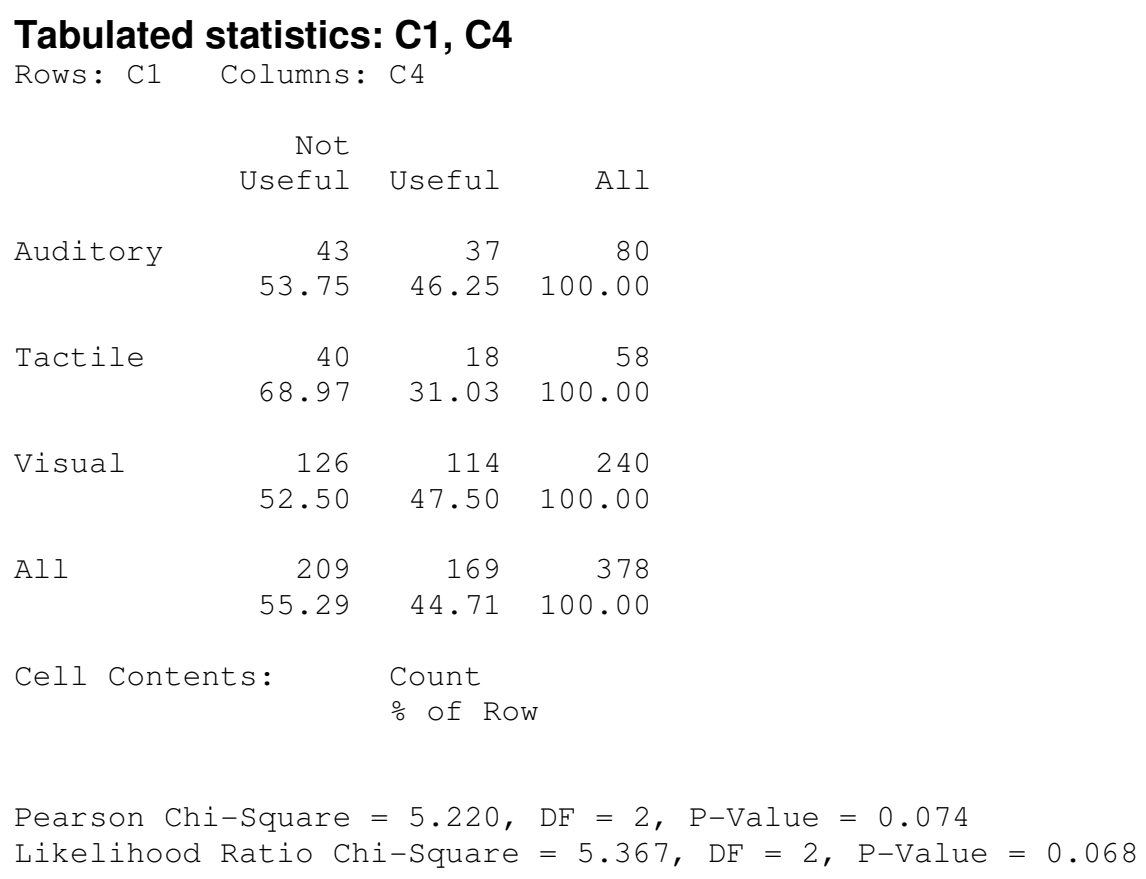

Feature 4: Handwriting your own digital notes on top of lecture slides using the tablet $P C$

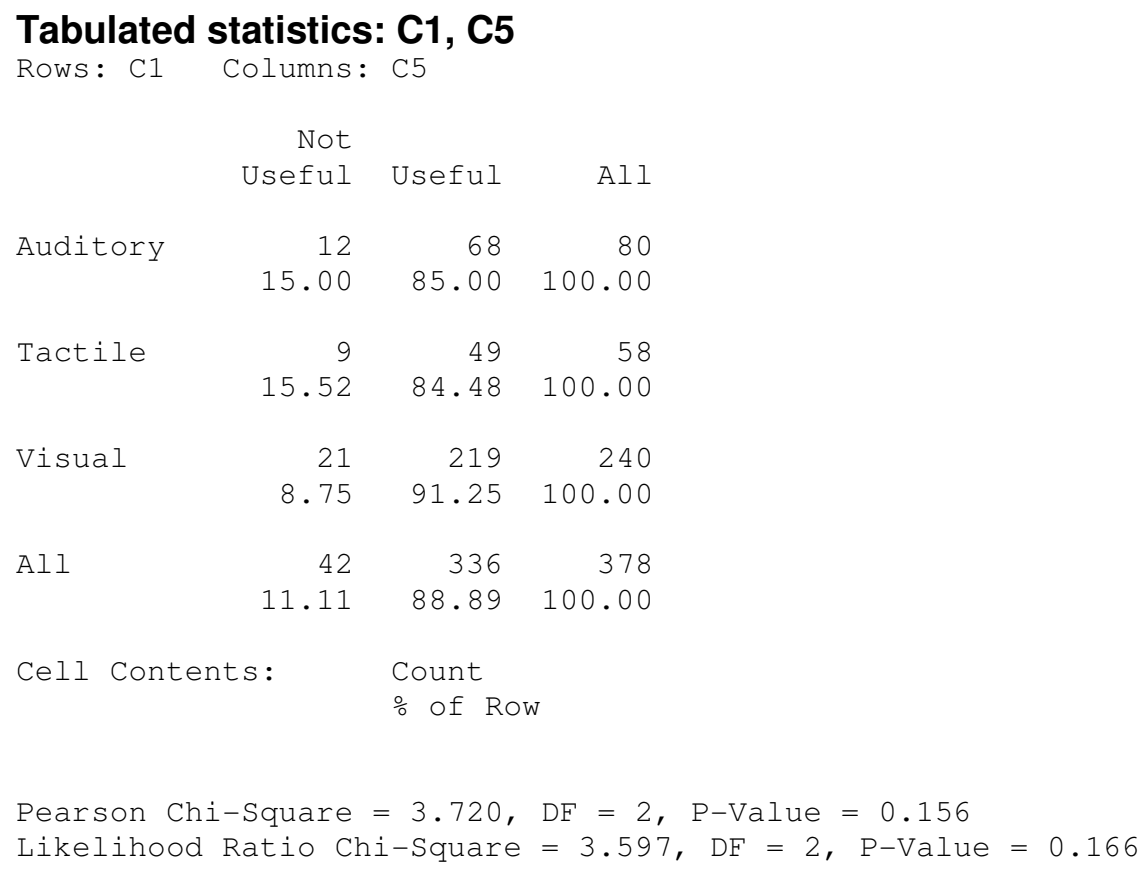


Feature 5: Separate views for lecture notes with instructors' annotations and lecture notes with your own annotations

\section{Tabulated statistics: $\mathbf{C 1}, \mathbf{C 6}$}

Rows: $\mathrm{C} 1$ Columns: $\mathrm{C} 6$

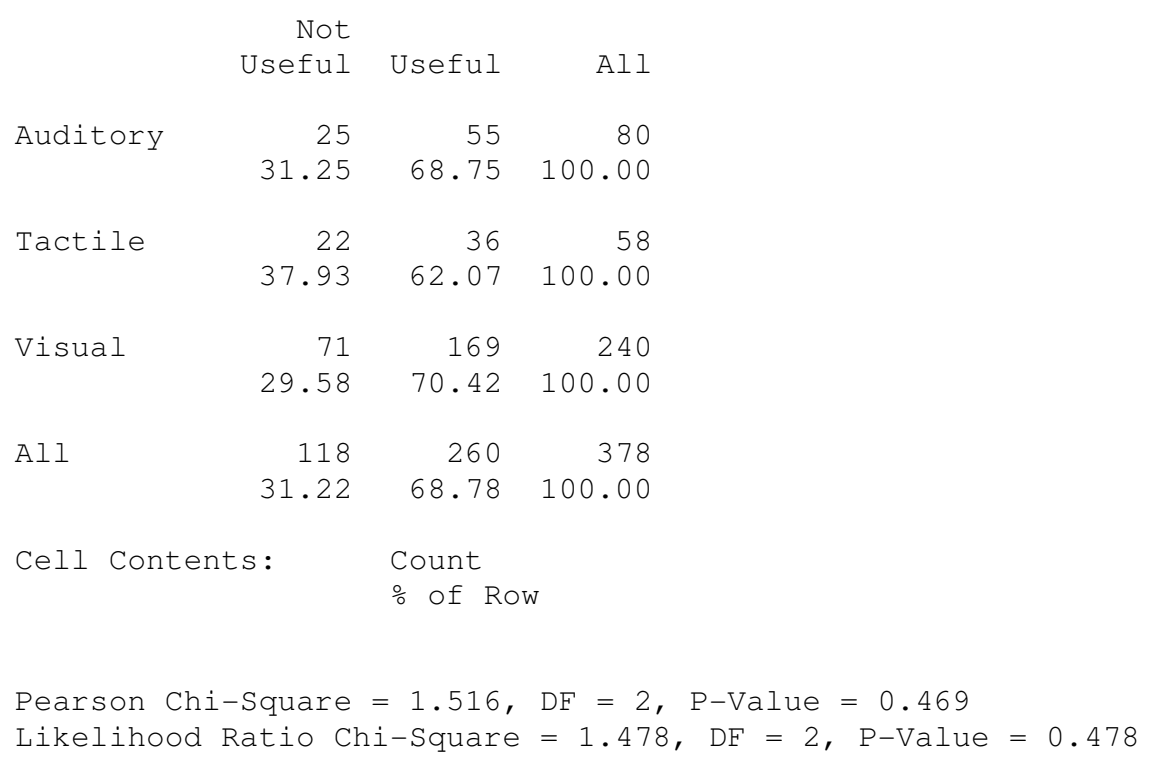

Feature 6: Sending instant electronic questions to instructors during lecture Tabulated statistics: $\mathbf{C 1}, \mathbf{C 7}$

Rows: $\mathrm{C} 1$ Columns: $\mathrm{C} 7$

\begin{tabular}{|c|c|c|c|}
\hline & $\begin{array}{r}\text { Not } \\
\text { Useful }\end{array}$ & Useful & All \\
\hline Auditory & $\begin{array}{r}52 \\
65.00\end{array}$ & $\begin{array}{r}28 \\
35.00\end{array}$ & $\begin{array}{r}80 \\
100.00\end{array}$ \\
\hline Tactile & $\begin{array}{r}35 \\
60.34\end{array}$ & $\begin{array}{r}23 \\
39.66\end{array}$ & $\begin{array}{r}58 \\
100.00\end{array}$ \\
\hline Visual & $\begin{array}{r}160 \\
66.67\end{array}$ & $\begin{array}{r}80 \\
33.33\end{array}$ & $\begin{array}{r}240 \\
100.00\end{array}$ \\
\hline All & $\begin{array}{r}247 \\
65.34\end{array}$ & $\begin{array}{r}131 \\
34.66\end{array}$ & $\begin{array}{r}378 \\
100.00\end{array}$ \\
\hline $11 \mathrm{Co}$ & & \multicolumn{2}{|l|}{ Count } \\
\hline
\end{tabular}

Pearson Chi-Square $=0.830, \mathrm{DF}=2$, P-Value $=0.660$

Likelihood Ratio Chi-Square $=0.818, \mathrm{DF}=2, \mathrm{P}$-Value $=0.664$ 
Feature 7: Sending anonymous electronic questions to instructors during lecture

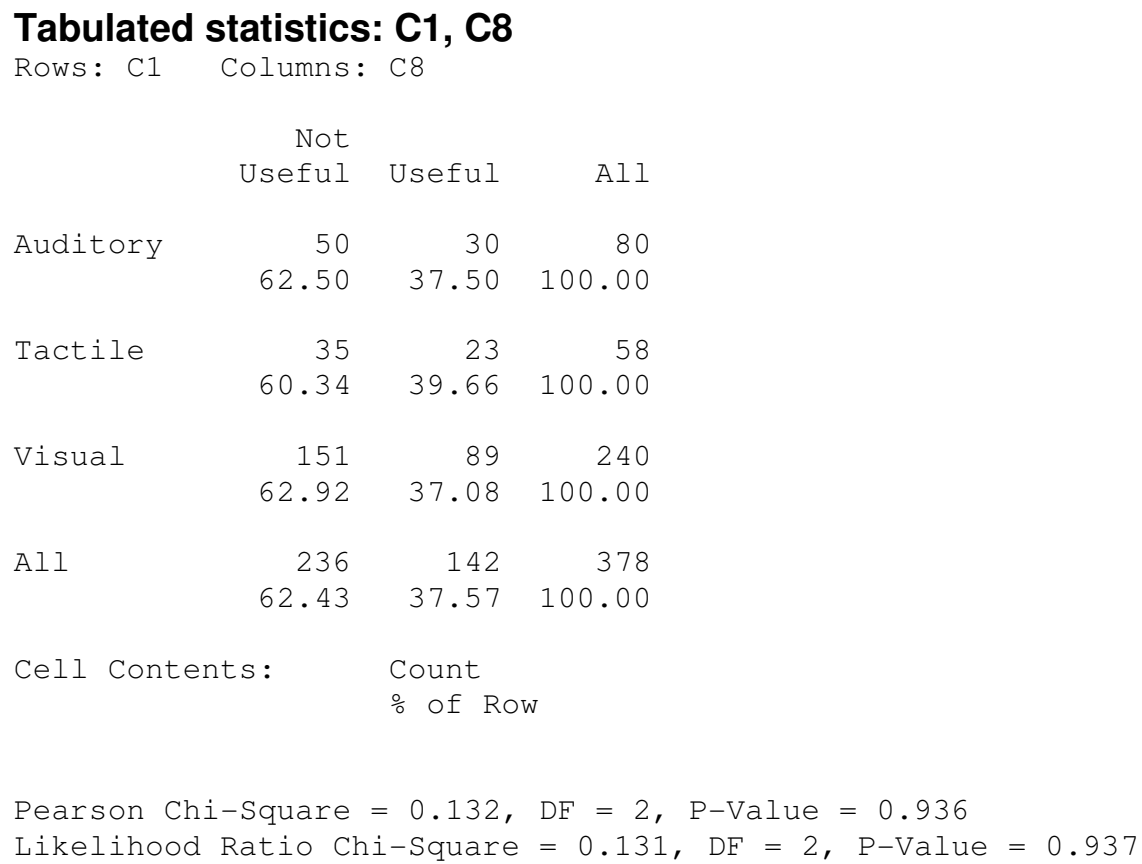

Feature 8: Taking real-time quizzes or assessments on the tablet PC and submit them to the instructor electronically

Tabulated statistics: $\mathbf{C 1}, \mathbf{C 9}$

Rows: C1 Columns: C9

\begin{tabular}{|c|c|c|c|}
\hline & $\begin{array}{r}\text { Not } \\
\text { Useful }\end{array}$ & Useful & All \\
\hline Auditory & $\begin{array}{r}31 \\
38.75\end{array}$ & $\begin{array}{r}49 \\
61.25\end{array}$ & $\begin{array}{r}80 \\
100.00\end{array}$ \\
\hline Tactile & $\begin{array}{r}25 \\
43.10\end{array}$ & $\begin{array}{r}33 \\
56.90\end{array}$ & $\begin{array}{r}58 \\
100.00\end{array}$ \\
\hline Visual & $\begin{array}{r}101 \\
42.08\end{array}$ & $\begin{array}{r}139 \\
57.92\end{array}$ & $\begin{array}{r}240 \\
100.00\end{array}$ \\
\hline All & $\begin{array}{r}157 \\
41.53\end{array}$ & $\begin{array}{r}221 \\
58.47\end{array}$ & $\begin{array}{r}378 \\
100.00\end{array}$ \\
\hline Cell Cont & ts: & $\begin{array}{l}\text { Count } \\
\circ \text { of Ro }\end{array}$ & \\
\hline
\end{tabular}


Feature 9: Instructors share students' electronic submissions to the class via the tablet $P C$

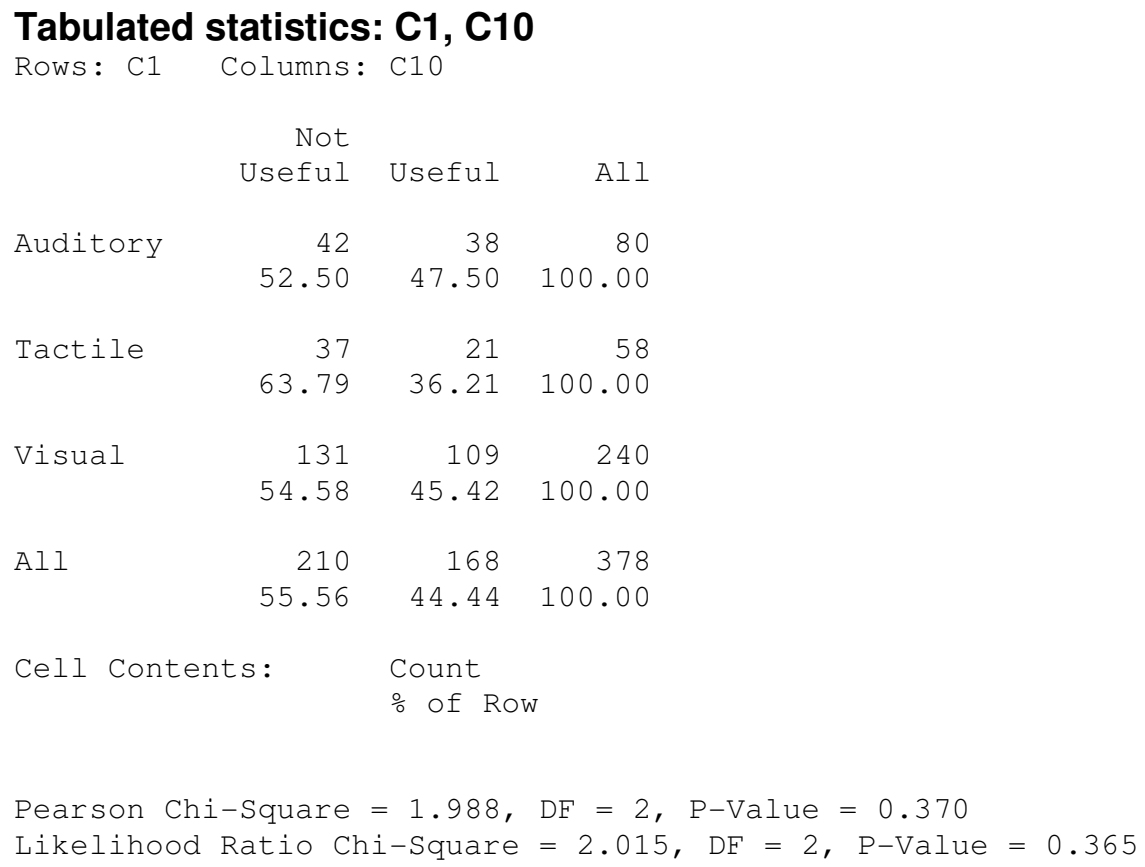

Feature 10: Recording instructors' voices during lecture

Tabulated statistics: C1, C11

Rows: C1 Columns: C11

\begin{tabular}{|c|c|c|c|}
\hline & $\begin{array}{r}\text { Not } \\
\text { Useful }\end{array}$ & Useful & All \\
\hline Auditory & $\begin{array}{r}30 \\
37.50\end{array}$ & $\begin{array}{r}50 \\
62.50\end{array}$ & $\begin{array}{r}80 \\
100.00\end{array}$ \\
\hline Tactile & $\begin{array}{r}26 \\
44.83\end{array}$ & $\begin{array}{r}32 \\
55.17\end{array}$ & $\begin{array}{r}58 \\
100.00\end{array}$ \\
\hline Visual & $\begin{array}{r}93 \\
38.75\end{array}$ & $\begin{array}{r}147 \\
61.25\end{array}$ & $\begin{array}{r}240 \\
100.00\end{array}$ \\
\hline All & $\begin{array}{r}149 \\
39.42\end{array}$ & $\begin{array}{r}229 \\
60.58\end{array}$ & $\begin{array}{r}378 \\
100.00\end{array}$ \\
\hline Cell Cont & ts: & $\begin{array}{l}\text { Count } \\
\div \text { of } R 0\end{array}$ & \\
\hline
\end{tabular}


Feature 11: When reviewing lecture notes, recorded instructors' voices are synchronized with the slide you are on and the notes that you took during class

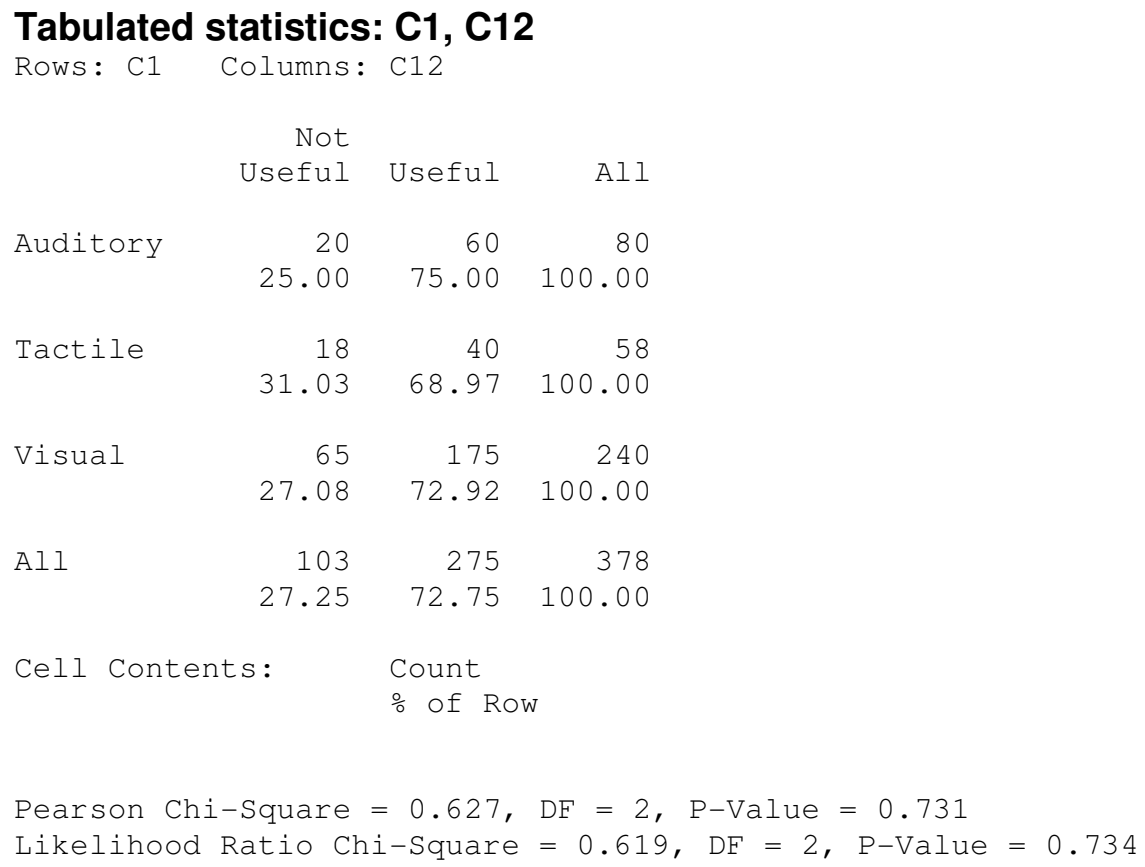

Feature 12: Using speech recognition capabilities to convert instructors' voices to text Tabulated statistics: C1, C13

Rows: C1 Columns: C13

\begin{tabular}{|c|c|c|c|}
\hline & $\begin{array}{r}\text { Not } \\
\text { Useful }\end{array}$ & Useful & All \\
\hline Auditory & $\begin{array}{r}38 \\
47.50\end{array}$ & $\begin{array}{r}42 \\
52.50\end{array}$ & $\begin{array}{r}80 \\
100.00\end{array}$ \\
\hline Tactile & $\begin{array}{r}32 \\
55.17\end{array}$ & $\begin{array}{r}26 \\
44.83\end{array}$ & $\begin{array}{r}58 \\
100.00\end{array}$ \\
\hline Visual & $\begin{array}{r}142 \\
59.17\end{array}$ & $\begin{array}{r}98 \\
40.83\end{array}$ & $\begin{array}{r}240 \\
100.00\end{array}$ \\
\hline All & $\begin{array}{r}212 \\
56.08\end{array}$ & $\begin{array}{r}166 \\
43.92\end{array}$ & $\begin{array}{r}378 \\
100.00\end{array}$ \\
\hline Cell Cont & ts: & $\begin{array}{l}\text { Count } \\
\div \text { of } R 0\end{array}$ & \\
\hline
\end{tabular}


Feature 13: Reviewing your notes in the order that you wrote them by using the tablet PC to replay the handwritten notes stroke-by-stroke

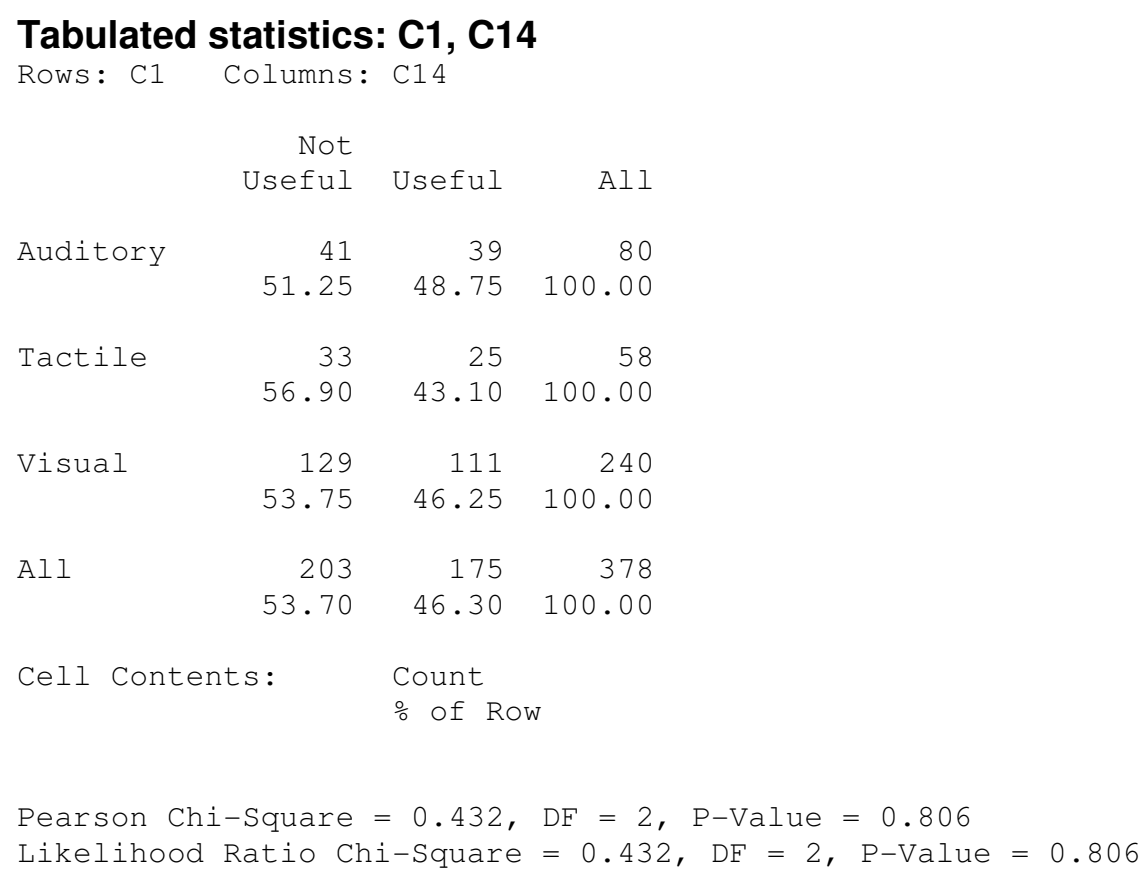

Feature 14: Ink strokes change color over time to differentiate notes taken during different periods of the lecture

\section{Tabulated statistics: C1, C15}

\begin{tabular}{lrrr} 
& $\begin{array}{r}\text { Not } \\
\text { Useful }\end{array}$ & Useful & All \\
Auditory & 29 & 51 & 80 \\
& 36.25 & 63.75 & 100.00 \\
Tactile & 27 & 31 & 58 \\
& 46.55 & 53.45 & 100.00 \\
Visual & & & \\
& 46.25 & 53.75 & 100.00 \\
All & & & 240 \\
& 44.18 & 55.82 & 100.00 \\
Cell Contents $:$ & \multicolumn{3}{c}{ Count } \\
& & $\%$ of Row
\end{tabular}

Pearson Chi-Square $=2.589, \mathrm{DF}=2, \mathrm{P}$-Value $=0.274$

Likelihood Ratio Chi-Square $=2.623, \mathrm{DF}=2, \mathrm{P}$-Value $=0.269$ 
Feature 15: Handwritten notes using the tablet PC are automatically converted to printed text

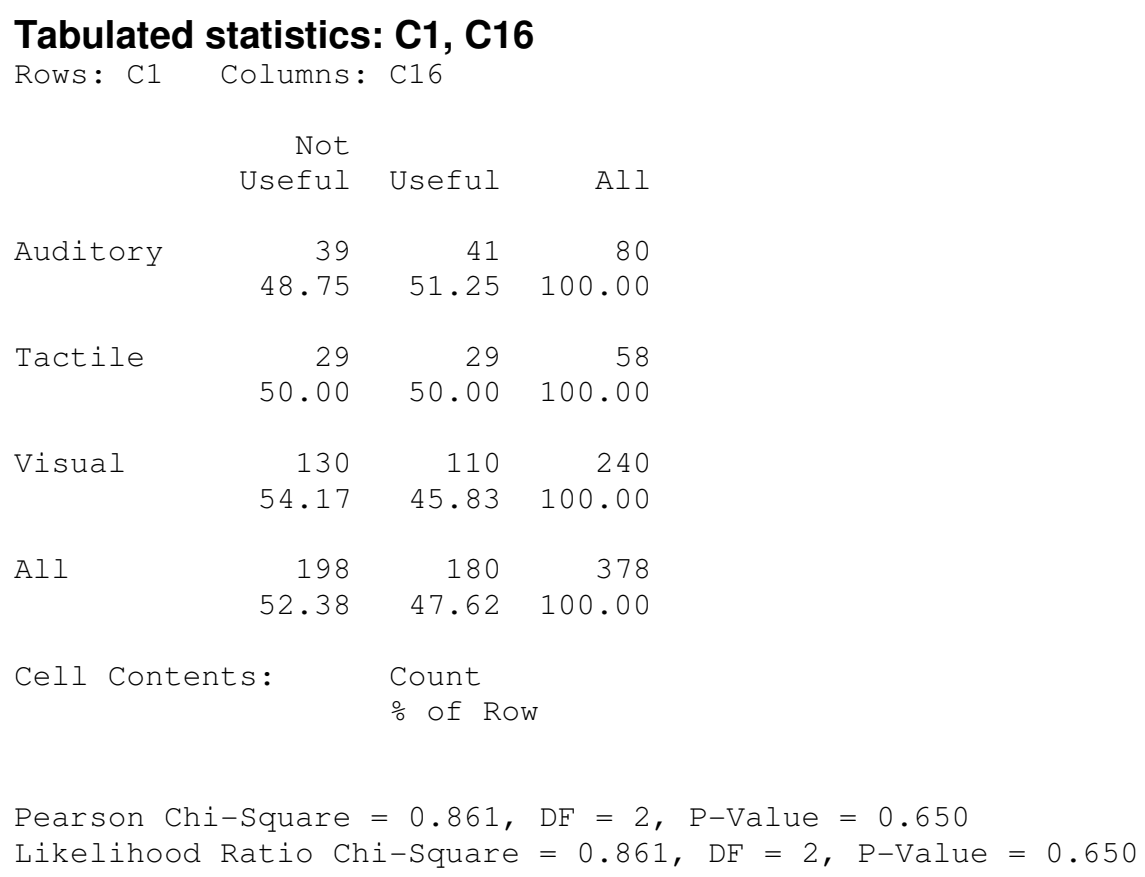

Feature 16: Using the tablet PC to search through handwritten notes for keywords Tabulated statistics: $\mathbf{C 1}, \mathbf{C 1 7}$

Rows: C1 Columns: C17

\begin{tabular}{|c|c|c|c|}
\hline & $\begin{array}{r}\text { Not } \\
\text { Useful }\end{array}$ & Useful & All \\
\hline Auditory & $\begin{array}{r}24 \\
30.00\end{array}$ & $\begin{array}{r}56 \\
70.00\end{array}$ & $\begin{array}{r}80 \\
100.00\end{array}$ \\
\hline Tactile & $\begin{array}{r}17 \\
29.31\end{array}$ & $\begin{array}{r}41 \\
70.69\end{array}$ & $\begin{array}{r}58 \\
100.00\end{array}$ \\
\hline Visual & $\begin{array}{r}84 \\
35.00\end{array}$ & $\begin{array}{r}156 \\
65.00\end{array}$ & $\begin{array}{r}240 \\
100.00\end{array}$ \\
\hline All & $\begin{array}{r}125 \\
33.07\end{array}$ & $\begin{array}{r}253 \\
66.93\end{array}$ & $\begin{array}{r}378 \\
100.00\end{array}$ \\
\hline Cell Cont & t. $s:$ & $\begin{array}{l}\text { Count } \\
\frac{\circ}{0} \text { of Ro }\end{array}$ & \\
\hline
\end{tabular}


Feature 17: Having access to blank slides to take additional notes

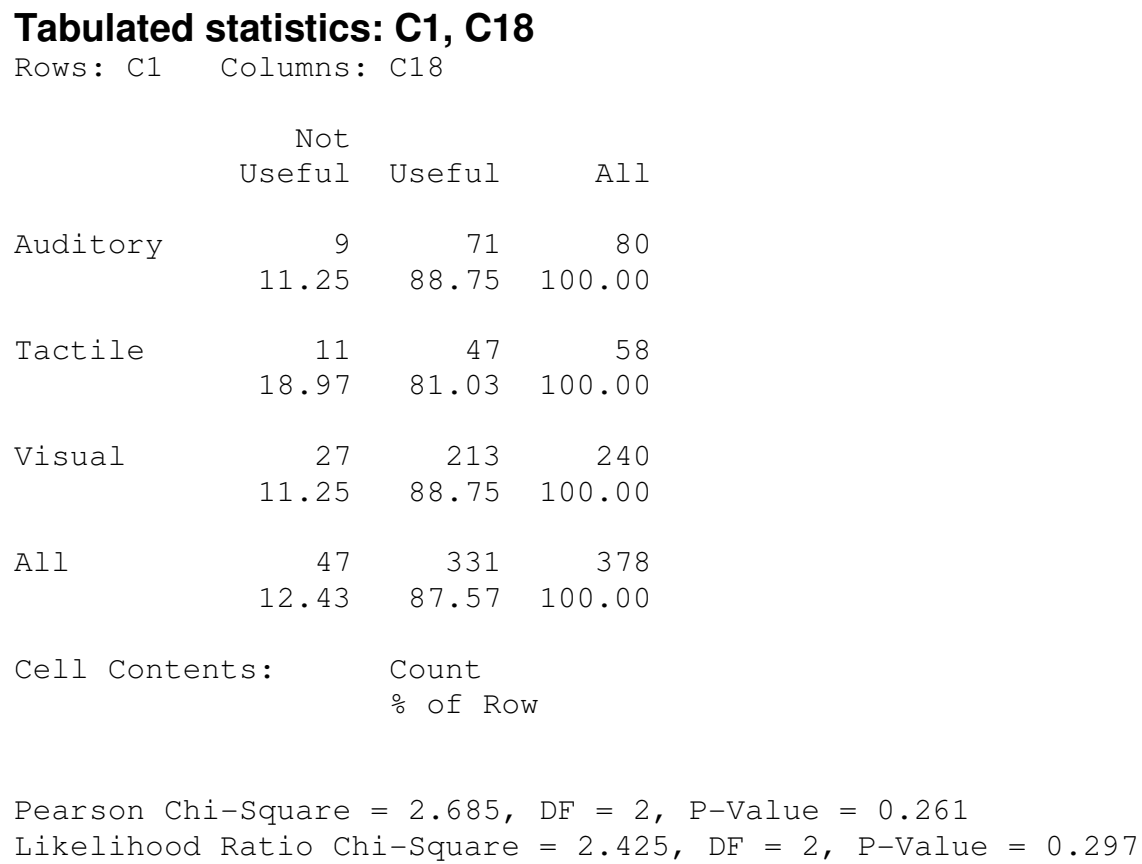

Feature 18: Navigating through all lecture slides without being restricted to the slide that the instructor is lecturing on

Tabulated statistics: C1, C19

Rows: C1 Columns: C19

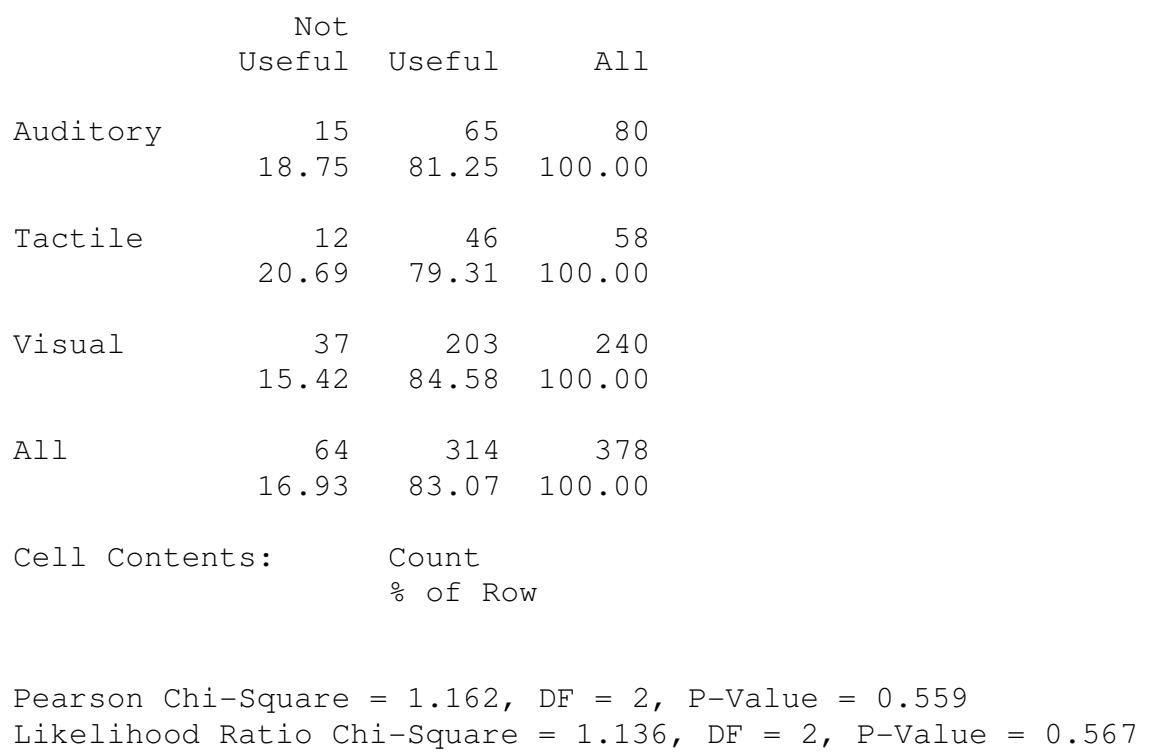


Feature 19: Highlighting key words or ideas using the tablet PC

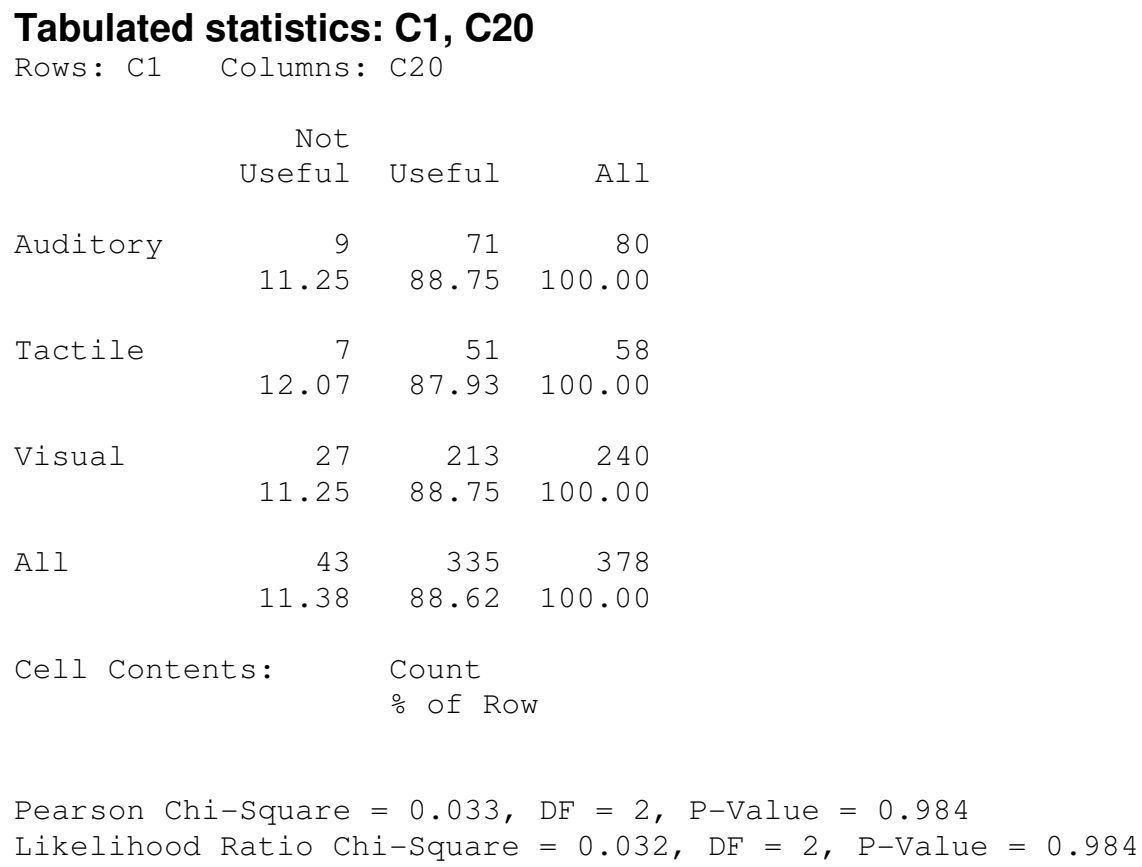

Feature 20: Erasing ink marks or strokes written using the tablet pen

\section{Tabulated statistics: C1, C21}

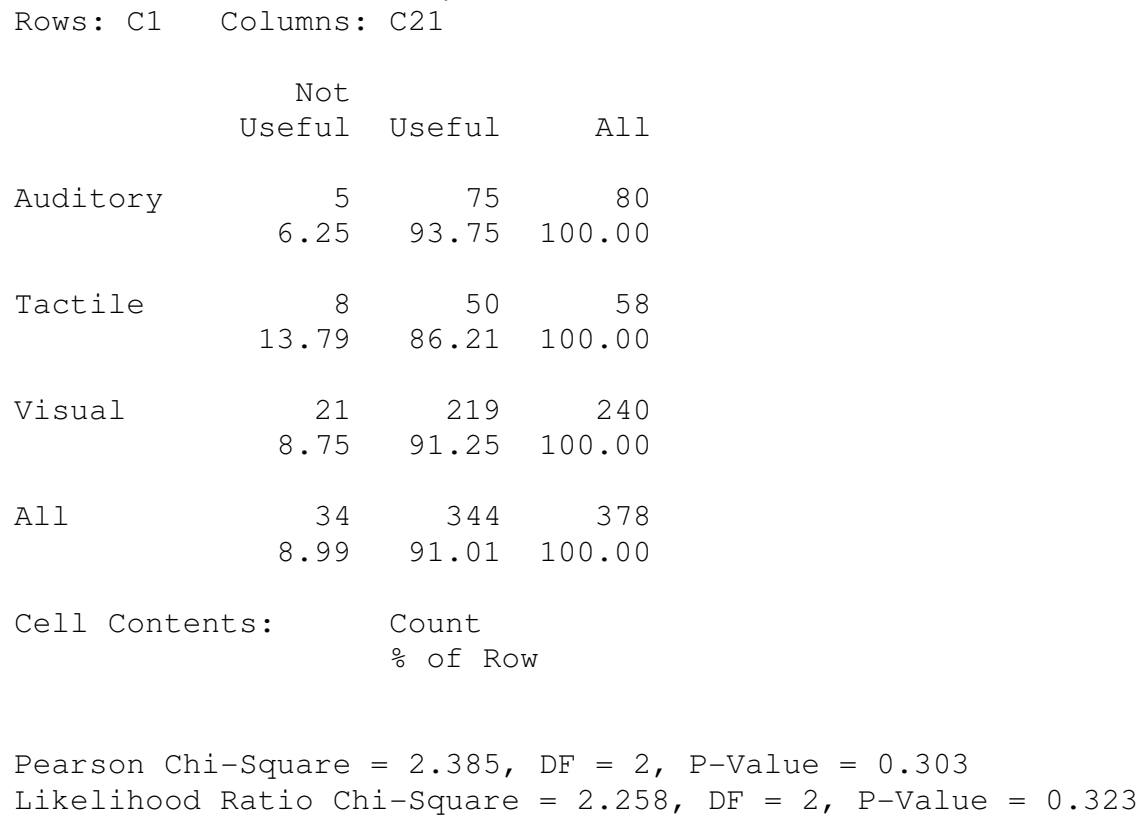




\section{Feature 21: Changing to different color ink when taking notes}

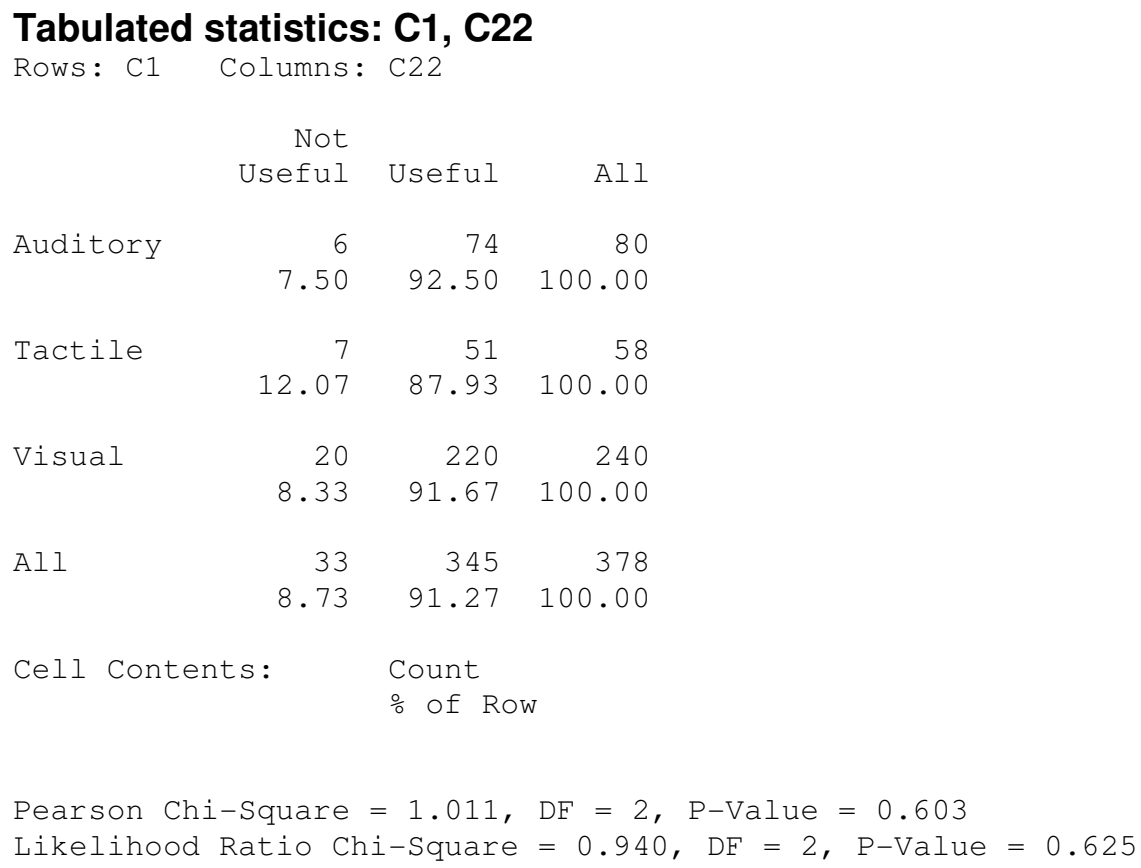

Feature 22: Peer-to-peer networking of tablet PCs to allow you to share applications or chat with your instructors or other students

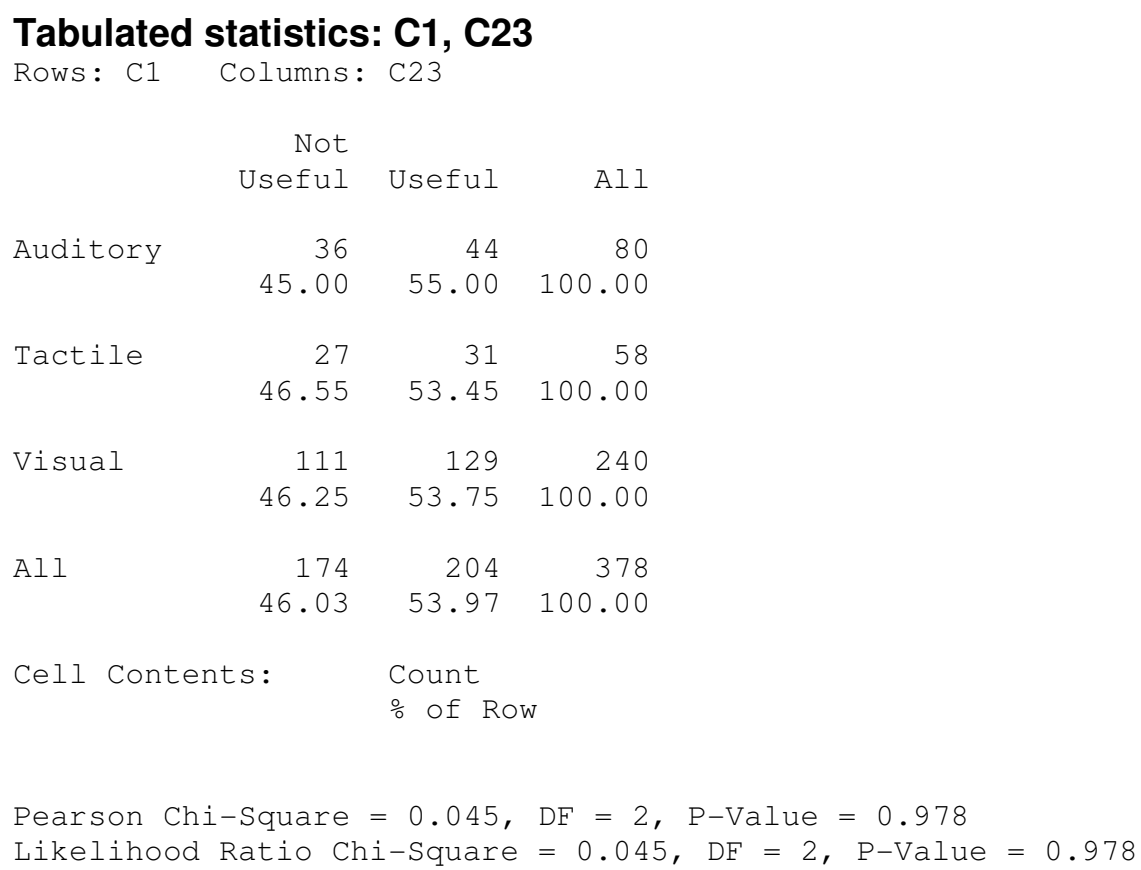




\title{
APPENDIX C: Statistical Analysis for Survey
}

\author{
Average Rating for Visual
}

\begin{tabular}{|c|c|c|c|c|}
\hline \multicolumn{6}{|c|}{ Statistical } & \multicolumn{4}{c|}{ Analysis for Visual Learners (241 Sample Size) } \\
\hline Features & Mode & Median & Mean & Stdev \\
\hline $\mathbf{1}$ & 5 & 5 & 4.55 & 0.79 \\
\hline $\mathbf{2}$ & 5 & 4 & 4.20 & 0.95 \\
\hline $\mathbf{3}$ & 3 & 3 & 3.44 & 1.05 \\
\hline $\mathbf{4}$ & 5 & 5 & 4.47 & 0.90 \\
\hline $\mathbf{5}$ & 4 & 4 & 3.91 & 1.00 \\
\hline $\mathbf{6}$ & 3 & 3 & 3.13 & 1.01 \\
\hline $\mathbf{7}$ & 3 & 3 & 3.23 & 1.05 \\
\hline $\mathbf{8}$ & 4 & 4 & 3.56 & 0.97 \\
\hline $\mathbf{9}$ & 3 & 3 & 3.39 & 0.99 \\
\hline $\mathbf{1 0}$ & 4 & 4 & 3.75 & 1.05 \\
\hline $\mathbf{1 1}$ & 5 & 4 & 4.08 & 0.99 \\
\hline $\mathbf{1 2}$ & 3 & 3 & 3.43 & 1.10 \\
\hline $\mathbf{1 3}$ & 3 & 3 & 3.42 & 1.10 \\
\hline $\mathbf{1 4}$ & 3 & 4 & 3.59 & 1.09 \\
\hline $\mathbf{1 5}$ & 3 & 3 & 3.38 & 1.09 \\
\hline $\mathbf{1 6}$ & 4 & 4 & 3.80 & 0.97 \\
\hline $\mathbf{1 7}$ & 5 & 4 & 4.29 & 0.85 \\
\hline $\mathbf{1 8}$ & 4 & 4 & 4.18 & 0.83 \\
\hline $\mathbf{1 9}$ & 5 & 4.5 & 4.34 & 0.83 \\
\hline $\mathbf{2 0}$ & 5 & 5 & 4.44 & 0.85 \\
\hline $\mathbf{2 1}$ & 5 & 5 & 4.48 & 0.81 \\
\hline $\mathbf{2 2}$ & 3 & 4 & 3.60 & 1.02 \\
\hline & & & & \\
\hline
\end{tabular}




\section{Average Ratings for Auditory}

\begin{tabular}{|c|c|c|c|c|}
\hline \multicolumn{5}{|c|}{ Statistical Analysis for Auditory Learners (82 sample size) } \\
\hline Features & Mode & Median & Mean & Stdev \\
\hline $\mathbf{1}$ & 5 & 5 & 4.49 & 0.78 \\
\hline $\mathbf{2}$ & 4 & 4 & 4.20 & 0.83 \\
\hline $\mathbf{3}$ & 3 & 3 & 3.51 & 1.03 \\
\hline $\mathbf{4}$ & 5 & 5 & 4.45 & 0.81 \\
\hline $\mathbf{5}$ & 5 & 4 & 3.98 & 0.99 \\
\hline $\mathbf{6}$ & 3 & 3 & 3.26 & 0.96 \\
\hline $\mathbf{7}$ & 3 & 3 & 3.25 & 1.06 \\
\hline $\mathbf{8}$ & 4 & 4 & 3.70 & 0.86 \\
\hline $\mathbf{9}$ & 3 & 3 & 3.54 & 0.79 \\
\hline $\mathbf{1 0}$ & 4 & 4 & 3.74 & 0.99 \\
\hline $\mathbf{1 1}$ & 5 & 4 & 4.16 & 0.86 \\
\hline $\mathbf{1 2}$ & 3 & 4 & 3.59 & 1.14 \\
\hline $\mathbf{1 3}$ & 4 & 3 & 3.39 & 1.07 \\
\hline $\mathbf{1 4}$ & 4 & 4 & 3.78 & 0.98 \\
\hline $\mathbf{1 5}$ & 3 & 4 & 3.53 & 0.93 \\
\hline $\mathbf{1 6}$ & 4 & 4 & 3.99 & 0.77 \\
\hline $\mathbf{1 7}$ & 5 & 4.5 & 4.39 & 0.68 \\
\hline $\mathbf{1 8}$ & 4 & 4 & 4.15 & 0.81 \\
\hline $\mathbf{1 9}$ & 5 & 5 & 4.40 & 0.76 \\
\hline $\mathbf{2 0}$ & 5 & 5 & 4.56 & 0.61 \\
\hline $\mathbf{2 1}$ & 5 & 5 & 4.51 & 0.64 \\
\hline $\mathbf{2 2}$ & 3 & 4 & 3.71 & 1.03 \\
\hline & & & & \\
\hline
\end{tabular}




\section{Average Ratings for Tactile}

\begin{tabular}{|c|c|c|c|c|}
\hline \multicolumn{5}{|c|}{ Statistical Analysis for Tactile Learners (59 Sample Size) } \\
\hline Features & Mode & Median & Mean & Stdev \\
\hline $\mathbf{1}$ & 5 & 5 & 4.38 & 0.83 \\
\hline $\mathbf{2}$ & 4 & 4 & 4.09 & 1.05 \\
\hline $\mathbf{3}$ & 3 & 3 & 3.10 & 1.05 \\
\hline $\mathbf{4}$ & 5 & 5 & 4.33 & 0.98 \\
\hline $\mathbf{5}$ & 4 & 4 & 3.74 & 0.91 \\
\hline $\mathbf{6}$ & 3 & 3 & 3.16 & 1.09 \\
\hline $\mathbf{7}$ & 3 & 3 & 3.07 & 1.14 \\
\hline $\mathbf{8}$ & 4 & 4 & 3.59 & 1.06 \\
\hline $\mathbf{9}$ & 3 & 3 & 3.22 & 0.86 \\
\hline $\mathbf{1 0}$ & 4 & 4 & 3.59 & 1.16 \\
\hline $\mathbf{1 1}$ & 4 & 4 & 3.91 & 1.01 \\
\hline $\mathbf{1 2}$ & 3 & 3 & 3.40 & 1.11 \\
\hline $\mathbf{1 3}$ & 3 & 3 & 3.29 & 0.96 \\
\hline $\mathbf{1 4}$ & 4 & 4 & 3.47 & 1.01 \\
\hline $\mathbf{1 5}$ & 3 & 3.5 & 3.41 & 1.08 \\
\hline $\mathbf{1 6}$ & 4 & 4 & 3.91 & 0.90 \\
\hline $\mathbf{1 7}$ & 4 & 4 & 4.09 & 0.84 \\
\hline $\mathbf{1 8}$ & 4 & 4 & 4.09 & 0.82 \\
\hline $\mathbf{1 9}$ & 4 & 4 & 4.22 & 0.82 \\
\hline $\mathbf{2 0}$ & 5 & 5 & 4.36 & 0.83 \\
\hline $\mathbf{2 1}$ & 5 & 4 & 4.31 & 0.80 \\
\hline $\mathbf{2 2}$ & 3 & 4 & 3.57 & 1.11 \\
\hline & & & & \\
\hline
\end{tabular}




\section{REFERENCES}

[1] Aase, M. and Kurfess, F. 2004. Utilizing Learning Styles for Interactive Tutorials. In Proceedings of the IEEE international Conference on Advanced Learning Technologies (Icalt'04) - Volume 00 (August 30 - September 01, 2004). ICALT. IEEE Computer Society, Washington, DC, 828-830.

[2] Abowd, G. D., Atkeson, C. G., Brotherton, J., Enqvist, T., Gulley, P., and LeMon, J. 1998. Investigating the capture, integration and access problem of ubiquitous computing in an educational setting. In Proceedings of the SIGCHI Conference on Human Factors in Computing Systems (Los Angeles, California, United States, April 18 - 23, 1998). C. Karat, A. Lund, J. Coutaz, and J. Karat, Eds. Conference on Human Factors in Computing Systems. ACM Press/Addison-Wesley Publishing Co., New York, NY, 440-447. DOI= http://doi.acm.org/10.1145/274644.274704

[3] Abowd, G. D., Atkeson, C. G., Feinstein, A., Hmelo, C., Kooper, R., Long, S., Sawhney, N., and Tani, M. 1996. Teaching and learning as multimedia authoring: the classroom 2000 project. In Proceedings of the Fourth ACM international Conference on Multimedia (Boston, Massachusetts, United States, November 18 22, 1996). MULTIMEDIA '96. ACM Press, New York, NY, 187-198. DOI= http://doi.acm.org/10.1145/244130.244191

[4] Anderson, R., Anderson R., Simon, B., Wolfman, S., VanDeGrift, T., \& Yasuhara, K. Experiences with a Tablet PC Based Lecture Presentation System in Computer Science Courses. In Proc. of SIGCSE ’04, pp. 56-60.

[5] Anderson, R., Hoyer, C., Prince, C., Su, J., Videon, F., and Wolfman, S. 2004. Speech, ink, and slides: the interaction of content channels. In Proceedings of the 12th Annual ACM international Conference on Multimedia (New York, NY, USA, October 10 - 16, 2004). MULTIMEDIA '04. ACM Press, New York, NY, 796-803. DOI= http://doi.acm.org/10.1145/1027527.1027713

[6] Anderson, R. J., Hoyer, C., Wolfman, S., and Anderson, R. A Study of Digital Ink in Lecture Presentation. In Proceedings of CHI 2004 (Vienna, Austria), April 2429, 2004.

[7] Berque, D., Bonebright, T., and Whitesell, M. 2004. Using pen-based computers across the computer science curriculum. SIGCSE Bull. 36, 1 (Mar. 2004), 61-65. DOI= http://doi.acm.org/10.1145/1028174.971324

[8] Berry, M. and Hamilton, M. 2006. Mobile computing, visual diaries, learning and communication: changes to the communicative ecology of design students through mobile computing. In Proceedings of the 8th Austalian Conference on Computing Education - Volume 52 (Hobart, Australia, January 16 - 19, 2006). D. 
Tolhurst and S. Mann, Eds. ACM International Conference Proceeding Series, vol. 165. Australian Computer Society, Darlinghurst, Australia, 35-44.

[9] Brotherton, J. \& Abowd, G., Rooms take note: room takes notes!, Proc. AAAI Symposim on Intelligent Environments, 1998,23-30.

[10] Buckalew, C. and Porter, A. 1994. The lecturer's assistant. In Proceedings of the Twenty-Fifth SIGCSE Symposium on Computer Science Education (Phoenix, Arizona, United States, March 10 - 12, 1994). SIGCSE '94. ACM Press, New York, NY, 193-197. DOI= http://doi.acm.org/10.1145/191029.191105

[11] Coffield, F., Moseley, D., Hall, E., \& Ecclestone, K. (2004). Learning styles and pedagogy in post-16 learning: A systematic and critical review. London: Learning and Skills Research Centre. Available at https://www.lsneducation.org.uk/cims/order.aspx? code=041543\&src=XOWEB. Last accessed 12 April 2006.

[12] Colligo. Retrieved June 22, 2007, from http://www.colligo.com/products/workgroupedition/index.asp

[13] M.L. Conner, Learn More Now: 10 Simple Steps to Learning Better, Smarter, \& Faster, New Jersey: John Wiley \& Sons, Inc., 2004.

[14] Corel Grafigo 2. Retrieved June 22, 2007, from http://www.corel.com/servlet/Satellite?pagename=Corel3/Products/Display\&pid= $\underline{1047022702391}$

[15] Davis, R. C., Landay, J. A., Chen, V., Huang, J., Lee, R. B., Li, F. C., Lin, J., Morrey, C. B., Schleimer, B., Price, M. N., and Schilit, B. N. 1999. NotePals: lightweight note sharing by the group, for the group. In Proceedings of the SIGCHI Conference on Human Factors in Computing Systems: the CHI Is the Limit (Pittsburgh, Pennsylvania, United States, May 15 - 20, 1999). CHI '99. ACM Press, New York, NY, 338-345. DOI= http://doi.acm.org/10.1145/302979.303107

[16] Denning, T., Griswold, W. G., Simon, B., and Wilkerson, M. 2006. Multimodal communication in the classroom: what does it mean for us?. SIGCSE Bull. 38, 1 (Mar. 2006), 219-223. DOI= http://doi.acm.org/10.1145/1124706.1121410

[17] DyKnow. Retrieved June 22, 2007, from http://www.dyknow.com/

[18] EverNote. Retrieved June 22, 2007, from http://www.evernote.com/en/products/evernote/

[19] Felder, R.M., "Matters of Style," ASEE Prism, Vol. 6, No. 4, 1996, pp. 18-23, http://www.ncsu.edu/felder-public/Papers/LS-Prism.htm. 
[20] Felder, R.M., (a) "Meet Your Students. 1. Stan and Nathan," Chemical Engineering Education, vol. 23, no. 2, 1989, pp. 68-69; (b) "Meet Your Students. 4. Jill and Perry," Chemical Engineering Education, vol. 25, no. 4, 1991, pp. 196197; (c) "Meet Your Students. 5. Edward and Irving," Chemical Engineering Education, vol. 28, no. 1, 1994, pp. 36-37; (d) "Meet Your Students. 6. Tony and Frank," Chemical Engineering Education, vol. 29, no. 4, 1995, pp. 244-245.

[21] Felder, R.M., and R. Brent, "Understanding Student Differences," Journal of Engineering Education, Vol. 94, No. 1, 2005, pp. 57-72, http://www.ncsu.edu/felder-public/Papers/Understanding_Differences.pdf.

[22] Felder, R.M., Felder, G.N., and Dietz, E.J., "The Effects of Personality Type on Engineering Student Performance and Attitudes," Journal of Engineering Education, Vol. 91, No. 1, 2002, pp. 3-17.

[23] Felder, R.M., and L.K. Silverman, "Learning and Teaching Styles in Engineering Education," Engr. Education, vol. 78, no. 7, 1988, pp. 674-681.

[24] Felder, R. M., Woods, D. R., Stice, J. E., \& Rugaricia, A. (2000). The future of engineering education: Teaching methods that work, Chem Engr Education, 34(1), 26-39.

[25] GoBinder. Retrieved June 22, 2007, from http://www.gobinder.com/gobinder2006.aspx

[26] Frank Hanisch, Meike Muckenhaupt, Franz J. Kurfess, and Wolfgang Straßer: The AHES Taxonomy: Extending Adaptive Hypermedia to Software Components. AH 2006: 342-345

[27] HP Pavilion tx 1000 Entertainment Tablet PC. Retrieved June 22, 2007, from http://www.tabletpc2.com/Review-HP_TX1000_Entertainment_Tablet_PC$\underline{\text { Article70020426.html }}$

[28] HP TC4200. Retrieved June 22, 2007, from http://www.ecomelectronics.com/prodinfo.phtml?id=1807\&ref=nextag

[29] Hsieh, G., Wood, K., and Sellen, A. 2006. Peripheral display of digital handwritten notes. In Proceedings of the SIGCHI Conference on Human Factors in Computing Systems (Montréal, Québec, Canada, April 22 - 27, 2006). R. Grinter, T. Rodden, P. Aoki, E. Cutrell, R. Jeffries, and G. Olson, Eds. CHI '06. ACM Press, New York, NY, 285-288. DOI= http://doi.acm.org/10.1145/1124772.1124815

[30] Kam, M., Wang, J., Iles, A., Tse, E., Chiu, J., Glaser, D., Tarshish, O., and Canny, J. 2005. Livenotes: a system for cooperative and augmented note-taking in 
lectures. In Proceedings of the SIGCHI Conference on Human Factors in Computing Systems (Portland, Oregon, USA, April 02 - 07, 2005). CHI '05. ACM Press, New York, NY, 531-540. DOI= http://doi.acm.org/10.1145/1054972.1055046

[31] Koile, K. and Singer, D. 2006. Improving learning in CS1 via tablet-PC-based inclass assessment. In Proceedings of the 2006 international Workshop on Computing Education Research (Canterbury, United Kingdom, September 09 10, 2006). ICER '06. ACM Press, New York, NY, 119-126. DOI= http://doi.acm.org/10.1145/1151588.1151607

[32] Kurtz, B. L., Fenwick, J. B., and Ellsworth, C. C. 2007. Using podcasts and tablet PCs in computer science. In Proceedings of the 45th Annual Southeast Regional Conference (Winston-Salem, North Carolina, March 23 - 24, 2007). ACM-SE 45. ACM Press, New York, NY, 484-489. DOI= http://doi.acm.org/10.1145/1233341.1233428

[33] Learning Styles Assessment: Ageless Learner. Retrieved June 21, 2007, from http://www.agelesslearner.com/assess/learningstyle.html

[34] Lenovo Thinkpad X60 Tablet PC. Retrieved June 22, 2007, from http://www.tabletpc2.com/Review-Lenovo_X60_Tablet_PCArticle70023900.html

[35] Memletics Learning Styles Inventory. Retrieved June 22, 2007, from http://www.learning-styles-online.com/inventory/

[36] Merriam-Webster Online. Retrieved June 22, 2007, from http://www.m-w.com/

[37] Montgomery, S. (1995) “Addressing Diverse Learning Styles through the Use of Multimedia” ASEE/IEEE Frontiers/Ed. '95

[38] Muckenhaupt, M., Hanisch, F., Kurfess, F. \& Straßer, W. (2006). AHES: An Adaptive Hypermedia Engine for Software Components. In P. Kommers \& G. Richards (Eds.), Proceedings of World Conference on Educational Multimedia, Hypermedia and Telecommunications 2006 (pp. 991-998). Chesapeake, VA: AACE.

[39] Myers, B. A., Stiel, H., and Gargiulo, R. 1998. Collaboration using multiple PDAs connected to a PC. In Proceedings of the 1998 ACM Conference on Computer Supported Cooperative Work (Seattle, Washington, United States, November 14 - 18, 1998). CSCW '98. ACM Press, New York, NY, 285-294. DOI= http://doi.acm.org/10.1145/289444.289503 
[40] O’Brien, T., Bernold, L.E., Akroyd, D. (1998). Myers-Briggs Type Indicator and Academic Achievement in Engineering Education. International Journal of Engineering Education, 14:5, 311-315

[41] OneNote Home Page. Retrieved June 22, 2007, from http://office.microsoft.com/en-us/onenote/default.aspx

[42] Peiper, C., Warden, D., Chan, E., Capitanu, B., and Kamin, S. 2005. eFuzion: development of a pervasive educational system. SIGCSE Bull. 37, 3 (Sep. 2005), 237-240. DOI= http://doi.acm.org/10.1145/1151954.1067510

[43] PhatWare PhatPad. Retrieved June 22, 2007, from http://www.phatware.com/phatpad/index.html

[44] da Graça Pimentel, M., Prazeres, C., Ribas, H., Lobato, D., and Teixeira, C. 2005. Documenting the pen-based interaction. In Proceedings of the 11th Brazilian Symposium on Multimedia and the Web (Pocos de Caldas - Minas Gerais, Brazil, December 05 - 07, 2005). R. P. Fortes, Ed. WebMedia '05, vol. 125. ACM Press, New York, NY, 1-8. DOI= http://doi.acm.org/10.1145/1114223.1114232

[45] Power Presenter. Retrieved June 22, 2007, from http://www.adesso.com/productmanuals/Power\%20presenter\%20RE.pdf

[46] Presentation Program. Retrieved June 22, 2007, from http://en.wikipedia.org/wiki/Presentation_program

[47] Ratto, M., Shapiro, R. B., Truong, T. M., \& Griswold,W. G. The ActiveClass project: Experiments in encouraging classroom participation. In CSCL 2003, pp. 477-486.

[48] Rößling, G., Trompler, C., Muehlhäuser, M., Köler, S., Wolf, S. Enhancing Classroom Lectures with Digital Sliding Blackboards. 9th ITICSE, June 2004.

[49] Simon, B., Anderson, R., Hoyer, C., and Su, J. 2004. Preliminary experiences with a tablet $\mathrm{PC}$ based system to support active learning in computer science courses. In Proceedings of the 9th Annual SIGCSE Conference on innovation and Technology in Computer Science Education (Leeds, United Kingdom, June 28 30, 2004). ITiCSE '04. ACM Press, New York, NY, 213-217. DOI= http://doi.acm.org/10.1145/1007996.1008053

[50] Stice, J.E. (1987). "Using Kolb's Learning Cycle to Improve Student Learning," Engineering Education, 77(5), 291-196, Feb. 1987.

[51] Subhlok, J., Johnson, O., Subramaniam, V., Vilalta, R., and Yun, C. 2007. Tablet PC video based hybrid coursework in computer science: report from a pilot project. In Proceedinds of the 38th SIGCSE Technical Symposium on Computer 
Science Education (Covington, Kentucky, USA, March 07 - 11, 2007). SIGCSE '07. ACM Press, New York, NY, 74-78. DOI= http://doi.acm.org/10.1145/1227310.1227339

[52] TabletKiosk's Sahara i440D Tablet PC. Retrieved June 22, 2007, from http://www.tabletpc2.com/SneakPeek-TabletKiosk_i440D_TabletPCArticle7001407.htm

[53] Toshiba R400 Tablet PC. Retrieved June 22, 2007, from http://www.tabletpc2.com/First_Impressions_Toshiba_R400_Tablet_PC$\underline{\text { Article70020308.html }}$

[54] E. Triantafillou, A. Pomportsis, \& E. Georgiadpu, AES-CS: Adaptive Educational System based on cognitive styles, Proc. of the AH2002 Workshop, Malaga, Spain, 2002, 10-20.

[55] Tutty, J., White, B., and Pascoe, R. 2005. Experiences from a wireless-enabled tablet classroom. In Proceedings of the 7th Australasian Conference on Computing Education - Volume 42 (Newcastle, New South Wales, Australia). A. Young and D. Tolhurst, Eds. ACM International Conference Proceeding Series, vol. 106. Australian Computer Society, Darlinghurst, Australia, 165-172.

[56] UW Classroom Presenter. Retrieved June 22, 2007, from http://www.cs.washington.edu/education/dl/presenter/

[57] Weiser, M. 1999. Some computer science issues in ubiquitous computing. SIGMOBILE Mob. Comput. Commun. Rev. 3, 3 (Jul. 1999), 12. DOI= http://doi.acm.org/10.1145/329124.329127

[58] Westfall, L. (2005). The What, Why, Who, When, and How of Software Requirements. ASQ World Conference on Quality and Improvement Proceedings, 97-104.

[59] Whittaker, S., Hyland, P., and Wiley, M. 1994. FILOCHAT: handwritten notes provide access to recorded conversations. In Proceedings of the SIGCHI Conference on Human Factors in Computing Systems: Celebrating interdependence (Boston, Massachusetts, United States, April 24 - 28, 1994). B. Adelson, S. Dumais, and J. Olson, Eds. CHI '94. ACM Press, New York, NY, 271-277. DOI= http://doi.acm.org/10.1145/191666.191763

[60] Wilkerson, M., Griswold, W. G., and Simon, B. 2005. Ubiquitous presenter: increasing student access and control in a digital lecturing environment. In Proceedings of the 36th SIGCSE Technical Symposium on Computer Science Education (St. Louis, Missouri, USA, February 23 - 27, 2005). SIGCSE '05. ACM Press, New York, NY, 116-120. DOI= http://doi.acm.org/10.1145/1047344.1047394 
[61] Willis, C. L. and Miertschin, L. 2004. Tablet PC's as instructional tools or the pen is mightier than the 'board!. In Proceedings of the 5th Conference on information Technology Education (Salt Lake City, UT, USA, October 28 - 30, 2004). CITC5 '04. ACM Press, New York, NY, 153-159. DOI= http://doi.acm.org/10.1145/1029533.1029572

[62] Windows Journal. Retrieved June 22, 2007, from http://www.microsoft.com/windowsxp/using/tabletpc/russel_03january20.mspx 